JULIO HENRIQUE ROSA CRODA

\title{
Patogênese da síndrome pulmonar hemorrágica na leptospirose humana.
}

Tese apresentada à Faculdade de Medicina da Universidade de São Paulo para a obtenção do título de Doutor em Ciências

\author{
Área de concentração: Patologia \\ Orientadora: Profa. Dra. Maria Irma Seixas \\ Duarte
}

São Paulo 
JULIO HENRIQUE ROSA CRODA

\title{
Patogênese da síndrome pulmonar hemorrágica na leptospirose humana.
}

Tese apresentada à Faculdade de Medicina da Universidade de São Paulo para a obtenção do título de Doutor em Ciências

\author{
Área de concentração: Patologia \\ Orientadora: Profa. Dra. Maria Irma Seixas \\ Duarte
}

São Paulo 


\title{
Dados Internacionais de Catalogação na Publicação (CIP)
}

\author{
Preparada pela Biblioteca da
}

Faculdade de Medicina da Universidade de São Paulo

Creprodução autorizada pelo autor

\section{Croda, Julio Henrique Rosa}

Patogênese da síndrome pulmonar hemorrágica na leptospirose humana / Julio Henrique Rosa Croda. -- São Paulo, 2008

Tese(doutorado)--Faculdade de Medicina da Universidade de São Paulo. Departamento de Patologia.

Área de concentração: Patologia.

Orientadora: Maria Irma Seixas Duarte.

Descritores: 1.Leptospirose/etiologia 2.Síndrome pulmonar por Hantavírus 3.Insuficiência respiratória 4.Imunoglobulina A 5.Autopsia 


\section{DEDICATÓRIA}

À minha esposa, amiga e co-autora de todas as minhas realizações, Mariana.

À minha filha Maria, meu maior presente de Deus, que dividiu com esta tese a atenção em seus primeiros dias de vida.

Aos meus pais Arquimino e Marlene, modelos de amor incondicional.

À minha irmã, Luciane e meus sobrinhos Matheus e Vitória.

Aos pacientes, estímulo maior do meu trabalho 


\section{AGRADECIMENTOS}

À professora Maria Irma Seixas Duarte, minha orientadora e modelo exemplar de ser - humano, por ter acreditado em mim até mais que eu mesmo.

À todos do laboratório da disciplina de patologia de moléstias transmissíveis da USP, que me acolheram tão calorosamente: Carla pelo apoio e ajuda essencial na execução do projeto. Roose pelo tempo dispendido na revisão das lâminas e pelos valiosos conselhos. Rosana, pela paciência e doçura. Amaro pela amizade e por cooperar na minha luta. Elaine e Fernanda pela ajuda na realização da imunohistoquímica. Cleusa, Monica e Naiura por tornarem o ambiente de trabalho tão agradável e leve.

Ao Professor Albert Ko a quem devo minha paixão pela pesquisa, por todos esses anos de ensino e apoio, e por ter cedido soro de pacientes participantes de sua pesquisa para este estudo.

Ao Professor Mitermayer Galvão dos Reis que se tornou muito mais que um mestre, pela sua sinceridade e confiança nesta minha trajetória.

Aos colegas do Laboratório de Patologia e Biologia Molecular da Fiocruz Bahia (CpqGM) pelos 10 anos de convívio, pelas lutas e sonhos divididos.

Ao Prof. Antonio Carlos Nicodemo, pelo ensino e atenção. Parte deste projeto não seria possível sem seu auxílio.

À Jozélio Freire de Carvalho, pela disposição em auxiliar na execução do projeto, testando os soros dos pacientes.

À minha família cuiabana, pelo apoio e compreensão nesta difícil fase de nossa vida, tão repleta de mudanças. 
À FAPESP pelo financiamento de parte deste projeto.

À Deus, por me permitir reconhecê-lo em todos os momentos da minha vida. 


\section{NORMATIZAÇÃO ADOTADA}

Esta tese esta de acordo com as seguintes normas, em vigor no momento desta publicação:

Referências: adaptado de International Committee of Medical Journals Editors (Vancouver)

Universidade de São Paulo. Faculdade de Medicina. Serviço de Biblioteca e Documentação. Guia de apresentação de dissertações, teses e monografias. Elaborado por Anneliese Carneiro da Cunha, Maria Julia de A. L. Freddi, Maria F. Crestana, Marinalva de Souza Aragão, Suely Campos Cardoso, Valéria Vilhena. $2^{\mathrm{a}}$ ed. São Paulo: Serviço de Biblioteca e Documentação; 2005.

Abreviaturas dos títulos dos periódicos de acordo com List of Journals Indexed in Index Medicus. 


\section{SUMÁRIO}

LISTA DE ABREVIATURAS E SIGLAS

LISTA DE SÍMBOLOS

LISTA DE FIGURAS

LISTA DE TABELAS

RESUMO

SUMMARY

1. INTRODUÇÃO.

2. OBJETIVOS

2.1. Objetivos gerais............................................................................ 5

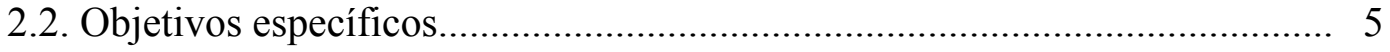

3. REVISÃO DA LITERATURA................................................................................. 6

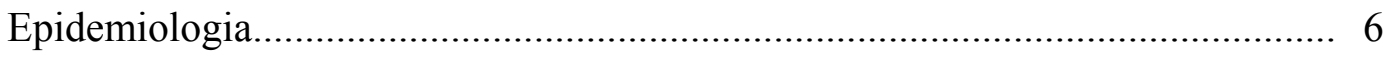

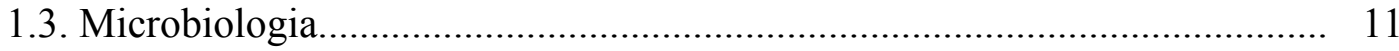

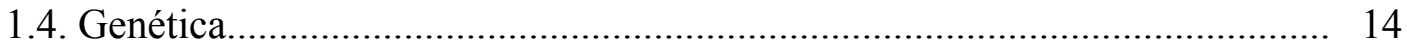

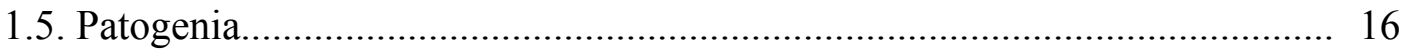

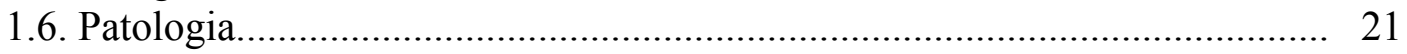

1.7. Manifestações Clínicas............................................................................... 24

1.8. Diagnóstico e exames complementares....................................................... 29

1.9. Prevenção e tratamento............................................................................ 34

3.1. Fenômenos hemorrágicos na leptospirose................................................. 36

3.2. Epidemiologia e manifestação clínica da síndrome pulmonar hemorrágica na leptospirose........................................................................................... 41

3.3. Patologia e patogênese da síndrome hemorrágica pulmonar na leptospirose. 43

\section{MÉTODOS.}

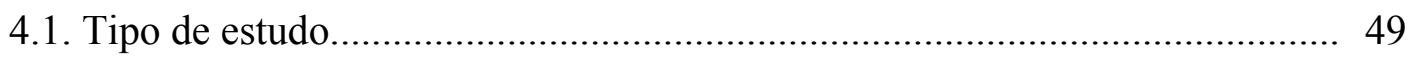

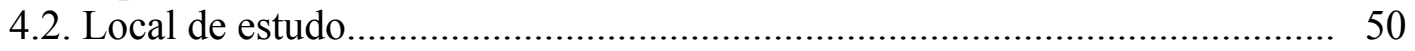

4.3. População de estudo.............................................................................. 50

4.4. Critérios de inclusão................................................................................ 51

4.5. Critérios de exclusão................................................................................ 51

4.6. Aspectos epidemiológicos, clínicos e laboratoriais........................................ 52

4.7. Processamento do material e avaliação semi-quantitativa dos eventos histopatológicos............................................................................................ 53

4.8. Método imuno-histoquímico....................................................................... 54 
4.9. Avaliação sorológica dos auto-anticorpos............................................. 57

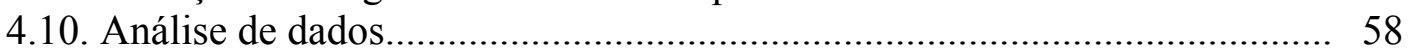

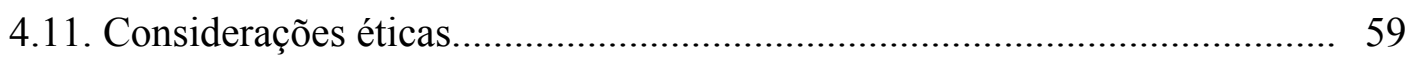

5. RESULTADOS.......................................................................................................... 60

5.1. Dados demográficos e epidemiológicos.............................................. 60

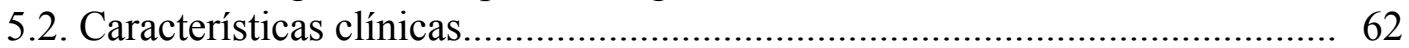

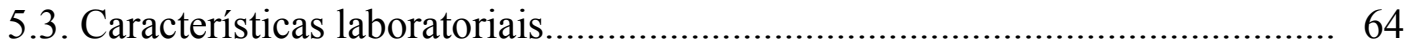

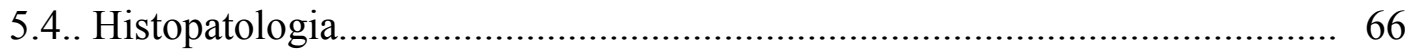

5.5. Avaliação Imuno-histoquímica.............................................................. 70

5.6. Ausência de anticorpos anti-membrana basal e anti-fosfolípide nos soros de pacientes com SPHL............................................................................. 79

6. DISCUSSÃO

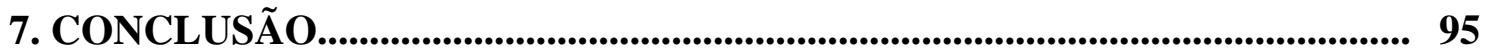

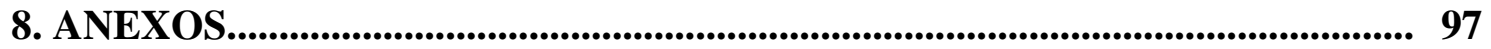

8.1. Anexo A - Aprovação pela CaPPesq........................................................ 97

8.2. Anexo B - Questionário aplicado à coleta de dados................................. 98

9. REFERÊNCIAS BIBLIOGRÁFICAS..................................................... 104

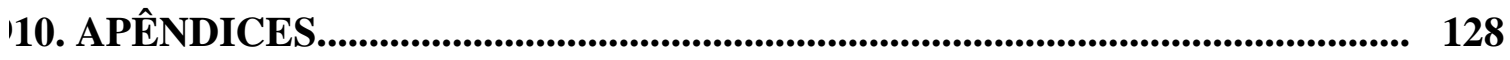

10.1. Apêndice A - Artigo submetido ao "The journal of Pathology"............ 128 



\section{LISTA DE ABREVIATURAS E SIGLAS}

11-DH-TXB2 11-dehydrogenatetromboxane B2/ 11-desidrogenato tromboxano B2

aCL Anticorpo anticardiolipina

ALT Alanina aminotransferase

ANOVA Análise de variância

AST Aspartato aminotransferase

C3 Complemento tipo 3

CIVD Coagulação intravascular disseminada

CpqGM Centro de Pesquisa Gonçalo Moniz

CSA Catalysed Signal Amplification / Sinal de amplificação sinalizada

DAD Dano alveolar difuso

DNA Deoxiribonucleic acid / ácido deoxirribonucléico

DO Densidade óptica

Dr/Dra Doutor/Doutora

Ed. Edição

EHS Engelbreth-Holm-Swarm

ELISA Enzyme-Linked Immunosorbent Assay / ensaio imunoenzimático

EMJH Ellinghausen-McCullough-Johnson-Harris

EpiData Programa para elaboração de banco de dados

et al. E outros

FAPESP $\quad$ Fundação de Amparo à Pesquisa do Estado de São Paulo 


$\begin{array}{ll}\text { FiO2 } & \text { Fração inspirada de oxigênio } \\ \text { flaB } & \text { Gene flagelina B } \\ \text { Ig } & \text { Imunoglobulina } \\ \text { IgA } & \text { Imunoglobulina tipo A } \\ \text { IgG } & \text { Imunoglobulina tipo G } \\ \text { IgM } & \text { Imunoglobulina tipo M } \\ \text { Ligs } & \text { Immunoglobulin like proteins / proteínas do tipo imunoglobulina } \\ \text { LIM } & \text { Laboratório de Investigação Médica } \\ \text { LipL32 } & \text { Lipoproteína 32 } \\ \text { LPS } & \text { Lipopolissacarídeo } \\ \text { pafAH } & \text { PAF acetilhidrolase } \\ \text { PaO2 } & \text { Pressão parcial de oxigênio } \\ \text { PBS } & \text { Tampão salino tamponado } \\ \text { PCR } & \text { Reação da polimerase em cadeia } \\ \text { PG } & \text { Peptideoglicano } \\ \text { Prof/Profa } & \text { Professor/Professora } \\ \text { SABC } & \text { Streptavidin-Biotin Peroxidase / Estreptavidina-biotina peroxidase } \\ \text { SAS } & \text { Statistical Analysis Software / Programa de análise estatística } \\ \text { SDS } & \text { Sódio dodecil sulfato } \\ \text { SPHL } & \text { síndrome pulmonar hemorrágica na leptospirose } \\ \text { TAT } & \text { complexo trombina-antitrombina III } \\ \text { TGO } & \text { Transaminase glutâmico-oxaloacética } \\ & \end{array}$


TGP

TLR

TNF- $\alpha$

USP
Transaminase glutâmico-pirúvica

Tool Like receptor / Receptores "Toll Like"

Fator de necrose tumoral alfa

Universidade de São Paulo 


\section{LISTA DE SÍMBOLOS}

$\begin{array}{ll}\% & \text { Porcentagem } \\ \mathrm{cm} /< & \text { Maior / Menor } \\ \mathrm{g} & \text { Centímetro } \\ \mathrm{kDa} & \text { Grama } \\ \mathrm{mA} & \text { Kilodaltons / quilodaltons } \\ \mathrm{Mb} & \text { MiliAmpere } \\ \mathrm{mg} / \mathrm{dl} & \text { Megabase } \\ \mathrm{mL} & \text { Miligrama por decilitro } \\ \mathrm{mm} & \text { mililitro } \\ \mathrm{mm} 3 & \text { Milimetro } \\ \mathrm{mmHg} & \text { Milimetro cúbico } \\ \mathrm{mmol} / \mathrm{L} & \text { Milímetro de mercúrio } \\ \mathrm{n} & \text { Milimol por litro } \\ \mathrm{ng} & \text { Tamanho da amostra } \\ { }^{\circ} \mathrm{C} & \text { Nanograma } \\ \mathrm{rpm} & \text { Graus Celsius } \\ \mu \mathrm{gg} / \mathrm{mL} & \text { Rotações por minuto } \\ \mu \mathrm{Ml} & \text { Micrograma por mililitro } \\ \mathrm{Mm} & \text { Microlitro } \\ \mathrm{m} & \text { Micrometro } \\ \mathrm{m} & \end{array}$




\section{RESUMO}

Croda J. Patogênese da síndrome pulmonar hemorrágica na leptospirose humana [tese]. São Paulo: Faculdade de Medicina, Universidade de São Paulo; 2008. 127p.

A leptospirose é uma zoonose de alta morbidade em humanos e um importante problema de saúde pública. Causada por bactérias do gênero Leptospira, a doença apresenta diversas formas clínicas e é especialmente importante em países em desenvolvimento. Síndrome pulmonar hemorrágica é a maior causa de óbito em pacientes com formas severas da doença. Os mecanismos patogênicos relacionados à síndrome pulmonar hemorrágica na leptospirose humana são desconhecidos. Com o objetivo de avaliar estes mecanismos patogênicos, 30 necrópsias (tecido pulmonar) de pacientes com síndrome pulmonar hemorrágica na leptospirose e 7 controles foram avaliados. Para determinar a participação os mecanismos patogênicos envolvidos, experimentos de histologia e imunohistoquímica ( $\operatorname{IgM}, \operatorname{IgG}, \operatorname{Ig} \mathrm{A}$, and $\mathrm{C} 3$ ) foram realizados em amostras de tecidos pulmonares, bem como dosagem sérica de auto-anticorpos específicos (anticardiolipina e anti-membrana basal) de amostras pareadas de soros de pacientes com leptospirose com e sem síndrome hemorrágica pulmonar e de indivíduos doadores de banco de sangue. Nos achados patológicos, os pacientes com síndrome hemorrágica pulmonar na leptospirose diferem dos controles com hemorragia pulmonar em alguns aspectos: moderada ou intensa presença de macrófagos na luz alveolar (97\% versus $29 \%$, respectivamente; $\mathrm{p}<0.01)$; presença de membrana hialina na superficie alveolar $(100 \%$ versus $0 \%$ respectivamente; $\mathrm{p}<0.01$ ); intensa necrose e regeneração de pneumócitos II 
$(100 \%$ versus $0 \%$, respectivamente; $\mathrm{p}<0.01)$; e presença de plasmócitos no septo aveolar $(80 \%$ versus $29 \% ; \mathrm{p}<0.02)$. Nenhuma diferença estatisticamente significativa foi observada em relação ao número de outras células no septo alveolar. Leptospiras intactas foram raramente observadas. A detecção de antígeno de leptospira não foi correlacionada com a intensidade de hemorragia pulmonar. Em nenhum dos tecidos pulmonares estudados foi evidenciado alterações microscópicas sugestivas de coagulação intravascular disseminada. Deposição de imunoglobulina foi detectada na superfície alveolar de 18 de 30 pacientes com síndrome pulmonar hemorrágica na leptospirose. Três padrões de marcação de imunoglobulina e complemento foram observados em tecido pulmonar de pacientes com hemorragia pulmonar e leptospirose: (A) marcação linear delicada, como uma membrana, recobrindo a superfície luminal alveolar de pneumócitos I e II; (MF) marcação multifocal, aleatória ao longo do septo; e (I) marcação fraca granular, focal, intra-alveolar. Não houve diferenças significativas na concentração de auto-anticorpos contra membrana basal nos diferentes grupos estudados. Observamos diferenças significativas nos títulos de anticorpos IgM anticardiolipina entre a primeira e segunda amostra, nos pacientes com e sem hemorragia pulmonar $(\mathrm{p}<0.01$ e $\mathrm{p}=0.04$, respectivamente). Aumento significativo nos títulos de anticorpos anti-cardiolipina da classe $\operatorname{IgG}$, bem como na relação $\operatorname{IgG} / \operatorname{IgM}$, foi observado apenas nos pacientes com hemorragia pulmonar $(\mathrm{p}=0.01$ e $\mathrm{p}=0.01)$. Nós concluímos que o comprometimento pulmonar na leptospirose humana grave ocorre principalmente sob a forma de uma pneumopatia hemorrágica com características peculiares, cujo quadro morfológico difere de outras hemorragias pulmonares. Caracteriza-se pela deposição linear de imunoglobulina (IgM, IgG e $\operatorname{IgA}$ ) e 
complemento(C3) na superfície luminal alveolar de pneumócitos I e II e multifocal nos septos alveolares. Associa-se à intensa necrose de pneumócitos I e II, regeneração de pneumócitos II, além de inflamação septal e alveolar. 


\section{SUMMARY}

Croda J. Pathogenesis of leptospirosis pulmonary hemorrhage syndrome in human [thesis]. São Paulo: "Faculdade de Medicina, Universidade de São Paulo"; 2008. 127p.

Leptospirosis is a zoonotic disease that is a cause of high morbidity and mortality in humans and is an important public health problem. Caused by bacteria of Leptospira genus, this disease presents diverse clinical manifestations and is especially important in developing countries. Leptospirosis pulmonary hemorrhage syndrome is the major cause of death in patients with the severe form of leptospirosis. The pathogenic mechanisms of this syndrome are unknown. With the purpose of identifying these pathogenic mechanisms, 30 necropsies (pulmonary samples) from patients with leptospirosis pulmonary hemorrhage syndrome and seven controls were evaluated. . To determine whether the immune system is involved, histology and immunohistochemistry (IgM, IgG, IgA, and C3) experiments were performed on lung tissue samples, as well sera measurements of autoantibodies (against the basal membrane and anti-cardiolipin) were performed in leptospirosis patients with and without pulmonary hemorrhage syndrome (in paired samples) and in healthy donors from a blood bank. We found that patients with leptospirosis pulmonary hemorrhage syndrome differed from control pulmonary hemorrhage patients in several features: the presence of moderate to high levels of macrophages in the alveolar space $(77 \%$ versus $29 \%$, respectively; $p=0.02)$, the presence of the focal hyaline membrane on alveolar surface $(100 \%$ versus $0 \% ; p<0.01)$, extensive necrosis and regeneration of pneumocyte II cells $(100 \%$ versus $0 \% ; p<0.01)$ 
and the presence of plasma cells in the alveolar septum ( $77 \%$ versus $29 \%$, respectively; $p=0.02$ ). No statistically significant differences were observed in the number of others cells in the alveolar septae. Intact leptospires were rarely detected. Leptospiral antigen was not correlated with the intensity of the lesions. None of the patients showed microscopic evidence for disseminated intravascular coagulation. Immunoglobulin deposits were detected on the alveolar surface of 18/30 leptospirosis patients with pulmonary hemorrhage. Three staining patterns were observed for the immunoglobulins and $\mathrm{C} 3$ in the lung tissues of leptospirosis patients with pulmonary hemorrhage syndrom: (A) delicate linear staining adjacent to the alveolar surface, like a membrane covering the luminal surface of type I and II pneumocyte cells; (MF) random, multifocal staining along the alveolar septum; and (I) weak, focal intra-alveolar granular staining.. We were not able to show any significant difference in autoantibodies concentration in the different groups. We found significant difference between the titles of anticardiolipin IgM antibodies in the first and second sera sample from leptospirosis patients with and without pulmonary hemorrhage $(\mathrm{p}<0.01$ e $\mathrm{p}=0.04$, respectively). The increased in the titles of anti-cardiolipin $\mathrm{IgG}$ antibodies, as well $\mathrm{IgG} / \mathrm{IgM}$ ratio was observed only in patients with pulmonary hemorrhage $(\mathrm{p}=0.01$ and $\mathrm{p}=0.01)$. We concluded that the pulmonary involvement on severe human leptospirosis have particular characteristics, which the morphologic aspect differ from the others causes of lung hemorrhage. It was distinguished by linear deposition of immunoglobulin and complement $(\mathrm{C} 3 \mathrm{C})$ on the luminal alveolar surface of pneumocyte I and II cells. This event was associated with pneumocyte I and II cells necrosis, pneumocyte II regeneration and septal and alveolar inflammation. 


\section{INTRODUÇÃO}

A leptospirose é uma doença infecto-contagiosa que acomete os animais domésticos, silvestres e o homem, sendo classificada como uma importante antropozoonose $^{1-3}$. A doença é causada por diferentes espécies do gênero Leptospira e produz um largo espectro de manifestações clínicas, desde uma doença influenza-símile, auto-limitada, até formas graves como a síndrome de Weil, caracterizada por icterícia, insuficiência renal aguda e hemorragia. Embora a leptospirose seja amplamente distribuída e ocorra de forma endêmica em várias partes do globo ${ }^{4,5}$, os conhecimentos acerca da biologia e patologia das leptospiras ainda são limitados ${ }^{1,6}$.

A doença foi primeiramente descrita pelo médico alemão Adolf Weil, em 1886, como uma doença infecciosa que causava esplenomegalia, nefrite e icterícia. Por esse motivo a forma grave da doença em humanos é denominada Doença de Weil ${ }^{1,}$. Stimson et al. (1907) foram os primeiros a visualizar o microrganismo em cortes histológicos de rins corados pela prata, oriundos de um paciente com diagnóstico de febre amarela. As leptospiras formavam agregados nos rins e individualmente apresentavam forma em ponto de interrogação, sendo por isso denominadas Spirochaeta interrogans $^{1,7}$. O primeiro isolamento de leptospiras patogênicas foi feito por Inada et al. (1916), no Japão, onde os pesquisadores realizaram estudos clássicos de infecção 
experimental, inoculando em cobaias sangue de um paciente com doença ictérica febril. Analisando o tecido hepático dos animais, evidenciaram a presença de um espiroquetídeo, denominando-o Spirochaeta icterohaemorrhagiae. Noguchi et.al (1918), conseguiram classificar o agente em um novo gênero, Leptospira (do grego leptós, fino, pequeno, delicado e speira, espira, novelo) denominando a espécie patogênica de Leptospira icterohaemorrhagiae e incluindo também neste gênero, devido a similaridades morfológicas, a Spirochaeta biflexa ${ }^{1,7}$.

Em 1922, Wadsworth relatou o primeiro caso de leptospirose humana devido à exposição ao rato ${ }^{1,7}$.

A lesão tecidual primordial da leptospirose parece ser a lesão endotelial, levando às hemorragias nos tecidos ${ }^{1}$. As hemorragias são uma importante complicação da leptospirose e contribuem para a letalidade da doença ${ }^{8,9}$. A hemólise apresenta vantagens para a bactéria, ao disponibilizar ferro e ácidos graxos que são essenciais para o seu crescimento. A fonte de ferro mais abundante no hospedeiro é o heme e leptospiras são capazes de usar heme e hemoglobina in vitro ${ }^{10}$. Hemorragias, anemia hemolítica, hemoglobinemia, hemoglobinúria e icterícia são achados decorrentes da hemólise e lesão endotelial ${ }^{11-13}$. A trombocitopenia é comumente observada nas formas graves da leptospirose, podendo ocorrer em decorrência de hemorragias, citotoxicidade e agregação plaquetária 9, 11-14. A ocorrência de coagulação intravascular disseminada (CIVD) permanece controversa na patogenia da leptospirose ${ }^{9,14,15}$ 
A infecção por leptospiras patogênicas produz espectro de doença bastante variado, desde formas subclínicas até formas severas, potencialmente letais, como a síndrome da hemorragia pulmonar. O completo mecanismo patogênico da doença permanece, até o momento, não totalmente compreendido. Questões como quais seriam os fatores determinantes desta variedade de apresentação da doença, continuam sem uma explicação clara ${ }^{3}$.

O comprometimento pulmonar caracteriza-se ao exame radiológico pela presença de infiltrado pulmonar difuso ou localizado, usualmente com apresentação mais severa que na forma anictérica. A insuficiência respiratória é atribuída às alterações da difusão do oxigênio através da membrana alvéolo-capilar decorrente do edema e extravasamento de sangue no interstício pulmonar no interior de alvéolos, assim como pelo aumento do shunt arteriovenoso pulmonar ${ }^{1,7}$.

No Brasil, a hemorragia pulmonar constitui o principal fator de risco para o óbito com taxas de letalidade para essa forma da doença superior a 50\% ${ }^{16,17}$.

O tratamento da insuficiência respiratória constitui o aspecto de maior impacto na redução na letalidade da forma grave. O paciente deve ter a sua pressão parcial de oxigênio $\left(\mathrm{pO}_{2}\right)$ monitorizada e mantida acima de $80 \mathrm{~mm} \mathrm{Hg}$. Para tanto, deve-se utilizar todas as técnicas terapêuticas para o tratamento da insuficiência respiratória, inclusive ventilação mecânica. Nestas situações preconiza-se a ventilação protetora com hipercapneia permissiva (volume corrente $<6 \mathrm{ml} / \mathrm{Kg}$ e pressão expiratória final positiva 
elevada). Deve-se evitar reposição hídrica em excesso para não agravar o quadro de insuficiência respiratória instalada. A monitorização hemodinâmica pode ser de valor para auxiliar no adequado controle da reposição volêmica ${ }^{18,19}$.

Mesmo com as atuais bases terapêuticas como: instituição de diálise precoce, melhor controle da insuficiência renal e a utilização de estratégias de ventilação protetora utilizadas nos casos de SPHL, há uma ineficácia para reduzir significativamente a alta letalidade desta forma de manifestação na leptospirose ${ }^{17,19}$.

Novas terapêuticas têm sido propostas para pacientes com SPHL, baseadas na ainda escassa evidência do mecanismo patogenético desta forma de manifestação da leptospirose. Estudos recentes, em modelos animais, demonstraram que alguns dos fenômenos relacionados à hemorragia pulmonar são imuno-mediados, principalmente relacionados a depósito de imunoglobulinas e complemento nos septos alveolares ao longo da membrana basal (Goodpasture símile) ${ }^{15}$. Seguindo os modelos de tratamento baseado em doenças auto-imunes, um estudo de série de casos publicado em 2006 evidenciou redução de $62 \%$ para $18 \%$ na mortalidade nos pacientes com leptospirose e hemorragia pulmonar que utilizaram metilprednisolona ${ }^{20}$. Não há ainda ensaios clínicos validando estes achados.

O melhor entendimento dos mecanismos de lesão envolvidos na síndrome pulmonar hemorrágica na leptospirose nos permitirá propor novas terapêutica específicas a fim de diminuir a alta letalidade associada a essa forma da doença. 


\section{OBJETIVOS}

\subsection{Objetivos gerais}

1. Determinar os mecanismos envolvidos na lesão pulmonar em pacientes que foram a óbito com síndrome de pulmonar hemorrágica na leptospirose.

\subsection{Objetivos específicos}

1. Descrever características clínicas e epidemiológicas dos pacientes com SPHL que foram a óbito e submetidos à necropsia no período de 1988 a 2005, no serviço de verificação de óbito do HCFMUSP.

2. Avaliar em humanos as principais alterações morfológicas e estruturais do pulmão de pacientes com leptospirose e hemorragia pulmonar.

3. Detectar depósitos de imunoglobulinas (IgM, $\operatorname{IgG}$ e $\operatorname{Ig} \mathrm{A})$ e complemento no tecido pulmonar de pacientes com leptospirose e hemorragia pulmonar.

4. Determinar se auto-anticorpos específicos são responsáveis pela lesão pulmonar em pacientes com leptospirose e hemorragia pulmonar. 


\section{REVISÃO DA LITERATURA}

\subsection{Epidemiologia}

Embora a leptospirose tenha distribuição mundial, a grande maioria dos casos ocorre nos países tropicais e em desenvolvimento onde a doença se apresenta de forma endêmica $^{1,3}$. Somente na última década a leptospirose ganhou atenção como um importante problema de saúde pública global. Atribuí-se este reconhecimento à emergência da SPHL (síndrome pulmonar hemorrágica na leptospirose) em todo o mundo 2, 16, 17, 21-24, à identificação de surtos de leptospirose durante desastres ${ }^{25-28}$, atividades de recreação e turismo ${ }^{29-31}$, e às grandes epidemias como a ocorrida na Tailândia no final da década de 1990, onde mais de 45.000 casos de leptospirose foram identificados ${ }^{32}$. A maior incidência da doença ocorre durante as estações chuvosas e provavelmente se deve a surtos pós-exposição à água contaminada ${ }^{5,33}$. A Organização Mundial de Saúde estima que mais de um milhão de casos de leptospirose ocorra por ano ${ }^{34}$. Entretanto, a dificuldade para estabelecimento do diagnóstico da doença em pacientes que apresentam formas leves e a inexistência de um teste diagnóstico rápido e 
acessível, faz com que o impacto global da leptospirose seja subestimado sendo, portanto baseado principalmente nos pacientes com formas graves da doença ${ }^{35}$.

A doença é considerada a zoonose mais difundida no mundo, devido à habilidade do patógeno de induzir um estado de portador em uma gama extensa de animais selvagens e domésticos. Os roedores são os reservatórios principais de leptospiras, sendo o rato de esgoto (Rattus rattus e Rattus norvegicus) fundamental para a transmissão da doença no meio urbano ${ }^{36}$. No Brasil o Rattus norvegicus e o Rattus rattus são os reservatórios de L. interrogans serovar Copenhageni, o serovar responsável pelas epidemias urbanas da doença ${ }^{5}$. Existe uma grande diversidade de reservatórios ou hospedeiros de manutenção de leptospiras, compreendendo animais silvestres e domésticos, como caninos, bovinos, suínos, caprinos e ovinos. Cada serovar tende a ser mantido por um hospedeiro animal específico, sendo este serovar considerado adaptado à determinada espécie animal. As associações de reservatórios e serovares mais conhecidas são: cães e serovar Canicola, bovinos e serovar Hardjo, suínos e serovar Pomona, roedores e serovar Icterohaemorrhagiae ou serovar Copenhageni ou serovar Lai. A taxa de infecção em ratos varia segundo os autores de $10 \%{ }^{37,38}$ a $33 \%{ }^{38}$. Os reservatórios animais são cronicamente infectados nos rins pelos diferentes serovares de Leptospira ${ }^{1}$. Desta forma, a transmissão da leptospirose ocorre através da eliminação de leptospiras na urina ou secreções destes animais, contaminando coleções de água e solo, sendo a água o principal veículo de transmissão da doença ${ }^{2}$. As vias de transmissão clássicas da leptospirose são através do contato com a pele lesada e mucosa. O 
conhecimento dos serovares e seus hospedeiros de manutenção são essenciais para a compreensão da epidemiologia da doença em uma dada região ${ }^{1}$. O homem é sempre um hospedeiro incidental no ciclo da leptospirose ${ }^{7}$ (Figura 1). 


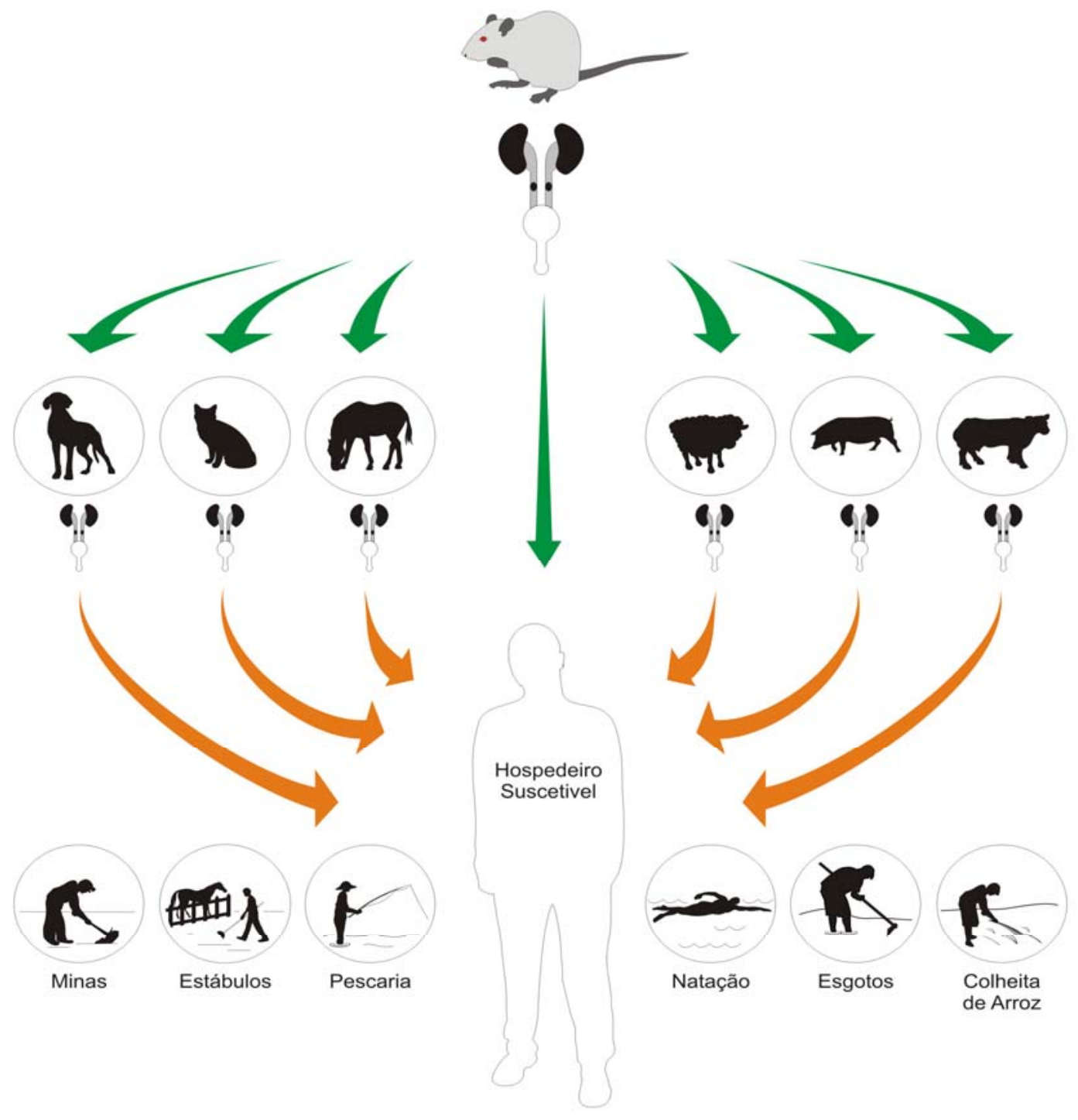

Figura 1 - Principais reservatórios da Leptospira e modos de transmissão humana, através da exposição a locais contaminados. Adaptado de Veronesi: Tratado de Infectologia, 2004. 
Mais de $80 \%$ dos casos de leptospirose grave são identificados na população masculina adulta $5,32,34,39-41$. Este achado tem sido justificado pelo dogma de que a leptospirose é uma doença ocupacional e esporádica, associada a profissões masculinas como agricultura, pecuária, mineração, manutenção de esgotos e serviços militares ${ }^{1,3}$. Embora a população de maior risco seja tradicionalmente representada por agricultores de subsistência da zona rural ${ }^{1,3,7}$, atualmente a leptospirose emerge como uma doença urbana que acomete os moradores pobres de comunidades carentes (favelas) de países em desenvolvimento ${ }^{2,42}$. A rápida urbanização e a crescente desigualdade social levaram a um dramático aumento da população nessas comunidades urbanas, onde a falta de saneamento básico favorece a transmissão da leptospirose pelos ratos. A importância da leptospirose urbana como problema de saúde pública deverá tornar-se ainda maior no futuro, pois as Nações Unidas estimam que nos próximos vinte e cinco anos a população de moradores de favelas dobrará de um para dois bilhões de pessoas ${ }^{43}$.

Atualmente, a maioria dos 3000 casos notificados anualmente ao Ministério da Saúde brasileiro é da forme grave da doença e acometem principalmente a população mais pobre que reside nas grandes favelas, sem saneamento básico ${ }^{2}$. Dados do estado de São Paulo revelam uma incidência anual de 0.53 por 100.000 habitantes ${ }^{44}$. As faixas etárias mais atingidas são as do adulto jovem, entre 20 e 40 anos, principalmente do sexo masculino com taxa de letalidade em torno de $15 \%{ }^{5}$, sendo o sorovar copenhageni (pertencente ao sorogrupo Icterohaemorrhagiae) o mais prevalente nessas áreas urbanas 
2. Estudos de soroprevalência indicam que 12, 7-15, 4\% da população das grandes cidades brasileiras apresentam exposição prévia para o agente ${ }^{33,45}$.

\subsection{Microbiologia}

As leptospiras são bactérias helicoidais móveis, constituídas por um corpo citoplasmático, um axóstilo enrolado em espiral e uma membrana envolvente que recobre ambas as estruturas. Variam de 6 a $25 \mu \mathrm{m}$ de comprimento por cerca de $0,1 \mu \mathrm{m}$ de diâmetro. Possuem dois endoflagelos que são inseridos subterminalmente (Figura 2). São aeróbias ou microaerófilas obrigatórios, compartilham características de bactérias Gram positivas e Gram negativas, porém com características singulares de parede, tais como o peptidoglicano ligado à membrana citoplasmática ${ }^{1,3,7}$. 


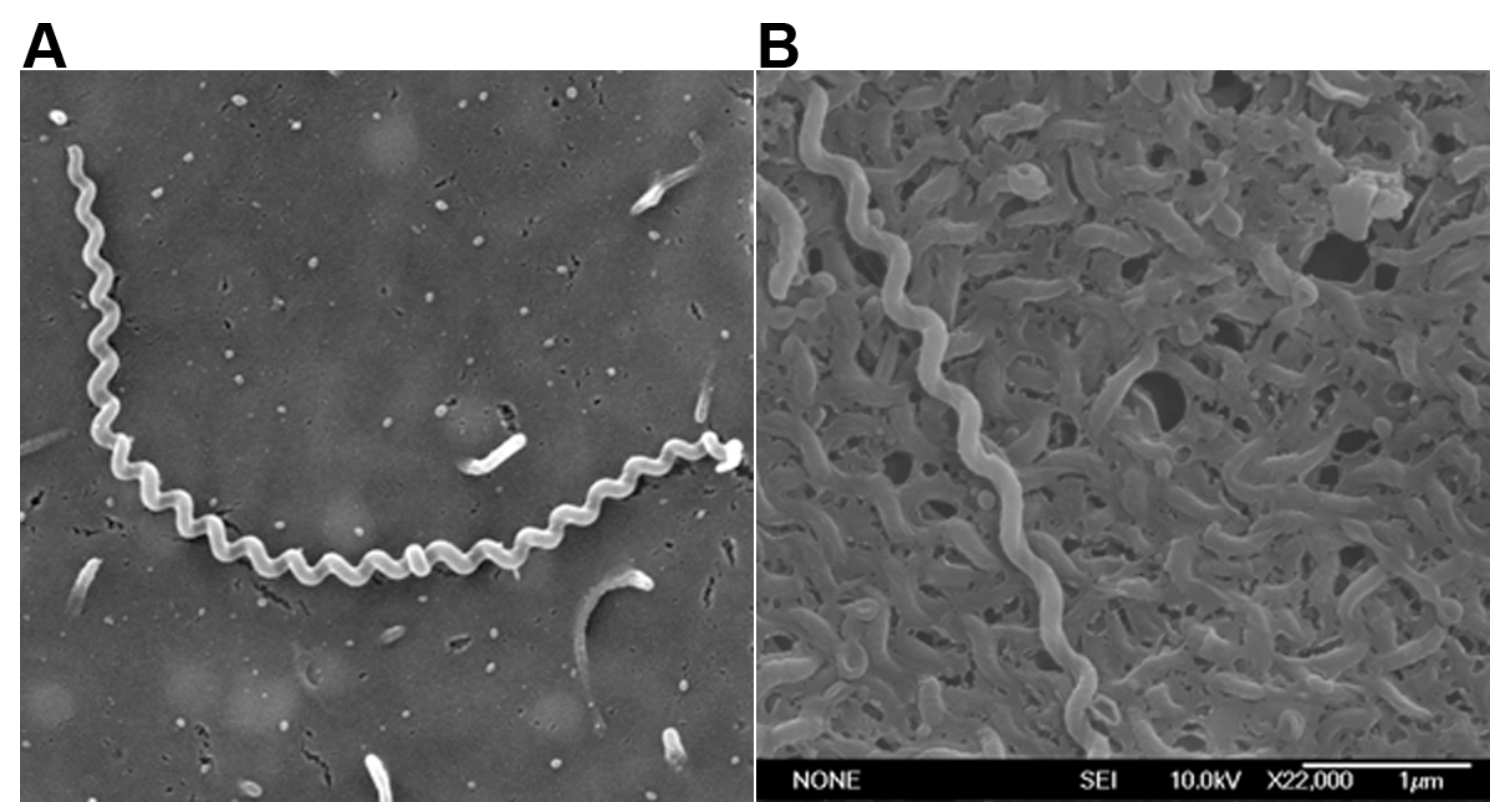

Figura 2 - Agente etiológico da leptospirose. Microscopia eletrônica de varredura da Letospira spp. Em célula MDCK (A) e em meio de cultura formando biofilme (B). Cortesia Claúdio Pereira Figueira e Paula Ristow.

São bactérias de difícil cultivo que não se coram pelos métodos usuais de coloração. A sua principal fonte de energia são os ácidos graxos de cadeia longa, sendo a amônia e o ferro nutrientes essenciais. Por estas características, para seu crescimento em meio artificial, são necessários meios especiais enriquecidos com albumina bovina, soro de coelho, vitaminas B1 e B12. O meio de cultura mais utilizado para o seu cultivo é o meio Ellinghausen-McCullough-Johnson-Harris (EMJH), que contém ácido oléico, soro albumina bovina como detoxificante e tween 80 como fonte de carbono ${ }^{46-48}$. O crescimento em meio de cultura pode variar de dois a 30 dias ${ }^{7}$. 
A leptospirose é causada por espécies de espiroquetas pertencentes ao gênero Leptospira. Pertencem à família Spirochaetales, ordem Leptospiraceae, gênero Leptospira, que compreende duas espécies: interrogans e biflexa. A espécie patogênica para o homem é a interrogans, e a de vida saprofítica ou aquática, não patogênica, é a biflexa. As espécies interrogans e biflexa são subdivididas em sorotipos ou sorovares com base nas suas características antigênicas. Os sorotipos antigenicamente relacionados formam um sorogrupo. A base taxonômica freqüentemente usada é o sorotipo ou sorovar, uma vez que as leptospiras possuem antígenos específicos relativamente estáveis reconhecidos pela capacidade de aglutinar anti-soros homólogos específicos. A espécie interrogans compreende mais de 200 sorovares ou sorotipos distribuídos em 24 sorogrupos. A L. biflexa é composta por mais de 60 sorovares ${ }^{3}$. No Brasil, os sorovares de maior importância são icterohaemorrhagiae e copenhageni. ${ }^{5}$

Com o desenvolvimento das técnicas de hibridização do DNA e da análise da homologia do DNA-DNA, a classificação das leptospiras vem sofrendo modificações. Por essas técnicas, o gênero foi dividido em 17 espécies, definidas por no mínimo 70\% de homologia no DNA relacionado, com no máximo 5\% de divergência (bases não pareadas). Destas, 14 espécies são consideradas patogênicas (L. interrogans, L. alexanderi, L. fainei, L. inadai, L. kirschneri, L. meyeri, L. borgpetersenii, L. wellii, L. noguchii, L. santarosai, genomospecies 1, genomospecies 4 e genomospecies 5) e 3 espécies não patogênicas (genomospecies 3, L. biflexa e L. wolbachii). Essa classificação coexiste com a classificação antiga, baseada na capacidade de aglutinar anti-soros 
homólogos específicos. Técnicas de tipagem baseadas no polimorfismo de genético vêm sendo validadas e dados iniciais demonstram a utilidade dessa ferramenta em substituição a soroaglutinação na identificação dos sorotipos ${ }^{3}$.

\section{3.. Genética}

Durante os últimos anos, evidenciou-se um extraordinário progresso no estudo da biologia molecular de espiroquetas do gênero Leptospira ${ }^{49-51}$, porém, o conhecimento da genética desta bactéria ainda é incipiente se comparado ao de outras espécies bacterianas. Os avanços no conhecimento da biologia das leptospiras são dificultados pela ausência de ferramentas genéticas adequadas e eficientes para o seu estudo ${ }^{52,53}$. O seqüenciamento genético completo de três cepas patogênicas de Leptospira ${ }^{6,54-56}$ e de uma saprófita, L. biflexa ${ }^{6}$, trouxe novas perspectivas para o estudo dessa bactéria. O genoma de L. interrogans serovar Lai, uma leptospira que é altamente invasiva e causa doença grave, consiste de dois cromossomos circulares, um grande de 4,33 $\mathrm{Mb}$ e um pequeno de $0,35 \mathrm{Mb}$. O seu genoma possui conteúdo G-C médio de $36 \%$ e aproximadamente 4.700 seqüências abertas de leitura ou open reading frames (ORFs), dentre as quais mais de $50 \%$ não exibem similaridades com proteínas de função conhecida ou proteínas de outros organismos ${ }^{54}$. BOURHY et al. (2007) descreveram a presença de uma região fágica de $54 \mathrm{~kb}$ com características de ilha de patogenicidade 
que pode se excisar do genoma de L.interrogans serovar Lai, formando um plasmídio circular ${ }^{57}$. Já L. borgpetersenii Hardjo, que infecta bovinos, possui uma perda genômica de $700 \mathrm{~kb}$ em relação a $L$. interrogans, o que hipoteticamente pode tornar este microrganismo menos adaptado à vida fora do hospedeiro ${ }^{56}$. O genoma de L.biflexa possui 3,9 $\mathrm{Mb}$ e um plasmídio circular ${ }^{6}$. A genômica comparada de membros patogênicos e saprófitas de Leptospira deverão revelar conhecimentos fundamentais sobre a virulência e biologia destas espiroquetas.

O seqüenciamento dos genomas de Leptospira também contribuiu para estudos de transcrição global ou microarrays. Estes estudos demonstraram haver diferenças na expressão de genes de quimiotaxia, motilidade e proteínas de membrana externa, entre outros, quando temperaturas de cultivo ambientais e fisiológicas foram comparadas ${ }^{58,59}$. A análise transcricional também foi utilizada para a triagem de genes que codificam para proteínas de membrana externa, as quais podem ser candidatas ao desenvolvimento de novas vacinas ${ }^{59}$. Estudo recente revelou que a osmolaridade fisiológica teve importância na regulação de vários genes, inclusive de fatores de virulência em potencial como ligB, sph2 e lfhA (lenA) ${ }^{60}$.

Apesar do conhecimento dos genomas de leptospiras ter gerado uma base para o esclarecimento da patogenia da leptospirose, a identificação de fatores de virulência de leptospiras ainda permanece especulativa, pois apenas estudos in vitro e in silico foram realizados até o momento ${ }^{52,61,62}$. O insucesso em manipular geneticamente bactérias do gênero Leptospira e a falta de ferramentas genéticas para as espécies patogênicas 
impossibilitaram a realização de estudos que comprovem os postulados moleculares de Koch para genes de virulência ${ }^{63}$; e as pesquisas na área não elucidaram o papel de determinantes putativos de virulência ${ }^{53,64}$. Ristow et al. (2007) identificaram o primeiro fator de virulência obtido através de mutagênese randômica utilizando o transposon mariner. Com a interrupção do gene Loa22, existiu uma diminuição da virulência dessas cepas mutantes que não expressavam a proteína Loa22 quando comparadas com a selvagem ${ }^{65}$. Mais recentemente, Croda et al. (2008) demonstraram pela primeira vez a possibilidade de mutagênese dirigida em cepas patogênicas de leptospiras através de recombinação homologa do gene $\operatorname{LigB}{ }^{66}$. O desenvolvimento de essa nova ferramenta permitirá determinar fatores de virulência na leptospirose.

\section{4. . Patogenia}

A dinâmica da patogenia da leptospirose é complexa e multifatorial. A motilidade e morfologia das leptospiras favorecem a sua penetração através da pele lesada e mucosa. Após a infecção segue-se uma rápida disseminação da bactéria na corrente sanguínea do hospedeiro e após 48 horas pode-se isolar a leptospira em praticamente todos os órgãos, inclusive no líquido cefalorraquiano. A motilidade parece ser fator preponderante para esta rápida disseminação. Dos 4768 genes identificados pelo seqüenciamento do genoma, pelo menos 50 estão relacionados com a motilidade ${ }^{54}$, 
55. A multiplicação ou leptospiremia dura em média de 3 a 10 dias. Este período compreende a primeira fase da doença, dita não imune, onde se manifesta uma sintomatologia branda e inespecífica. Após esta fase, ocorre o desenvolvimento de anticorpos específicos pelo sistema imune e as leptospiras irão se localizar nos órgãos alvo, como rins, fígado, pulmões e musculatura esquelética, provocando a sintomatologia clássica da doença. O lúmen dos túbulos renais, área do organismo onde os anticorpos estão em níveis baixos, parece ser o local preferencial da colonização por leptospiras. Uma vez a infecção instalada, pode haver a evolução para uma doença aguda em hospedeiros sensíveis, o desenvolvimento de imunidade protetora com eliminação do microrganismo ou desenvolvimento do estado de portador crônico ${ }^{7}$.

As leptospiras patogênicas têm como fator de virulência a capacidade de resistir à atividade bactericida do soro normal e, na ausência de anticorpos específicos, não são fagocitadas e destruídas pelos neutrófilos polimorfonucleares ou pelos macrófagos ${ }^{67,68}$. A resistência à ação do complemento, através da neutralização pelo fator $\mathrm{H}$, parece ser o mecanismo primordial da resistência bacteriana aos anticorpos, uma vez que apenas as cepas patogênicas expressam a proteína LfhA (proteína ligadora do fator $\mathrm{H}$ ). Já as leptospiras não patogênicas são rapidamente destruídas, via sistema complemento, e clareadas da circulação pelo sistema retículo-endotelial através da fagocitose ${ }^{54,55,69}$.

A afinidade das proteínas de superfície da leptospira para com as membranas celulares sugere uma interação inicial responsável pela aderência celular e invasão do 
microorganismo no hospedeiro. Proteínas relacionadas à aderência e invasão tem sido descritas descrito dentre elas LigA, LigB, Lsa21, LfhA (len) e LipL32 ${ }^{70-73}$. LigA e LigB ligam-se a fibronectina da matriz extracelular e são expressas apenas em cepas patogênicas, e exclusivamente durante o período da infecção, sendo implicada na adesão inicial e posterior invasão do hospedeiro ${ }^{74}$.

Estudo utilizando reação imuno-histoquímica com avaliação ultraestrutural do fígado e rim de cobaia infectado com L. interrogans, sorotipo copenhageni, encontrou antígeno nas membranas dos hepatócitos, nas células dos túbulos renais e nas células endoteliais dos capilares do interstício renal. Em seguida, o antígeno foi interiorizado pelas células hepáticas e tubulares e ocasionalmente, encontrado em lisossomos. Os fagolisossomas das células de Kupffer também continham restos de leptospiras degradadas, bem como antígenos. Leptospiras intactas também foram detectadas nos espaços intercelulares alargados, entre os hepatócitos, mostrando a importância da migração das leptospiras durante a fase septicêmica da doença na patogênese das lesões 75 .

As hipóteses para a patogênese das lesões sistêmicas na leptospirose propõem que as lesões dos órgãos mais intensamente acometidos sejam decorrentes da ação direta sobre as membranas das células parenquimatosas, inicialmente da leptospira íntegra e, a seguir, também pela ação dos produtos granulosos de sua degradação por macrófagos ${ }^{76}$. Inicialmente tal ação levaria somente a distúrbios funcionais dessas membranas, 
acarretando necrose em uma fase tardia. Genes identificados recentemente, que podem contribuir com a lesão tecidual são: a) receptores de proteínas quimiotáticas (presente apenas nas cepas patogênicas associados à quimiotaxia guiado por hemoglobina podendo explicar a predileção da leptospira em acometer vasos) b) hemolisinas, esfingomielinases e fosfolipases (responsável pela degradação tecidual e favorecimento da migração através do tecido) ${ }^{54,55}$.

Lipopolissacarideos (LPS) de leptospira são considerados menos tóxicos que os lipopolissacarideos de bactérias gram-negativas, principalmente por diferenças bioquímicas, físicas e de propriedades biológicas. Entre essas propriedades está a ativação de macrófagos via receptores Toll-Like (TLR) tipo 2, ao invés da ativação do TLR tipo 4 como na infecção por bactérias gram-negativas ${ }^{77}$.

Recentemente, diversos artigos tentam elucidar a resposta imune da infecção e seu papel na lesão tecidual. A participação de citocinas como mediadores de resposta inflamatória sistêmica na leptospirose foi evidenciada através do estímulo de células sadias com extrato bruto de leptospira ${ }^{78}$. Observou-se uma produção de resposta tipo Th1, pró-inflamatória, com níveis elevados de fator alfa de necrose tumoral (TNF- $\alpha$ ), estritamente relacionado à severidade do quadro clínico e a letalidade ${ }^{79}$. Outro fato que corrobora para tal observação foi à constatação que o peptidoglicano extraído da parede celular de Leptospira interrogans induz a liberação de TNF- $\alpha$ de monócitos humanos e ativa a aderência de neutrófilos às células endoteliais ${ }^{76}$. A indução de TNF- $\alpha$ por fatores 
tóxicos bacterianos desencadeia a resposta inflamatória local e sistêmica, resultando então em dano capilar.

Em estudo conduzido por Klimpel et al. (2003) foi demonstrado o valor do inoculo na influência do tipo de resposta. Grande número de leptospiras induz preferencialmente expansão de células $\mathrm{T}$ gama-delta, já valores menores induzem a expansão de células alfa-beta. As células T gama-delta estimuladas parecem secretar interferon gama. Esses achados indicam que as células gama delta podem exercer papel fundamental na resposta imune pró-inflamatória podendo ser uma ponte entre a resposta imune inata e a adquirida ${ }^{80}$.

Uma das principais características da leptospirose é o envolvimento renal com peculiaridades específicas desta doença. A lesão patológica básica é a nefrite intersticial 81, que induz uma insuficiência renal aguda não oligúrica e freqüentemente hipocalêmica. As alterações da função tubular precedem a diminuição da taxa de filtração glomerular, o que pode explicar a presença de hipocalemia. Estudos revelam que ocorre inicialmente um aumento nas frações de excreção de sódio e potássio e da razão potássio/sódio urinário, o que sugere que há um aumento na secreção distal de potássio, causado por aumento de sódio na chegada aos túbulos distais conseqüente à diminuição da reabsorção de sódio proximal ${ }^{82}$. 


\section{5. . Patologia}

No fígado, ocorre lesão de membrana celular e os achados de destrabeculação de hepatócitos são produzidos por lesão real da membrana celular (Figura 3). Existe colestase, mais acentuada na região centro-lobular ${ }^{75,83}$. A microscopia eletrônica revela alterações nos microvilos dos colangíolos, dilatação da cisterna de Golgi e do retículo endoplasmático, ao lado de aumento de lisossomas. Todo o conjunto sugere alterações no aparelho bile-excretor. Existem evidências experimentais de indução de apoptose de hepatócitos durante a infecção ${ }^{84}$.

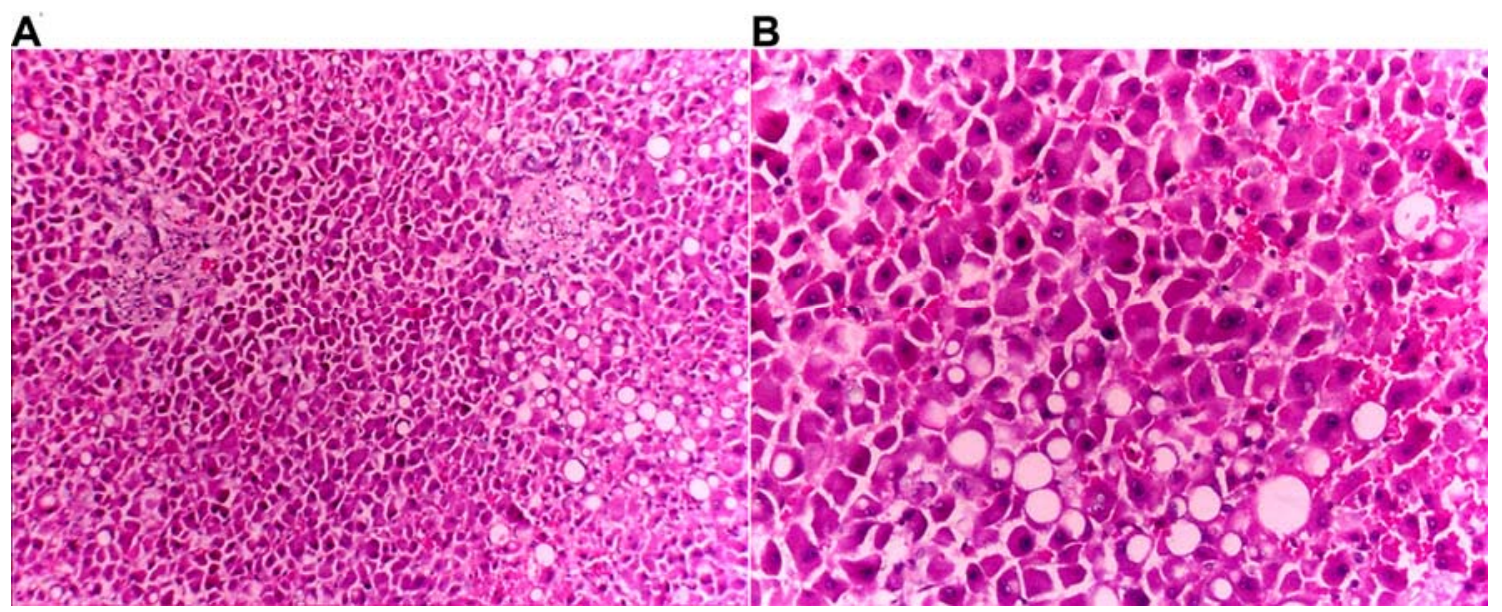

Figura 3 - Fígado evidenciando o padrão clássico de destrabeculação dos hepatócitos com perda da coesão entre eles (A). (x100). Em maior aumento (x400) evidência esteatose de alguns hepatócitos (B). Cortesia Maria Irma Seixas Duarte. 
No trato digestivo, a capilaropatia exterioriza-se pelo o aparecimento de sufusões hemorrágicas e edema da mucosa gástrica e/ou do intestino delgado dando origem com freqüência a extensas hemorragias gastrintestinais ${ }^{85,86}$.

Nos rins as principais alterações são: nefrite intersticial e necrose tubular aguda, resultantes da migração das leptospiras pelos rins e deposição de antígenos em glomérulos e túbulos. Verifica-se a presença de uma proliferação das células mesangiais e nefrite intersticial representada por acúmulo de mononucleares, particularmente linfócitos e histiócitos, acompanhado de edema, vasodilatação, congestão e tumefação endotelial (Figura 4) ${ }^{81,86}$. A necrose tubular aguda ocorre principalmente nos túbulos distais, caracterizada por túbulos dilatados, revestidos por células epiteliais baixas e de citoplasma basófilo, representando regeneração epitelial. $\mathrm{Na}$ luz, ocasionalmente, observa-se cilindros hialinos $(21,22)$ (Figura 5). 


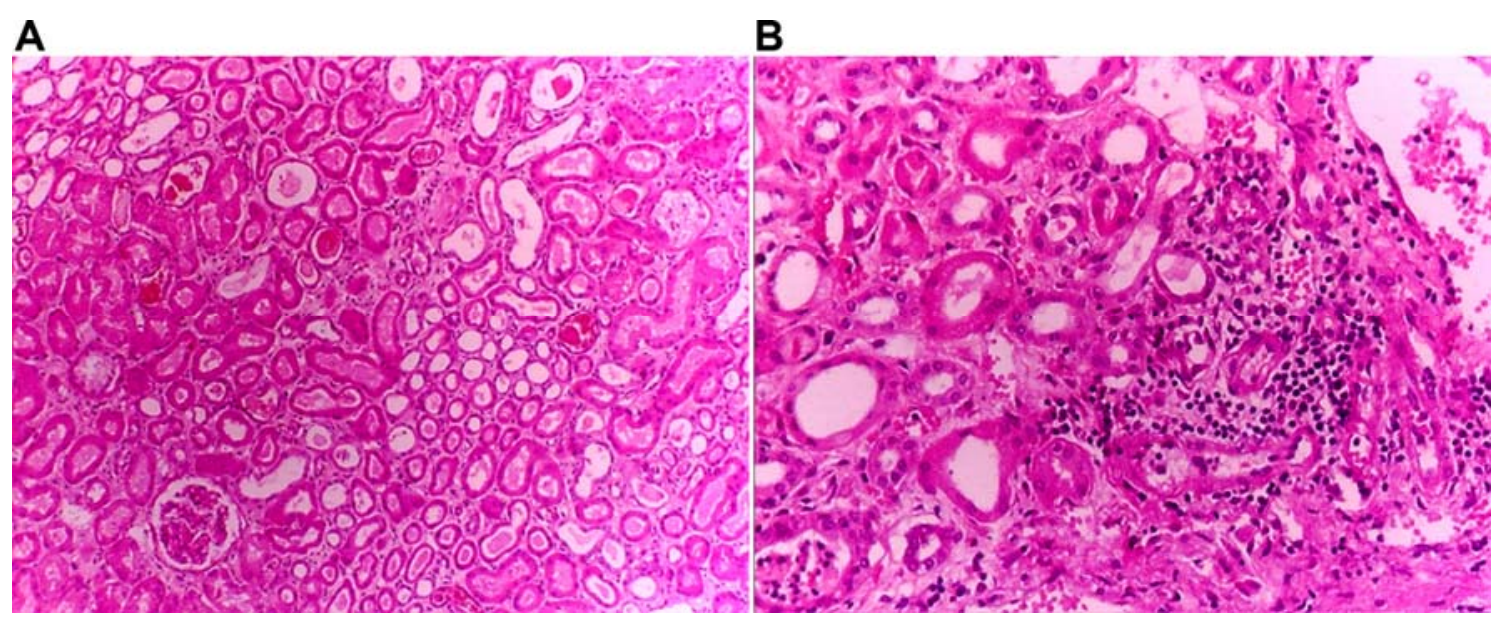

Figura 4 - Rim evidenciando necrose tubular (A) (x100) e infiltrado inflamatório mononuclear característico da nefrite intersticial (B) (x 400). Cortesia Maria Irma Seixas Duarte.

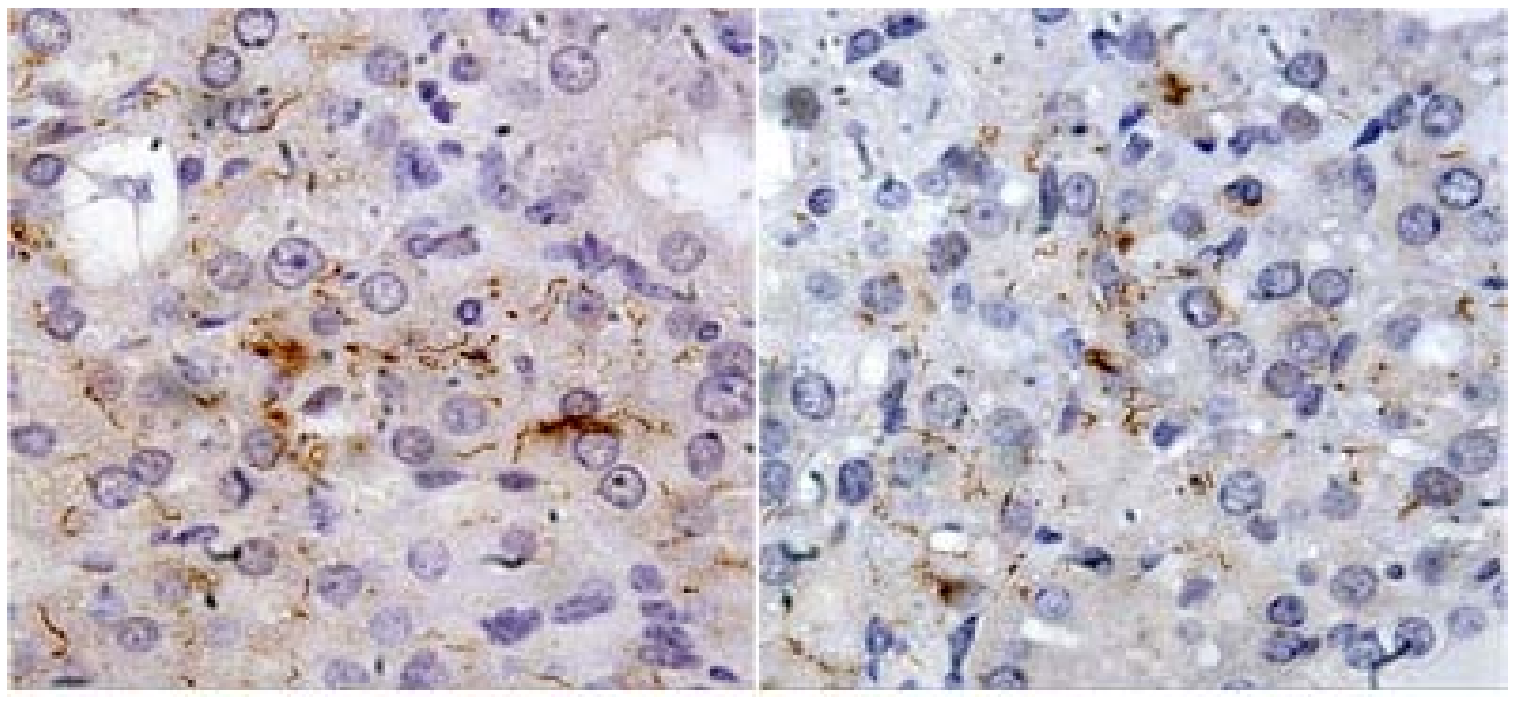

Figura 5: Reação imuno-histoquimica de rim de hamsters demonstrando imunomarcação para Leptospira. (x400). 
No coração é descrito miocardite intersticial e arterite coronária e necrose hialina de fibras miocárdicas e focos de hemorrágia ${ }^{86,87}$.

Outros órgãos ou tecidos também são afetados como as leptomeninges que exibem infiltrado inflamatório mononuclear. Nos músculos estriados são identificados focos de miosite ${ }^{85,86}$. As características patológicas do acometimento pulmonar serão descritas posteriormente.

\subsection{Manifestações Clínicas}

A maioria das infecções são assintomáticas ou auto-limitadas (Influenza-símile). Todavia, uma pequena fração (5\% a $15 \%)$ pode progredir para formas graves como a síndrome de Weil (icterícia, insuficiência renal e fenômenos hemorrágicos) e síndrome pulmonar hemorrágica ${ }^{1,7,88}$.

O período de incubação é variável, usualmente de 7 a 14 dias com extremos de 1 a 30 dias $^{7}$. A leptospirose pode apresentar uma evolução bifásica. O primeiro período é o de leptospiremia que dura de quatro a sete dias. Segue-se um período de defervescência em lise de um a dois dias, seguida de período de recrudescência da febre e dos sintomas, que pode durar de 4 a 30 dias correspondendo ao segundo período ou 
fase imune da leptospirose. Este modelo bifásico comumente não é observado nas formas mais graves da doença ${ }^{7}$.

$\mathrm{Na}$ chamada forma anictérica a doença tem início abrupto com febre, acompanhada de calafrios, cefaléia e mialgia principalmente nos músculos da panturrilha, podendo acometer outros grupos musculares. A rigidez de nuca pode refletir acometimento meníngeo. Anorexia, náuseas, vômitos, diarréia, prostração, dores articulares e hiperemia ou hemorragia conjuntival são freqüentemente observados nestes pacientes. $\mathrm{Na}$ pele podem ocorrer exantemas máculo-papulares, eritematosos, urticariformes, petequiais ou hemorrágicos. Outros sintomas menos freqüentes podem ocorrer, tais como: adenopatia cervical, parotidite, orquite, epididimite e prostatite ${ }^{7}$.

Seguindo-se a defervescência inicia-se, após um a dois dias, a fase imune. É nesta fase que os anticorpos específicos começam a ser detectados no soro. A principal manifestação clínica na fase imune das formas anictéricas é a meningite do tipo linfocitária benigna, caracterizada por cefaléia intensa, vômitos e sinais de irritação meníngea. As manifestações clínicas são semelhantes àquelas que ocorrem nas meningites virais. Em Salvador, a meningite por Leptospira representou $7.1 \%$ das meningites assépticas identificadas no Hospital Couto Maia, Salvador em 112 crianças com idade de 3 meses a 15 anos ${ }^{89}$. Diversas manifestações neurológicas têm sido mais raramente descritas, tais como encefalite, paralisias focais, espaticidade, nistagmo, convulsões, distúrbios visuais de origem central, neurite periférica, paralisia de nervos 
cranianos, radiculite, síndrome de Guillain-Barré e mielite. Hemorragia cerebral, meníngea ou pulmonar podem ocasionalmente ocorrer na ausência de icterícia ou insuficiência renal ${ }^{7}$.

O acometimento ocular, caracterizado por uveíte, pode surgir da terceira semana até a um ano após o desaparecimento da sintomatologia, variando, em média, de quatro a oito meses. Caracteriza-se clinicamente por irite, iridociclite e, ocasionalmente, coriorretinite, podendo ser uni ou bilateral, autolimitada, com ou sem episódios recorrentes ou, ainda, como processo crônico. As alterações oculares geralmente desaparecem espontaneamente ${ }^{1,7}$.

$\mathrm{Na}$ forma ictérica ou "síndrome de Weil", ocorre o quadro clínico anteriormente descrito, acompanhado de severa disfunção hepática, demonstrada pela presença de icterícia combinada ou não com insuficiência renal aguda, fenômenos hemorrágicos, alterações cardíacas, hemodinâmicas, pulmonares e da consciência. A taxa de letalidade nesses casos pode chegar a $>10 \%$ na síndrome de Weil e $>50 \%$ na hemorragia pulmonar $1,2,7,88$

O reconhecimento de fatores de risco associado à mortalidade deve ser investigado no sentido de reduzir a letalidade associado à doença. Dupont et al.(1999) identificou os seguintes fatores: dispnéia, oligúria, leucócitos maiores que 12.900, alteração no eletrocardiograma e infiltrado no exame radiológico ${ }^{90}$. Panaphut et al. (2002) descreveu outros fatores como: hipotensão, oligúria, hipercalemia e presença de 
estertores pulmonares $^{22}$. Ko et al. (1999) relatou alteração do estado mental, idade superior a 37 anos, insuficiência renal e insuficiência respiratória ${ }^{5}$. Daher et al. (1999) descreveu apenas oligúria como fator de risco ${ }^{91}$. Abgueguen et al. (2008) identificou icterícia e alterações no eletrocardiograma ${ }^{92}$. Doudier et al. (2006) relatou hipotensão, oligúria e estertores pulmonares ${ }^{93}$. Chang (2005) determinou que pacientes que apresentavam relação AST/ALT maior que 3, possuíam pior prognóstico ${ }^{94}$. Chawla (2004) refere que sexo masculino, etilismo, idade superior que 50 anos, disfunção de múltiplos órgãos, SARA, entubação orotraqueal e acidose metabólica estavam associados ao óbito ${ }^{95}$. Tantitanawatet al. (2003) identificou como fatores de pior prognóstico plaquetas $<100.000 \mathrm{cel} / \mathrm{mm} 3$, insuficiência respiratória, hemoptise, oligúria e acidose ${ }^{96}$. Avaliando estes estudos percebemos que alterações pulmonares, insuficiência renal (sobretudo oligúrica) e alterações hemodinâmicas no momento da admissão, são os principais fatores associados ao óbito.

A icterícia ocorre de três a sete dias após o início da doença. Seu início é abrupto e se caracteriza por coloração amarelo-avermelhada, a assim chamada icterícia "rubínica". A icterícia é intensa e com freqüência, os níveis de bilirrubinas são superiores a $15 \mathrm{mg}^{5}{ }^{5,97}$. A urina é escura, e, geralmente não se observa acolia fecal.

O comprometimento renal na leptospirose caracteriza-se por elevação da uréia e creatinina, aumento da fração de excreção de sódio e alterações variáveis no exame de urina, tais como leucocitúria, hematúria, proteinúria e cristalúria. Oligúria ocorre com 
freqüência variável. A oligúria ocorreu em 36,5\%, enquanto a insuficiência renal foi observada em $71 \%$ dos casos ${ }^{97}$. A insuficiência renal aguda pode ser agravada pelas alterações hemodinâmicas, tais como desidratação e hipotensão arterial. É interessante observar que a acidose metabólica ocorre mais comumente nos pacientes oligúricos. Alcalose respiratória pode ocorrer na vigência de IRA. Diferentemente de outras formas de IRA, na leptospirose os níveis de potássio plasmático estão normais ou diminuídos, raramente elevados. Tal fenômeno é explicado pelo encontro de alta fração de excreção de potássio que acompanha a fração de excreção de sódio. A recuperação da filtração glomerular e da função tubular não necessariamente ocorre ao mesmo tempo e parece que os casos com IRA mais grave apresentam uma recuperação da capacidade de concentração urinária mais demorada ${ }^{91}$.

O envolvimento cardíaco é mais acentuado na forma ictérica da doença na forma de uma miocardite aguda. As manifestações mais comuns são alterações eletrocardiográficas e arritmia cardíaca, e, menos freqüentemente podem correr colapso cardiocirculatório e insuficiência cardíaca. Tais alterações podem ser agravadas pelas alterações metabólicas que ocorrem na doença, em especial a hipopotassemia ${ }^{1,7,88}$.

Os fenômenos hemorrágicos são relativamente freqüentes na síndrome de Weil podendo ocorrer na pele, mucosas ou órgãos internos. Cerca de $43 \%$ dos pacientes admitidos no Hospital Emilio Ribas em São Paulo apresentam algum tipo de sangramento de pele e mucosas, tais como petéquias e equimoses ${ }^{97}$. As hemorragias 
pulmonares podem variar desde leves, com presença de escarros hemoptóicos, até hemorragias maciças. Também em graus variados de intensidade, podem ocorrer hemorragias gastrintestinais, tais como melena, hematêmese ou enterorragia.

$\mathrm{Na}$ forma anictérica, a leptospirose pode ser confundida com doenças como a gripe, dengue e outras doenças virais, geralmente benignas e auto-limitadas, que cursam com cefaléia, febre e dores musculares ${ }^{2,3}$.

$\mathrm{Na}$ forma ictérica ou síndrome de Weil, o diagnóstico diferencial deve ser feito principalmente com a sepse por bactérias Gram negativas ou Gram positivas, hepatite alcoólica, infecção bacteriana aguda em hepatopatas crônicos, forma ictérica da febre tifóide, malária por P. falciparum, febre amarela, hepatites virais graves, colangites e colecistites e com a dengue hemorrágica ${ }^{3}$.

Há casos de com comprometimento pulmonar com pneumonite hemorrágica, sem icterícia e com evolução para insuficiência respiratória grave, muito similar à síndrome hemorrágica pelo Hantavírus ${ }^{21}$.

\section{7. . Diagnóstico e exames complementares}

O diagnóstico deve ser feito baseado em elementos de ordem epidemiológica associado a manifestações clínicas sugestivas, e confirmação laboratorial. Considera-se 
caso confirmado de leptospirose quando: 1) ocorrer isolamento da leptospira em algum espécime clínico ou 2) aumento de 4 vezes o título inicial ou título único maior ou igual 1:800 pela reação de soroaglutinação microscópica ou 3) detecção de anticorpos da classe IgM pela reação de ELISA ${ }^{1-3,7}$.

O isolamento da leptospira no sangue, urina ou líquor pode ser feito em meios de cultura apropriados, como o meio semi-sólido de Fletcher ou líquido de Stuart, ou, ainda, o meio EMJH. A cultura só pode ser considerada negativa após 6-8 semanas de crescimento em meio e condição apropriado ${ }^{7}$. Todavia, a sensibilidade permanece baixa mesmo quando colhida nos primeiros dias de sintomas.

Na prática, a maioria dos casos de leptospirose é diagnosticada por sorologia. Os anticorpos são detectáveis no sangue após 5 a 7 dias do início dos sintomas, e podem persistir por semanas ou meses após a cura ${ }^{98}$ (Figura 6). A sensibilidade dos testes em geral utilizados durante a primeira semana de doença é em torno de $25 \%{ }^{99}$. Os testes mais utilizados são ELISA-IgM e micro-aglutinação (MAT). A MAT é o padrão ouro, entretanto poucos laboratórios no Brasil estão aptos a realizar esse exame, principalmente por requerer laboratórios bem estruturados e treinamento técnico especializado.

A reação de polimerase em cadeia (PCR) tem se mostrado útil no diagnóstico de leptospirose principalmente em grandes centros de pesquisas. O principal fator limitante são o custo, a padronização e a necessidade de tecnologia apropriada disponível ${ }^{100}$. 
Estudos identificaram boa sensibilidade e especificidade para os testes diagnósticos baseados em proteínas recombinantes com LigB e LipL32. Tais proteínas estão sendo incorporado em plataforma de teste rápido, o que possibilitará o diagnóstico mais precoce da doença ${ }^{74,101-103}$.

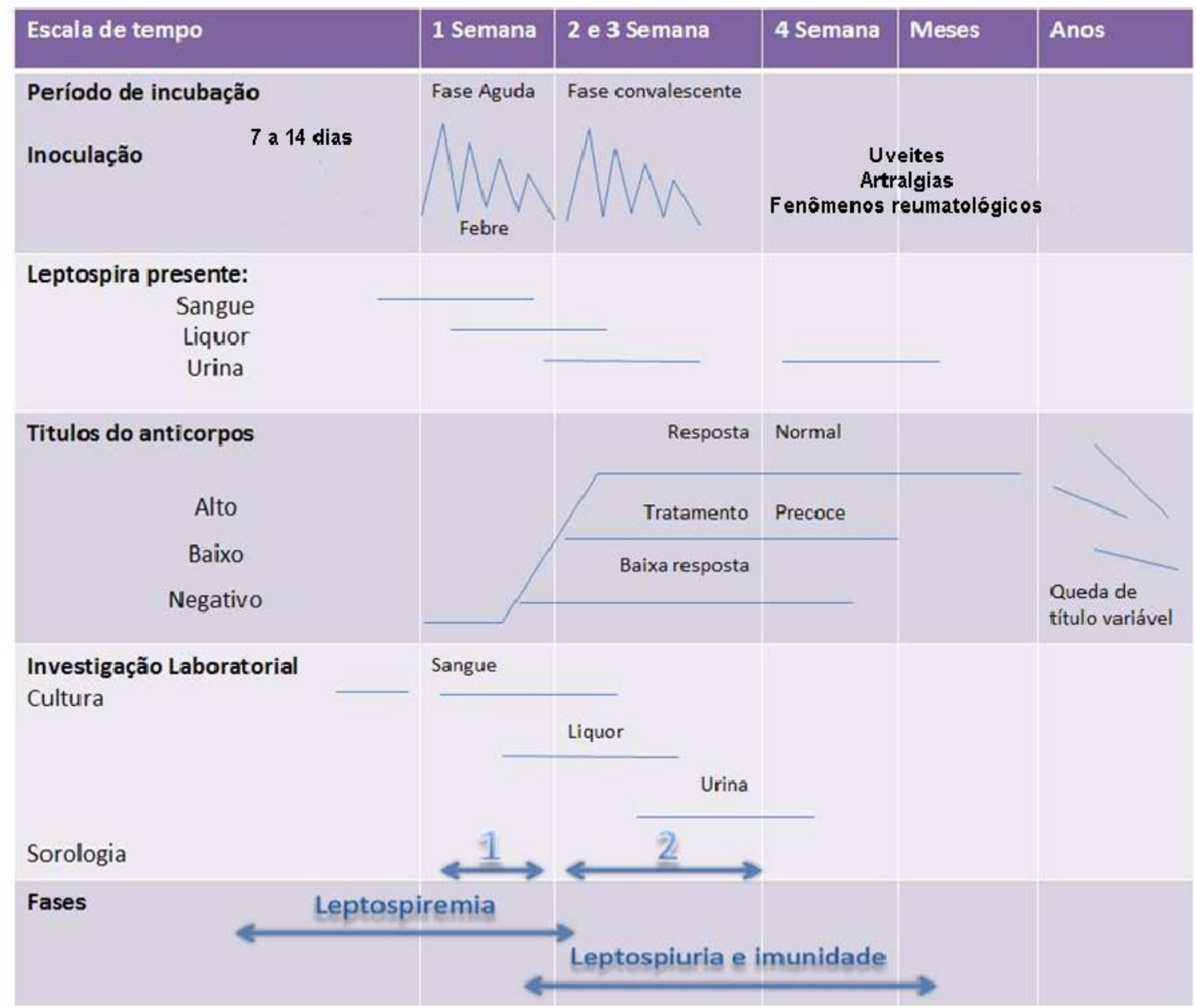

Figura 6 - Fases evolutivas da doença e correlação com os métodos diagnósticos disponíveis. 
Dentre os exames laboratoriais inespecíficos podem ser citados o leucograma, onde o mais característico é a presença de neutrofilia e de desvio à esquerda. A leucocitose, em geral, está presente em graus variados, podendo, em alguns casos, ser observada leucopenia ou mesmo leucócitos normais. A plaquetopenia é muito freqüente na síndrome de Weil que ocorre em nosso meio e a intensidade é variável, desde discreta até grave. A anemia pode ser de grau leve a moderado, podendo ser conseqüente ao quadro hemorrágico ${ }^{13}$.

As enzimas hepáticas (amininotransferases) estão pouco alteradas, em geral, em níveis inferiores a 500 UI. A fosfatase alcalina, a gamaglutamil transpeptidase e a creatinofosfoquinase encontram-se elevadas, em graus variáveis. A hiperbilirrubinemia pode ser intensa, à custa da fração direta ${ }^{3}$.

O comprometimento renal se revela pela elevação dos níveis plasmáticos da uréia e creatinina. A fração de excreção de sódio se eleva e a depuração da creatinina cai nos casos que evoluem com insuficiência renal aguda. O potássio, mesmo na presença de insuficiência renal aguda apresenta nível sérico normal ou diminuído. As alterações mais comuns do exame de urina são leucocitúria, proteinúria, cilindrúria, constituindo achados inespecíficos e de ocorrência variável ${ }^{1,3,7}$.

O liquido cefalorraquidiano encontra-se freqüentemente alterado. A pressão liquórica geralmente é normal e o aspecto do líquor é límpido e, nos casos com icterícia, é xantocrômico. A pleocitose geralmente não ultrapassa 500 cels $/ \mathrm{mm}^{3}$ à custa de 
linfócitos, embora em menor porcentagem de casos, possa haver predomínio de polimorfonucleares, principalmente no início da fase imune da doença. As proteínas se elevam pouco e a glicorraquia costuma ser normal ${ }^{89}$.

No coagulograma realizado na fase aguda pode haver alongamento do tempo de protrombina o qual geralmente se normaliza com a administração de vitamina $\mathrm{K}^{13,104}$.

O estudo radiológico do tórax pode ser normal ou mostrar infiltrado intersticial e/ou parenquimatoso localizados e bilaterais, uni ou bilateral, e algumas vezes velamentos difusos ${ }^{105}$. Na tomografia de tórax o achado principal consiste extensiva opacificidade tipo vidro-fosco em áreas desiguais de espaços alveolares ${ }^{106}$. (Figura 7). Mais raramente pode ocorrer derrame pleural. Não existe um padrão radiológico típico do comprometimento pulmonar na leptospirose.

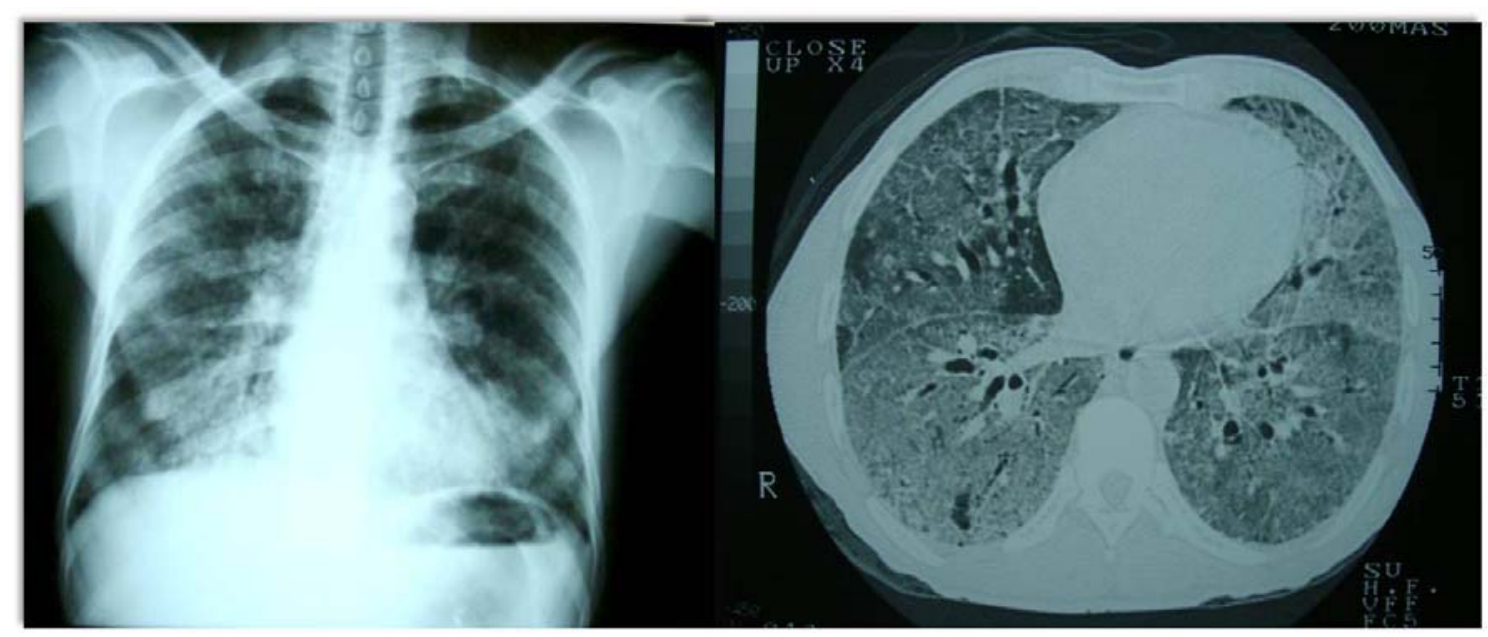

Figura 7 - Radiografia e tomografia de tórax de paciente com leptospirose grave e hemorragia pulmonar. Cortesia Amaro Nunes Duarte. 
O eletrocardiograma pode expressar o comprometimento do miocárdio na doença, como alterações da repolarização ventricular, do ritmo cardíaco, bloqueios ou sobrecarga das câmaras ${ }^{1,7}$.

\subsection{Prevenção e tratamento.}

Para indivíduos com alto risco de contaminação, pode-se recomendar a administração de antibiótico profilático (pré exposição). As populações mais indicadas a receber esse tipo de tratamento são militares, bombeiros e profissionais que irão se submeter à situação de risco por um tempo limitado. $\mathrm{O}$ antibiótico mais recomendado é a doxiciclina, com comprovada eficácia na proteção de indivíduos expostos. Recomendase dose de $200 \mathrm{mg} /$ dia via oral em intervalos semanais, até o fim da exposição ${ }^{107}$. A profilaxia secundária ainda é controversa. A recomendação dada por alguns autores consiste na administração de doxiciclina na dose de $100 \mathrm{mg}$ duas vezes ao dia durante 7 dias, para indivíduos pós expostos às situações de risco ${ }^{108,109}$.

As vacinas disponíveis para humanos são baseadas em extrato bruto da bactéria e só protegem contra os sorotipos contidos na mesma. Portanto, para ser eficiente a vacina precisa conter agrupados os sorovares mais prevalentes em cada região geográfica. China e Cuba, países com maior experiência na utilização dessas vacinas em humanos, 
relatam eficácia transitória e reações adversas importantes ${ }^{110,111}$. No Brasil, não existe vacina disponível para aplicação em humanos.

O tratamento da leptospirose dependerá da forma clínica da doença. De modo geral, a leptospirose é uma doença auto-limitada. As formas leves e moderadas requerem tratamento sintomático, hidratação e antibioticoterapia. Nas formas graves, a terapêutica de suporte é de suma importância e compreende principalmente a reposição volêmica e a correção dos distúrbios hidroeletrolíticos. Quando há insuficiência renal que não é revertida pela administração de fluídos, preconiza-se submeter o paciente a métodos dialíticos (preferencialmente hemofiltração ou hemodiálise clássica, na falta desta, diálise peritoneal). Estudo entre os pacientes do Hospital Emilio Ribas em São Paulo, demonstraram que a instituição de diálise precoce foi responsável pela redução da mortalidade em pacientes com hemorragia pulmonar de $66.7 \%$ para $16.7 \%{ }^{19}$.

Diversos estudos têm sugerido que a utilização de antibioticoterapia pode trazer benefícios aos pacientes com leptospirose, principalmente quando iniciados precocemente, até o quarto ou quinto dia após o início dos sintomas. Estudo duplo-cego, randomizado e controlado com placebo demonstrou que a administração da doxiclina na dose de 100mg, duas vezes ao dia foi benéfica em encurtar o curso da leptospirose quando administrada logo no começo das manifestações clínicas da doença, ou seja, nos três primeiros dias da doença ${ }^{112}$. Em estudo bem conduzido que utilizou a penicilina $G$ cristalina na dose de seis milhões de unidades por dia durante sete dias na leptospirose 
grave, foi possível demonstrar diminuição da febre e melhora da função renal, mesmo quando a penicilina foi administrada tardiamente ${ }^{113}$. Recentemente, diversos estudos têm demonstrando equivalência entre a Penicilina G cristalina e Ceftriaxone na dose de 1 grama por dia durante sete dias ${ }^{114}$.

\subsection{Fenômenos hemorrágicos na leptospirose}

Fenômenos hemorrágicos na leptospirose são uma das manifestações mais temidas nas formas graves da doença. Apesar de a hemorragia pulmonar ser a manifestação mais estudada e associada à alta mortalidade, existe nestes pacientes um comprometimento global da hemostase. Outras manifestações hemorrágicas na leptospirose incluem: hematúria, hematêmese, melena, petéquias, epistaxe, equimoses e hemorragia subaracnóide ${ }^{115}$. Achados anatomopatológicos revelam que na leptospirose ocorre uma tendência a fenômenos hemorrágicos acometendo vários órgãos de forma difusa 15, 116-118. Apesar desse potencial hemorrágico da leptospirose ter sido descrito desde 1886 por Weil, a sua fisiopatologia ainda é obscura com várias teorias controversas.

Teoricamente, a hemorragia ocorre por defeito na hemostasia primária (tampão plaquetário), disfunção na hemostasia secundária (estabilização do tampão hemostático com produção de fibrina), pela depleção das proteínas de coagulação, desarranjo nos 
mecanismos anticoagulantes (proteína $\mathrm{C}$ e $\mathrm{S}$ e antitrombina) ou por ativação da fibrinólise (plasmino mediada). Analisando os fenômenos hemorrágicos da leptospirose dentro destes parâmetros, percebemos que os estudos focam preferencialmente a hemostasia primária, com poucas evidências nos demais mecanismos.

Distúrbios na hemostasia primária são comumente encontrados no curso de várias doenças infecto-contagiosas. Na leptospirose, trombocitopenia é um achado prevalente e bem documentado, ocorrendo em 50-80\% dos pacientes e esta relacionada à severidade da doença, principalmente nas formas graves com insuficiência renal ${ }^{119}$. Estudos prévios não associaram presença ou intensidade da trombocitopenia com manifestações hemorrágicas, nem com mortalidade ${ }^{16,120}$. Todavia um estudo recente relacionou a presença de trombocitopenia com severidade da doença e risco de sangramento ${ }^{121}$.

A ocorrência de trombocitopenia seria explicada pela diminuição da trombopoiese ou por aumento da destruição periférica das plaquetas (imuno mediada ou não), ou mesmo a associação destes mecanismos. Alguns autores sugerem que a inibição da trombopoiese ocorreria por efeito tóxico direto da leptospira ${ }^{11,122}$. Estudos que exploraram a possibilidade do consumo de plaquetas por CIVD obtiveram resultados controversos. Edwards et al. (1986) concluiram por mensurações laboratoriais, que não existe essa correlação ${ }^{123}$. Nicodemo et al. (1997) não encontraram tal relação em estudos de necropsias humanas ${ }^{12}$. Todavia, recentemente, um estudo avaliando 18 pacientes com manifestações hemorrágicas da leptospirose, com 
mensurações de fibrinogênio, produtos de degradação da fibrina (D-Dímero), complexo trombina-antitrombina III (TAT) e fragmentos de protombina 1,2 $(\mathrm{F} 1+2)$, além de um escore para avaliação de presença de CIVD, concluiu que CIVD estava presente em 46\% dos pacientes com leptospirose ${ }^{121}$.

Em geral, a maior explicação para a trombocitopenia na leptospirose baseia-se na destruição periférica imuno-mediada de plaquetas. Alguns autores sugerem que exista um ainda desconhecido anticorpo antiplaquetário, porém com grande dificuldade técnica em reconhecê-lo e isolá-lo ${ }^{11,124}$. Um relato de caso evidenciou altos títulos de imunoglobulinas de superfície e C3d em paciente com leptospirose e trombocitopenia, e beneficio terapêutico após uso de corticoterapia, corroborando a hipótese de destruição plaquetária imuno-mediada ${ }^{125}$. Outros estudos confirmaram a destruição periférica plaquetária, baseado em análises de medula óssea que mostravam hipercelularidade e aumento dos megacariócitos ${ }^{125,126}$. Nicodemo et al. (1997) analisando tecido pulmonar postmortem de pacientes com leptospirose, sugerem que a trombocitopenia ocorreria por ativação, adesão e agregação de plaquetas a um endotélio vascular estimulado. Receptores plaquetários de superfície com alta afinidade às glicoproteínas subendoteliais de adesão, como por exemplo, fator von Willbrand, facilitariam este processo. Além disso, um achado neste estudo foi a presença de material amorfo elétron-denso interposto entre as superfícies das células endoteliais e das plaquetas aderidas, em locais sem exposição do subendotélio ${ }^{12}$. 
É sabido que células endoteliais desempenham um importante papel na regulação da coagulação e fibrinólise. O endotélio é capaz de expressar fatores teciduais, fator de von Willebrand e uma variedade de citocinas em resposta a vários patógenos. Yang et al. (2006) em um estudo utilizando modelo experimental revelaram evidência de ativação plaquetária baseado no aumento de níveis plasmáticos de 11-desidrogenato tromboxano B2 (11-DH-TXB2), sem aumento de D-dímero, TAT e produtos de degradação de fibrinogênio, além de ausência de trombo fibrino-plaquetário, ou seja, excluindo a presença de CIVD. Neste estudo houve aumento do nível trombomodulina, refletindo injuria de células endoteliais na leptospirose ${ }^{14}$. Além disso, Ren et al. (2003) identificaram um gene colA no sequenciamento genômico da cepa Lai, que codificaria colagenase microbiana, mediadora da injuria endotelial na leptospirose. Os outros achados incluem vários genes de L. interrogans que codificam proteínas homólogas às proteínas animais que exercem papel fundamental na hemostase, incluindo a proteína que se assemelha a PAF acetilhidrolase (pafAH) e outra proteína que mostrou semelhança aos domínios do fator de von Willebrand tipo A, havendo a possibilidade da ação destas proteínas na hemostasia na leptospirose ${ }^{54}$. A destruição periférica plaquetária imuno-mediada, parece ser a hipótese que melhor explica a trombocitopenia associada à doença.

Com maior evidência da participação das citocinas e mediadores inflamatórios na patogenia da doença, estudos tentaram avaliar esse padrão de resposta associado a injuria endotelial. Os níveis TNF- $\alpha$ estão estritamente relacionados à severidade do 
quadro clínico e a letalidade na leptospirose ${ }^{79}$. O peptidoglicano extraído da parede celular de Leptospira interrogans induz a liberação de TNF- $\alpha$ de monócitos humanos e ativa a aderência de neutrófilos às células endoteliais ${ }^{76}$. A indução de TNF- $\alpha$ por fatores tóxicos bacterianos desencadeia a resposta inflamatória local e sistêmica, resultando então em dano capilar. O papel da resposta inflamatória como desencadeador do dano celular endotelial vem ao encontro dos demais achados que implicam no papel imune na patogênese das manifestações hemorrágicas na leptospirose.

Outras substâncias como hemolisinas putativas podem estar implicadas na lesão endotelial, como Hap1 (hemolysis-associated protein 1) ou LipL32 (lipoprotein of Leptospira with $32 \mathrm{kDa})^{61,127}$, Sph (sphingomyelinase) ${ }^{128} \mathrm{e} \mathrm{Sph} 2{ }^{52}$.

Poucos estudos avaliaram a ativação do sistema fibrinolítico na leptospirose. Há relatos de aumento de produtos da degradação da fibrina, porém não há estudos avaliando as vias de regulação da fibrinólise, como o inibidor da ativação do plasminogênio tipo $1(\mathrm{PAI}-1)^{8,123,129-132}$.

Em resumo, não há dados conclusivos que expliquem qual o grande desencadeador dos fenômenos hemorrágicos na leptospirose. Em vários estudos as células endoteliais mostram-se como o alvo principal na leptospirose associada à hemorragia. 


\subsection{Epidemiologia e manifestação clínica da síndrome pulmonar} hemorrágica na leptospirose

Hemorragia pulmonar na leptospirose é reconhecida atualmente como a manifestação hemorrágica de maior importância nesta doença, especialmente após vários relatos de SPHL em todo o mundo 16, 17, 21, 23, 133-136. A prevalência destas manifestações pulmonares na leptospirose é variável de acordo com estudos em diversos lugares do mundo. Estudo realizado em Salvador-Bahia, entre 2003 e 2005, identificou 474 pacientes com leptospirose, sendo que 47 (10\%) destes apresentaram SPHL ${ }^{17}$. Em estudo prospectivo de 633 pacientes com leptospirose em Iquitos, Peru, sete pacientes (3.7\%) tiveram manifestações pulmonares severas, 5 morreram (4 de hemorragia pulmonar e 1 de SARA e insuficiência de múltiplos órgãos); todos pacientes com manifestações pulmonares eram provenientes da zona urbana (189 pacientes) ${ }^{24}$. Em uma coorte de 26 pacientes da Espanha, 17 apresentaram sintomas respiratórios (65\%) e 3 pacientes vieram a óbito decorrente de SARA ${ }^{137}$. Em geral, o pulmão é acometido em 10 a $70 \%$ dos casos com leptospirose $2,3,17,138$. Em 2006, a prevalência de hemorragia pulmonar na síndrome de Weil em pacientes da área metropolitana de São Paulo foi de $69 \%{ }^{139}$. A mortalidade relacionada à SPHL no Brasil varia de 55 a $74 \%{ }^{16,17}$.

A hemorragia pulmonar é a manifestação mais letal na leptospirose. Ela manifesta-se clinicamente com tosse, dispnéia e hemoptise, acompanhada de infiltrado 
pulmonar variável na radiografia de tórax. Os sintomas pulmonares como dor torácica, tosse, dispnéia e hemoptise ocorrem tanto na forma ictérica como na forma anictérica da doença. Outra temida manifestação pulmonar na leptospirose é a síndrome da angustia respiratória do adulto (SARA), associada à alta letalidade ${ }^{140,141}$.

SARA é classificada como um edema pulmonar, não cardiogênico, caracterizado pelo aumento da permeabilidade da membrana alvéolo-capilar, com extravasamento de células e proteínas para o interstício pulmonar. Consiste em um processo de edema pulmonar, não hidrostático ou não cardiogênico, acompanhado de uma hipoxemia persistente, associado a uma ampla lista de situações que predispõem ao seu desenvolvimento, e que pode atingir um índice de mortalidade, dependendo do fator etiológico envolvido, de $10 \%$ a $90 \%{ }^{142}$.

As formas de manifestação clínica do comprometimento pulmonar na leptospirose são variáveis. As manifestações externas de sangramento pulmonar nem sempre são evidentes, e pode variar de discreta hemoptise a hemorragia pulmonar maciça. A hemoptise estava presente em 50\% dos 168 pacientes com leptospirose na China entre 1959 e $1960{ }^{143}$ e em $13 \%$ dos 115 pacientes hospitalizados no Brasil ${ }^{91}$. Gouveia et al. (2008) evidenciaram que 15\% dos pacientes apresentavam sinais de hemorragia pulmonar no momento da admissão e $42 \%$ apresentaram sinais de insuficiência respiratória. Hemorragia pulmonar foi identificada em $40 \%$ dos pacientes apenas depois da entubação orotraqueal. Lesão pulmonar aguda (relação PaO2/Fio2 
$<300$ ) foi documentada em $76 \%$ dos pacientes que tiveram hemogasometria arterial realizada ${ }^{17}$. Em uma coorte da Espanha 17 de 26 pacientes apresentaram sintomas respiratórios sendo os mais freqüentes: dispnéia (7), hemoptise (7), tosse (6) e dor torácica tipo pleurítica $(5)^{137}$.

Garcia et al. (2000) identificaram que tabagismo seria fator de risco para o desenvolvimento de SPHL. Nos pacientes com leptospirose dispnéia, estertores pulmonares e infiltrados no exame radiológico do tórax estão associados a um prognóstico desfavorável $^{22,90}$

Estudo realizado no Instituto de Infectologia Emilio Ribas, São Paulo, avaliou o risco de óbito em pacientes com a forma grave de leptospirose e hemorragia pulmonar e identificaram fatores prognósticos independentes associados à mortalidade como: 1insuficiência renal aguda (oligúria, potássio $>4,0 \mathrm{mmol} / \mathrm{L}$ e creatinina maior que 265.2 umol/L mg/dl) e choque ${ }^{16}$.

\subsection{Patologia e patogênese da síndrome hemorrágica pulmonar na}

\section{leptospirose}

Hemorragia e congestão são os achados histológicos mais comuns descritos na SPHL. Infiltrado de monócitos e neutrófilos podem ocorrer, porém de forma discreta. Outros achados incluem edema pulmonar, deposição de fibrina, necrose e regeneração 
de pneumócito II. Formação de membrana hialina pode ocorrer, em um cenário de dano alveolar difuso. O tecido pulmonar geralmente demonstra um menor número de leptospiras quando comparados com o fígado, rim ou vasos sanguíneos, porém quando presentes, elas estão associadas a células endoteliais, estando no septo alveolar, aderidas às células endoteliais capilares. Material granular associado a macrófagos também foi evidenciado em tecidos pulmonares ${ }^{12}$.

Nicodemo et al. (1997) em estudo de 12 pacientes que vieram a óbito por leptospirose evidenciou: edema nos septos intra-aveolares; leve ou moderado infiltrado inflamatório com predomínio de macrófagos, linfócitos e plasmócitos; tumefação das células endoteliais; e hemorragia alveolar. A quantificação de antígeno de leptospira não foi correlacionada com a intensidade da lesão. Fibrina foi observada no lúmen alveolar e na superfície alveolar caracterizando o dano alveolar difuso. Não foram observados trombos característicos da coagulação intravascular disseminada. A microscopia eletrônica demonstrou tumefação da célula endotelial, aumento das vesículas de pinocitose, presença de corpos citoplasmáticos gigantes e emissão de pseudópodos. Agregados de plaquetas foram detectados no lúmen septal capilar e aderidos às células endoteliais com alterações morfológicas sugestivas de ativação plaquetária ${ }^{12}$.

Recentemente, para elucidação da patogênese de SPHL foram feitas investigações baseados principalmente em modelos de estudo animal. Estes estudos focam principalmente a provável etiologia imune como o grande desencadeador desta 
grave forma de manifestação da leptospirose.

Andrade et al. (2007) em estudo recente avaliou o transporte de íons a nível pulmonar para elucidar alguns achados na SHPL. Mostraram em modelo animal, que na leptospirose há diminuição da expressão proteica de subunidade alfa dos canais epiteliais de sódio $(\alpha-\mathrm{ENaC})$. Os pesquisadores também relataram que a expressão proteica basolateral de Na-K-2CL e do co-transportador NKCC1 estavam aumentadas. Não houve interferência na expressão proteína $\alpha-\mathrm{Na}-\mathrm{K}$ - adenosina, nem nos canais de aquaporina 5. Estes achados mostram o efeito da infecção por leptospira no sistema de transporte de íons pulmonar, o que seria responsável pela regulação de fluídos no espaço alveolar pelo pneumócito tipo II. A hipótese é que na leptospirose haja diminuição no número de proteína $\alpha-\mathrm{ENaC}$ com diminuição do transporte de sódio do lúmen para o interstício, com diminuição do gradiente osmótico. Os altos níveis de NKCC1 levariam a um aumento do influxo de sódio do espaço intersticial para as células epiteliais. Tudo isso levaria ao aumento da permeabilidade da membrana alvéolo-capilar, semelhantes às encontradas na SARA ${ }^{144}$.

Pereira et al. (2005) utilizando o modelo de mico, demonstrou por imunofluorescência a presença de material amorfo associado aos septos alveolares. Leptospiras intactas não foram observadas ${ }^{117}$.

Nally et al.(2004) demonstraram em modelo experimental, depósitos ao longo da membrana basal dos capilares septais de imunoglobulinas e complemento (C3) com 
padrão similar observado na síndrome Goospasture, sugerindo fenômeno de autoimunidade ${ }^{15}$. Também foi evidenciada hemorragia alveolar associado à leve ou moderado infiltrado inflamatório com predomínio de neutrófilos e macrófagos e poucos leptospiras foram observadas no pulmão quando comparados ao rim e fígado ${ }^{15}$.

A síndrome de Goodpasture é uma doença mediada pelo sistema imunológico, na qual auto-anticorpos contra a cadeia 3 alfa do colágeno tipo IV se ligam à membrana basal, alveolar e glomerular, causando glomerulonefrite progressiva e hemorragia pulmonar. O mecanismo de injúria renal e pulmonar é complexo. No rim, os anticorpos se ligam à membrana basal, principalmente ao colágeno tipo IV, ativa a cascata do complemento e de proteases, Tal ativação provoca ruptura da barreira glomerular e da cápsula de Bowman, causando proteinúria, hematúria e facilitando a formação de crescentes. Os linfócitos T CD4 e CD8+, macrófagos e neutrófilos participam da agressão produzindo, entre outros, interleucina 12 e interferon gama que medeiam à formação de crescentes $^{145,146}$. Tem sido descrita a relação entre o hábito de fumar e a probabilidade de desenvolvimento de hemorragia pulmonar na síndrome de Goodpasture. Atribui-se a componentes do tabaco a propriedade de aumentar a permeabilidade dos capilares pulmonares causando dano da membrana basal alveolar e exposição de auto-antígeno ${ }^{145-147}$.

Quatro estudos prévios demonstraram que a presença de anticorpos antifosfolípide em pacientes com leptospirose. Uma série de casos descrita por Rugman et al. (1991) associou a presença desses anticorpos com desfechos desfavoráveis ${ }^{148}$. Daher 
et al. (2002), entre 1999 e 2001, identificaram a presença de maiores títulos de anticorpos anti-fosfolípide nos pacientes com leptospirose e insuficiência renal, quando comparados a grupos de pacientes controles ${ }^{8}$. Os autores acima atribuíram que a presença desses anticorpos pode contribuir para os mecanismos fisiopatológicos relacionadas à vasculite da SPHL $^{8}$. Santiago et. al. (2004) relataram que 9 de 39 pacientes com leptospirose (23\%) apresentam anticorpos antifosfolípide IgG sendo que 4 em níveis baixos, 4 em níveis moderados e 1 em alto nível ${ }^{149}$. Tattevin et al.(2003) relataram que um paciente com leptospirose e hemorragia alveolar apresentou altos títulos de anticorpo antifosfolípide (84 UI) e associa a presença desse anticorpo a apresentações mais severas da doença ${ }^{150}$.

Pereira et al. (1998) demonstraram que camundongos $\mathrm{C} 3 \mathrm{H} / \mathrm{HeJ}$ são altamente susceptíveis a infecção letal por leptospira. Camundongos adultos, acima de 4 semanas, tornam-se resistentes. Esses autores demonstraram que camundongos depletados de CD4 e CD8 apresentam uma intensa hemorragia no tecido pulmonar associada a sinais de vasculite, com inflamação sustentada e amplificada no pulmão e rim e persistência da necrose tubular aguda. Esses achados sugerem a participação da resposta imune na patogênese da síndrome pulmonar hemorrágica na leptospirose ${ }^{151}$.

Yang et al. (2005) relatou um paciente com leptospirose que apresentou apenas tosse e febre e rapidamente desenvolveu insuficiência respiratória aguda. Intensa hemorragia pulmonar foi observada após entubação orotraqueal ${ }^{152}$. Após esse evento o 
paciente veio a óbito em menos de 16 horas após a instalação da insuficiência respiratória. A autópsia revelou hemorragia pulmonar difusa com formação de membrana hialina, aumento de macrófagos na luz alveolar e presença de deposição de imunoglobulina no septo alveolar e espaço alveolar ${ }^{152}$. Os autores sugerem que a produção de óxido nítrico e deposição de imunoglobulina podem ser responsáveis pelos casos fatais de leptospirose ${ }^{152}$.

Avaliando os estudos relacionados à patologia e aos mecanismos patogênicos da síndrome da hemorragia pulmonar encontrada nos pacientes com leptospirose, percebemos que tais mecanismos ainda são poucos conhecidos e provavelmente não estão associados à resposta inflamatória tecidual, nem tão pouco à lesão tecidual patógeno-específico no tecido. Dados como leve ou moderado infiltrado inflamatório associado à presença de pouca leptospira comparada a outros órgãos como fígado e rim, sugerem que mecanismos envolvidos na patogênese da lesão pulmonar podem estar envolvidos ou com a presença de auto-anticorpos ou toxinas de leptospiras produzidas à distância. Poucos estudos exploraram essas evidências em tecidos humanos. Estudos focando esta área podem ser fundamentais para o melhor esclarecimento da patogênese de SPHL e de outras manifestações que ocorrem na leptospirose, melhorando assim a abordagem clínica nestes pacientes. 


\section{MÉTODOS}

O presente estudo foi realizado sob orientação da Profa. Maria Irma Seixas Duarte. A histologia contida no estudo e as provas de imunohistoquímica foram realizadas no Laboratório da Disciplina de Patologia de Moléstias Transmissíveis da FMUSP. O Dr. Albert I. Ko (CPqGM - FIOCRUZ) cedeu soros de pacientes com leptospirose com e sem hemorragia pulmonar, identificados durante vigilância hospitalar ativa na cidade de Salvador. A quantificação de anticorpos anti-fosfolípide nesses soros foram realizadas no Laboratório de Investigação Médica (LIM-17) da Faculdade de Medicina da Universidade de São Paulo (FM-USP), em colaboração com o Dr. Jozélio Freire de Carvalho. A avaliação de anticorpos anti-membrana basal nesses soros foram quantificados na divisão de nefrologia, departamento de medicina da Universidade Valderbilt, em colaboração com o Dr. Billy G. Hudson.

\subsection{Tipo de estudo}

Estudo do tipo caso controle de pacientes com leptospirose com hemorragia pulmonar e controles com hemorragia pulmonar de outras causas, que foram submetidos à necrópsias no Departamento de Patologia da FMUSP, no período de 1988 a 2005. 


\subsection{Local de estudo}

O estudo foi desenvolvido no Laboratório da Disciplina de Patologia de Moléstias Transmissíveis do Departamento de Patologia da Faculdade de Medicina da Universidade de São Paulo e no serviço de verificação de óbito do HCFMUSP. Esse serviço atende a demanda de todo a cidade de São Paulo e eventualmente, demanda externa. O serviço de verificação de óbito mantém um acervo dos resultados de necropsias desde 1931. Além disso, um banco de blocos parafinados de tecidos de necropsias foi criado há mais de 2 décadas e é fonte constante de atualizações e pesquisas.

\subsection{População de estudo}

4.3.1. Casos: Pacientes com infecção por Leptospira, confirmada clínica e laboratorialmente, que foram a óbito com quadro de SPHL e cujas necropsias encontravam-se disponíveis nos arquivos do Departamento de Patologia da FMUSP,abrangendo o período de 1988 a 2005.

4.3.2. Controles: Fragmentos de pulmão de pacientes que foram a óbito com 
alterações histológicas compatíveis com hemorragia pulmonar de outras etiologias e a necropsia encontravam-se disponível no Arquivo do Departamento de Patologia da FMUSP no período de 1988 a 2005.

\subsection{Critérios de inclusão}

Pacientes com idade superior ou igual a 18 anos com diagnóstico confirmado de leptospirose e que apresentaram hemorragia pulmonar.

A confirmação de leptospirose foi determinada por:

- Título único $\geq 1: 400$ na microaglutinação (MAT) ou aumento de 4 vezes no título de amostras pareadas

- Cultura positiva para Leptospira

- Demonstração de antígenos de leptospira em qualquer tecido, através da reação de imuno-históquimica.

\subsection{Critérios de exclusão}

Foram excluídas necrópsias que não demonstraram material representativo, ou apresentavam evidência de autólise tissular, fixação inapropriada ou outra infecção 
bacteriana, viral ou fúngica.

\subsection{Aspectos epidemiológicos, clínicos e laboratoriais}

Foram coletados dados clínicos como: idade, sexo, raça, profissão, escolaridade, procedência, naturalidade e fonte provável de infecção como: lavoura, lixo, limpeza de caixa d'água, água ou lama de enchente, água de rio ou córregos ou lagos, fossa ou esgoto, criação de animais, carcaça de animais, contato direto com roedores. Outras variáveis que podem ser importantes na evolução dos pacientes também foram coletadas como a presença de comorbidades como: diabetes mellitus, doença pulmonar obstrutiva crônica, hipertensão arterial sistêmica, insuficiência renal crônica, insuficiência coronariana, cirrose, neoplasias, insuficiência cardíaca congestiva, história de tabagismo e etilismo.

As variáveis relacionadas à internação hospitalar foram: tempo decorrido do início dos sintomas até o momento da internação, sintomas apresentados na admissão (febre, cefaléia, mialgia, icterícia, hemorragias, sufusão conjuntival, náuseas, vômitos, diarréia, oligúria, meningismo, alterações cardíacas, alterações respiratórias e pressão arterial média), admissão na unidade de terapia intensiva, tempo da internação até o óbito, tempo de ventilação mecânica, uso de métodos dialíticos e uso de droga vasoativa. 
Foram coletados dados laboratoriais nas primeiras 24 horas de internação como: nível sérico de transaminases (AST- aspartato aminotransferase e ALT-alanina aminotransferase), bilirrubina, uréia, creatinina, sódio, potássio, hemoglobina, hematócrito, leucograma, plaquetas, pressão parcial de oxigênio $(\mathrm{PaO} 2)$ e fração de oxigênio inspirado (FiO2) no momento da internação hospitalar.

\subsection{Processamento do material e avaliação semi-quantitativa dos eventos}

\section{histopatológicos}

Os fragmentos de pulmão para exame histopatológico foram processados de acordo com procedimentos habituais de inclusão em parafina e microtomia, sendo os cortes corados pela hematoxilina-eosina. Os espécimes histológicos considerados adequados foram aqueles contendo no mínimo 50 estruturas alveolares para visualização à microscopia óptica.

Estes cortes corados foram avaliados em três níveis: luz alveolar, seu revestimento epitelial e septo alveolar. Graduamos os achados histopatológicos dos casos e controles, respeitando o julgamento do observador, em uma escala de 0 a 3 , correspondendo respectivamente a: 0 (ausente), 1 (discreto), 2 (moderado), 3 (intenso). Foram analisados os seguintes eventos:

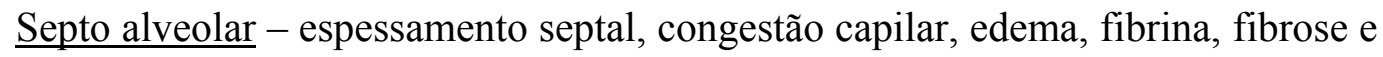
infiltrado (linfócitos, macrófagos, plasmócitos, neutrófilos e eosinófilos). 


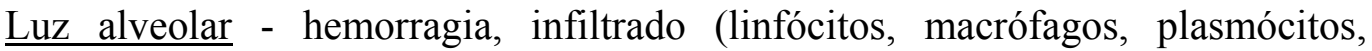
neutrófilos e eosinófilos), membrana hialina e presença de células gigantes multinucleadas.

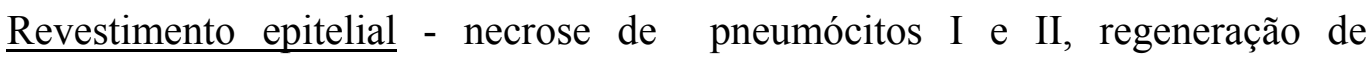
pneumócitos II

\subsection{Método imuno-histoquímico}

Cortes histológicos de $4 \mathrm{~mm}$ de espessura foram obtidos a partir de material embebido em parafina e colhidos em lâminas previamente preparadas com solução adesiva de 3 amino-propyltriethoxy-silane (Sigma Chemical Co., St. Louis, MO/USA, cód. A3648). Os cortes foram desparafinados em 2 banhos de xilol a $56^{\circ} \mathrm{C}$ durante 30 minutos e à temperatura ambiente durante 20 minutos, sendo posteriormente hidratados em seqüência decrescente de etanol (absoluto, 95\% e 70\%) e água corrente durante 10 minutos cada, e solução de PBS pH 7.4.

O método imuno-histoquímico utilizado foi o de Estreptavidina-biotina peroxidase (SABC, do inglês Streptavidin-Biotin Peroxidase) ${ }^{153}$. O bloqueio de peroxidase endógena foi feito em câmara escura com seis incubações em água oxigenada $3 \%$ por 10 minutos cada, e em seguida os preparados foram novamente lavados em água corrente e água destilada por 10 minutos cada, sendo colocados posteriormente em tampão $\mathrm{PBS}$ pH 7,4. 
A exposição antigênica, quando necessária, foi realizada por incubação em panela a vapor (Steam Cuisine $700 \mathrm{Hi}$ Speed - T-FAL) com tampão Target Retrieval Solution 10x concentrado (Dako - cód. S1699) durante 20 minutos após o aquecimento do tampão a temperatura de $85^{\circ} \mathrm{C}$ a $90^{\circ} \mathrm{C}$ ou ainda por digestão enzimática utilizando-se solução de tripsina 0,25\% (Sigma Chemical Co., St. Louis, MO/USA - cód. T-8253).

Os preparados foram novamente lavados em água corrente, água destilada e tampão PBS pH 7,4, por em média 5 minutos cada. Para bloqueio de proteínas inespecíficas do tecido, os preparados foram incubados em solução de leite desnatado (Molico, Nestlé) a 10\% durante 30 minutos a temperatura ambiente. Na etapa seguinte foi realizada incubação dos preparados com os anticorpos primários (Tabela 1), diluídos em solução de 1\% de albumina bovina fração V (Serva cód. 11930), acrescida de azida sódica $0,1 \%$ em PBS pH 7,4, "overnight" a $4^{\circ} \mathrm{C}$.

Tabela 1 - Relação de anticorpos primários para imunohistoquímica.

\begin{tabular}{llll}
\hline Anticorpo & Marca/código & Exposição antigênica & Diluição \\
\hline Ig de coelho anti-IgA humano & Dako/A0262 & - & $1: 4000$ \\
Ig de coelho anti-IgM humano & Dako/A0425 & - & $1: 4000$ \\
Ig de coelho anti-IgG humano & Dako/A0423 & - & $1: 4000$ \\
Ig de coelho anti-C3C humano & Dako/A0062 & - & $1: 200$ \\
Ig de coelho anti-Leptospira & IMT & Calor Umido/CSA & $1: 500$ \\
\hline
\end{tabular}

Após duas lavagens com tampão PBS pH 7,4 por cinco minutos cada, foi realizada a incubação com o anticorpo secundário anti-imunoglobulina de coelho e anti- 
imunoglobulina de camundongo produzido em cabra (Dako cód. K 492) diluído 1:500 em PBS pH 7,4 durante 30 minutos a $37^{\circ} \mathrm{C}$ ou ainda o anticorpo secundário antiimunoglobulina de cabra produzido em coelho (Dako cód. E0466) diluído 1:500 em PBS pH 7,4, para os anticorpos primários produzidos em cabra.

Os preparados foram novamente lavados em tampão PBS pH 7,4 e incubados com o complexo SABC (Dako cód. K492) diluído 1:500 em PBS pH 7,4 durante 30 minutos a $37^{\circ} \mathrm{C}$. Após nova lavagem em tampão $\mathrm{PBS}$ pH 7,4, a reação foi revelada com solução cromógena de diaminobenzidina (3,3' - diaminobenzidine, Sigma Chemical Co., St. Louis, MO/USA, cód. D5637) 0,03\% acrescida de 1,2 $\mathrm{ml}$ de água oxigenada 3\%. A intensidade de cor foi controlada ao microscópio óptico através dos controles positivos que acompanharam cada reação. Os preparados assim processados foram lavados em água corrente por 10 minutos, contra-corados com Hematoxilina de Harris por 20 segundos, lavados em água corrente, desidratados em etanol e diafanizados em xilol. A montagem das lâminas foi realizada com resina Permount (Fisher Scientific, Fair Lawn, NJ/USA, cód. SP15-100).

Alguns anticorpos necessitaram do emprego de um sistema de amplificação denominado CSA (Catalysed Signal Amplification Dako - cód. K 1500), que consiste na utilização do reagente biotinil tiramida após a incubação com o complexo SABC, durante 15 minutos. Esse reagente tem por finalidade a multiplicação da biotina presente no sistema. Após essa etapa, as lâminas foram incubadas com estreptavidina conjugada à enzima peroxidase e a reação revelada como descrito anteriormente. Os tempos de 
lavagem com tampão e incubações foram seguidos rigorosamente de acordo com instruções do fabricante ${ }^{153}$.

\subsection{Avaliação sorológica dos auto-anticorpos.}

No intuito de determinar quais auto-anticorpos estão envolvidos na patogênese da hemorragia pulmonar nos pacientes com leptospirose e hemorragia pulmonar, estabelecemos algumas colaborações. O Dr. Albert I. Ko (Centro de Pesquisa Gonçalo Moniz - Fundação Oswaldo Cruz, Ministério da Saúde) nos forneceu 96 amostras de soros de pacientes com leptospirose, com e sem SPHL obtidos durante o estudo de vigilância realizado em Salvador-BA no Hospital Couto Maia (HCM) desde 1996. O Dr. Eric G. Neilson e o Dr. Billy G. Hudson (Vanderbilt University School of Medicine, TN) realizaram análises sorológicas na diluição 1:100 por ELISA, para avaliar presença de auto-anticorpos específicos que se ligam aos componentes da membrana basal alveolar do hospedeiro, como o colágeno tipo IV e matriz extracelular. Nestas análises foram utilizadas proteínas recombinantes da região a1NC1, a2NC1, a3NC1, a5NC1 do colágeno tipo IV. Também analisamos o colágeno tipo IV digerido com pepsina de origem de placenta humana, o qual representa a parte central da molécula de colágeno tipo IV composta principalmente de cadeias a1 e a2 e não apresentam o domínio NC; e matrigel de sarcoma de camundongo do tipo Engelbreth-Holm-Swarm (EHS) rico em laminina I (MG). 
Com a colaboração do Dr. Jozélio Freire de Carvalho (LIM17-FMUSP) avaliamos a presença de anticorpos anticardiolipina (aCL) dos isotipos $\operatorname{IgG}$, e $\operatorname{IgM}$, por ELISA, como descrito por Gharavi et al. (1987) ${ }^{154}$. Para tanto, os soros foram testados na diluição de 1:50 em placas previamente sensibilizadas com cardiolipina purificada de coração bovino (Sigma Chem. Co., St Louis, MO, EUA) diluída em etanol gelado. Os poços das placas foram bloqueados com soro bovino fetal a 30\% em PBS. Os resultados foram expressos em unidades aCL IgG, IgM ou IgA. Para tanto, soros referência aCL positivos foram incluídos em cada ensaio para a composição de uma curva (DO vs. Unidades aCL de isotipo $\operatorname{IgG}$ ou $\operatorname{IgM}$ ). Um resultado positivo foi aquele superior ou igual a três desvios padrões da média da densidade óptica (DO) de dez controles de soros normais.

\subsection{Análise de Dados}

As variáveis avaliadas foram inseridas em banco de dados do programa EpiData, versão 3.0 e analisadas utilizando-se programa estatístico SAS versão 9.1.

Inicialmente foi avaliado o padrão de distribuição de cada variável, sendo a escolha do método estatístico baseado no padrão de distribuição da mesma. As variáveis que apresentavam distribuição assimétrica foram avaliadas por testes não-paramétricos (Kruskal-Wallis ou Mann-Whitney); as que apresentaram distribuição normal, por testes 
paramétricos (teste $\mathrm{T}$ de student ou ANOVA). Os dados dicotômicos ou categóricos foram analisados com o teste qui-quadrado ou teste exato de Fisher.

Os títulos de anticorpos anti-fosfolípide e anti-membrana basal foram inseridos no programa gráfico e estatístico GraphPad 5.0. As verificações das diferenças estatísticas foram realizadas através do teste estatístico Mann-Whitney quando comparados duas variáveis ou Kruskal-Wallis quando comparados mais de duas variáveis entre os soros de pacientes de pacientes com leptospirose e o grupo controle. Foram consideradas diferenças significativas quando o valor de $\mathrm{p}$ foi menor que 0,05 .

\subsection{Considerações éticas}

A execução da presente pesquisa só foi iniciada após apreciação pelo Comitê de Análise de Projetos de Pesquisa do Hospital das Clínicas (CAPPesq). O número do projeto junto a essa comissão é 813/05. Como se trata de estudo retrospectivo, não foi necessária a assinatura do termo de Consentimento Livre e Esclarecido. Todos os pacientes incluídos no presente estudo não poderão ser identificados, nem utilizados para outros propósitos que não estejam os descritos nesse projeto (Anexo 1). 


\section{RESULTADOS}

Durante o período de 1988 a 2005 foram identificadas 37 necropsias de pacientes com SHPL no departamento de patologia do FMUSP. Dentre elas, 7 necropsias foram excluídas por não apresentaram material representativo, ou haver evidência de autólise tissular, fixação inapropriada ou outras infecções associadas.

Dentre os 30 pacientes, 20 pacientes haviam sido internados no Hospital das Clínicas, da Universidade São Paulo; 5 no Instituto de Infectologia Emilio Ribas; 3 no Hospital Universitário da Universidade São Paulo; e 2 no Hospital das Clínicas de Ribeirão Preto da Universidade São Paulo.

\subsection{Dados demográficos e epidemiológicos}

Como as variáveis não apresentaram distribuição normal, foi utilizada a mediana para descrevê-las. Das 30 necropsias recuperadas, a maior parte foi de pacientes do sexo masculino (77\%), com mediana de idade de 48.5 anos (variando de 19 a 70 anos). Os pacientes em sua maioria eram da raça branca (19/30, 63\%), seguida da parda (6/30; $20 \%)$ e negra $(2 / 30,7 \%)$. As profissões mais freqüentes foram: pedreiro (3), do lar (3), doméstica (3), aposentado (2) e comerciante (2). Outras ocupações relatadas foram: vigia (1), estudante (1), eletricista (1) e bancário (1). Nove pacientes apresentavam algum tipo de comorbidade sendo a mais freqüente a hipertensão arterial sistêmica (5), 
seguida de insuficiência coronariana (2), insuficiência cardíaca congestiva (1) e doença pulmonar obstrutiva crônica (1). Nove pacientes eram tabagistas e sete eram etilistas (Tabela 2).

Dezessete pacientes residiam em São Paulo nos respectivos bairros: Santo Amaro (4), Guainazes (2), Tucuruvi (2), Butantan (1), Ipiranga (1), Jardim Amália (1), Jardim Ester (1), Jardim Oliveirinha (1), Jardim Princesa (1), Vila Fachini (1), Vila Nova Cachoeirinha (1) e Parque Pequeno (1). Dois pacientes residiam em Carapicuiba, 2 em Riberão Preto, 2 em São Bernado do Campo e 1 em Taboão da Serra. Dos 30 pacientes, 15 eram natural do estado de São Paulo, 3 da Bahia, 1 de Pernambuco, 1 de Minas Gerais, 1 do Paraná e 1 do Rio Grande do Sul.

Em relação à forma de aquisição da doença, algumas delas foram registradas no prontuário como o contato com roedores (9), água de enchentes (8), fossa ou esgoto (5), rio ou córrego (4) ou lixo (3) (Tabela 2). 
Tabela 2 - Características epidemiológicas dos pacientes com leptospirose e hemorragia pulmonar no período de 1988 a 2005.

\begin{tabular}{ll}
\hline Características & SPHL $^{1}$ (n=30) \\
\hline Idade, mediana (IR) & $48.5(40-56)$ \\
Sexo masculino, n(\%) & $23 / 30(77 \%)$ \\
& \\
Raça & $19 / 30(63 \%)$ \\
Branca, n(\%) & $6 / 30(20 \%)$ \\
Parda, n(\%) & $2 / 30(7 \%)$ \\
Negra, n(\%) & \\
Comorbidades & \\
Hipertensão arterial sistêmica, n(\%) & $5 / 30(17 \%)$ \\
Tabagismo, n(\%) & $9 / 30(30 \%)$ \\
Etilismo, n(\%) & $7 / 30(23 \%)$ \\
& \\
Exposição & \\
Roedores, n(\%) & $9 / 30(30 \%)$ \\
Água de enchentes, $(\%)$ & $8 / 30(27 \%)$ \\
Fossa ou esgoto, $\mathrm{n}(\%)$ & $5 / 30(17 \%)$ \\
Rio ou córrego, n(\%) & $4 / 30(13 \%)$ \\
Lixo, n(\%) & $3 / 30(10 \%)$ \\
\hline
\end{tabular}

NOTA: Variáveis contínuas foram apresentadas em mediana com amplitude interquartil (IR)

${ }^{1}$ Síndrome pulmonar hemorrágica na leptospirose

\subsection{Características clínicas}

A mediana de duração de sintomas antes de admissão hospitalar foi de 6 dias (variando de 4 a 13 dias).Os pacientes apresentavam os seguintes sintomas no momento 
da admissão hospitalar: febre $(26 / 26,100 \%)$, oligúria $(26 / 26,100 \%)$, mialgia $(23 / 24$ (96\%), icterícia (23/27, 85\%), cefaléia (17/23, 74\%), hemorragias $(17 / 23,74 \%)$, náuseas ou vômitos $(13 / 24,54 \%)$, alterações do ritmo cardíaco $(10 / 25,40 \%)$, sufusão conjuntival $(6 / 22,27 \%)$, confusão mental $(3 / 24,13 \%)$, diarréia $(6 / 24,25 \%)$ e meningismo $(2 / 24$, 8\%). Oitenta e um por cento dos pacientes já apresentavam algum tipo de alteração respiratória (taquipnéia ou insuficiência respiratória) no momento da admissão (Tabela 3). A mediana da pressão arterial foi de $45 \mathrm{mmHg}$ (variando entre $21-116 \mathrm{mmHg}$ ) A mediana de freqüência respiratório máxima nas primeiras 24 horas foi de 36 incursões respiratórias por minuto (variando de 14 a 40). Todos os pacientes necessitaram de ventilação mecânica com tempo médio de 2 dias (variando de 0 a 13 dias). Dezenove necessitaram de diálise (70\%), sendo que 9 pacientes usaram a diálise peritoneal, outros 7 utilizaram hemodiálise clássica e 3 utilizaram hemofiltração. A mediana de tempo de internação hospitalar foi de 3 dias (variando de 0 a 13 dias) (Tabela 3). Durante as primeiras 24 horas de admissão, a mediana de temperatura máxima corpórea foi de $38^{\circ} \mathrm{C}$ (variando de 36.1 a 42.0). 
Tabela 3 - Características clínicas dos pacientes com leptospirose e hemorragia pulmonar no período de 1988 a 2005.

\begin{tabular}{ll}
\hline Características & SPHL ${ }^{\mathbf{1}}$ (n=30) \\
\hline & \\
Sintomas clínicos na admissão & \\
Duração dos sintomas, mediana (IR) & 6 dias $(4-7)$ \\
Febre, n(\%) & $26 / 26(100 \%)$ \\
Oligúria, n(\%) & $26 / 26(100 \%)$ \\
Mialgia, n(\%) & $23 / 24(96 \%)$ \\
Icterícia, n(\%) & $23 / 27(85 \%)$ \\
Cefaléia, n(\%) & $17 / 23(74 \%)$ \\
Hemorragias, n(\%) & $17 / 23(74 \%)$ \\
Náuseas e Vômitos, n(\%) & $13 / 24(54 \%)$ \\
Alterações do ritmo cardíaco, n(\%) & $10 / 25(40 \%)$ \\
Sufusão conjuntival, n(\%) & $6 / 22(27 \%)$ \\
Diarréia, n(\%) & $6 / 24(25 \%)$ \\
Confusão mental, n(\%) & $3 / 24(12 \%)$ \\
Meningismo, n(\%) & $2 / 24(8 \%)$ \\
Pressão arterial, mediana (IR) & $45(21-100)$ \\
& \\
Evolução & \\
Uso de drogas vasoativas, n(\%) & \\
Duração da ventilação mecânica, mediana (IR) & 2 dias $(0-5)$ \\
Uso de diálises, n(\%) & $19 / 27(70 \%)$ \\
Duração da hospitalização, mediana (IR) & 3 dias (1-6) \\
\hline
\end{tabular}

NOTA: Variáveis contínuas foram apresentadas em mediana com amplitude interquartil (IR)

${ }^{1}$ Síndrome pulmonar hemorrágica na leptospirose

\subsection{Características laboratoriais}

A maioria dos pacientes apresentou trombocitopenia com mediana de plaquetas de 54.000 por $\mathrm{mm}^{3}$ (variando entre 10.000 e 222.000 por $\mathrm{mm}^{3}$ ); insuficiência renal com 
mediana de creatinina de $6.1 \mathrm{mg} / \mathrm{dl}$ (variando entre 0.6 a 14.2); e icterícia com mediana de bilirrubina total de $18.7 \mathrm{mg} / \mathrm{dl}$ (variando entre 10.6 a $25.0 \mathrm{mg} / \mathrm{dl}$ ), AST de 105 (variando entre 26 a $2570 \mathrm{mg} / \mathrm{dl}$ ) e ALT de $77 \mathrm{mg} / \mathrm{dl}$ (variando entre 12 a $1451 \mathrm{mg} / \mathrm{dl}$ ) (Tabela 4).

Tabela 4 - Características laboratoriais dos pacientes com leptospirose e hemorragia pulmonar no período de 1988 a 2005.

\begin{tabular}{ll}
\hline Características & SPHL $^{\mathbf{1}}(\mathbf{n}=\mathbf{3 0})$ \\
\hline Hematócrito, \% & $26(20-30)$ \\
Leucócitos, cels $/ \mathrm{mm}^{3}$ & $1.6 \times 10^{4}\left(1.1-1.9 \times 10^{4}\right)$ \\
Plaquetas, cels $/ \mathrm{mm}^{3}$ & $5.4 \times 10^{4}\left(3.6-10.0 \times 10^{4}\right)$ \\
Creatinina sérica, $\mathrm{mg} / \mathrm{dl}$ & $6.1(4.0-7.6)$ \\
Potássio sérico, meq/L & $4.7(4.2-5.9)$ \\
Bilirrubina Total, mg/dl & $18.7(10.6-25.0)$ \\
AST, mg/dl & $105(51-221)$ \\
ALT, mg/dl & $77(31-142)$ \\
Tempo de protrombina, INR & $1.35(1.00-1.40)$ \\
Tempo de tromboplastina parcial ativada & $1.1(0.9-1.5)$ \\
\hline
\end{tabular}

NOTA: Variáveis contínuas foram apresentadas em mediana com amplitude interquartil (IR); Aspartato aminotransferase (AST); alanina aminotransferase (ALT).

O nível sérico de potássio apresentou mediana de 4.7 meq/L (variando entre 3.4 a 8.4 meq/L). A mediana de relação $\mathrm{FiO} 2 / \mathrm{PaO} 2$ foi de 193 (variando 44 a 413). Dez pacientes tiveram amostra sorológica colhida para a realização da microaglutinação (MAT). Nove pacientes apresentaram títulos maiores que 1:400 já na primeira amostra. A mediana dos títulos para a primeira mostra foi de 1:800 (variando de 1:100 a 1:6400). 
Sete soros foram testados para leptospirose através ELISA-IgM, todos resultaram positivo. Uma hemocultura de seis coletadas apresentou positividade para Leptospira Interrogans sorovar Copenhageni. Em todos os casos a presença de Leptospira foi confirmada pela reação de imunohistoquímica realizada no tecido.

\section{4.. Histopatologia}

Os pacientes com SPHL apresentavam importante hemorragia alveolar, associada a discreto grau de infiltrado inflamatório, com predomínio de macrófagos. Em relação a luz alveolar, o infiltrado de macrófagos foi considerado moderado ou intenso em 23 dos espécimes de tecido pulmonar avaliados. Quinze amostras de tecido pulmonar apresentavam discreto ou moderado infiltrado de neutrófilos na luz alveolar. Linfócitos foram discretamente observados na maioria dos cortes histológicos do tecido pulmonar avaliados (29/30). Plasmócitos estavam ausentes ou discretamente presentes na luz alveolar em 18 e 12 das secções de tecido pulmonar avaliadas, respectivamente. Na maior parte dos casos avaliados ocorreu espessamento septo alveolar, congestão e edema (em 28, 29 e 29, respectivamente). Associado a esta alteração septal foi evidenciado discreto infiltrado de linfócitos, plasmócitos e macrófagos (Figura 8). Neutrófilos estiveram ausentes nos septos alveolares em 20 dos casos. Em nenhum dos cortes do tecido pulmonar estudados foram evidenciadas alterações microscópicas sugestivas de coagulação intravascular disseminada (CIVD). 


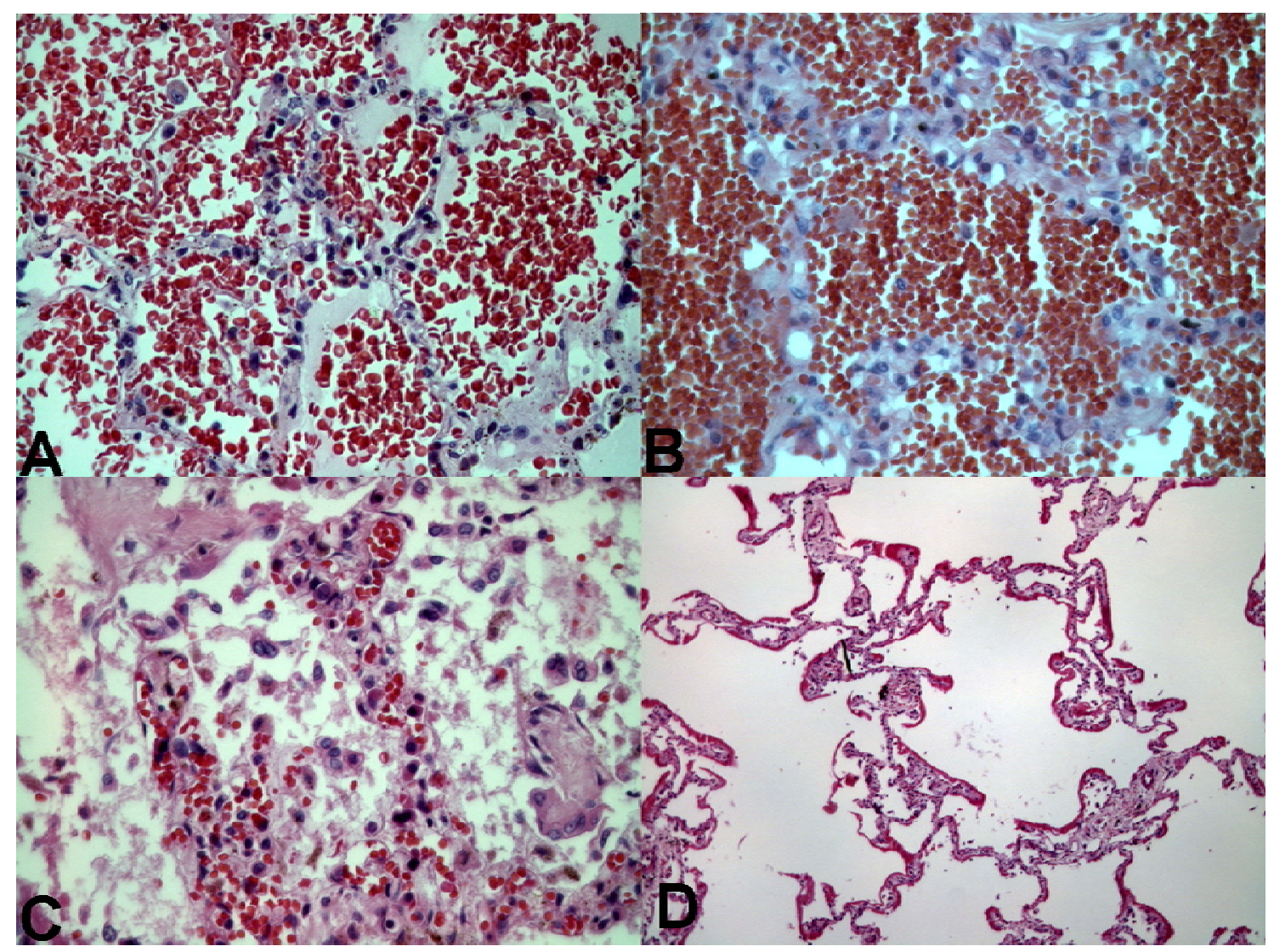

Figura 8 - Histologia do tecido pulmonar de quatro de pacientes com leptospirose e hemorragia pulmonar (A,B,C e D). A e B apresentam intensa hemorragia no espaço alveolar associada a discreto infiltrado inflamatório septal. $\mathrm{C}$ apresenta intenso infiltrado de macrófagos em espaço alveolar associado à regeneração de pneumócitos II. D apresenta membrana hialina nos septos alveolares. HE ( x 400)

Os pacientes com SPHL $(n=30)$ diferiram dos controles com hemorragia pulmonar $(n=7)$ em alguns aspectos: moderada ou intensa presença de macrófagos na luz alveolar (97\% versus $29 \%$, respectivamente; $\mathrm{p}<0.01)$; presença de membrana hialina na superfície alveolar $(100 \%$ versus $0 \%$ respectivamente; $\mathrm{p}<0.01)$; intensa necrose de pneumócitos I e II e regeneração de pneumócitos II (100\% versus 0\%, respectivamente; 
$\mathrm{p}<0.01)$; e presença de plasmócitos no septo alveolar $(80 \%$ versus $29 \%$; $\mathrm{p}<0.02)$.

Nenhuma diferença estatisticamente significativa foi observada em relação ao número de macrófagos, linfócitos, neutrófilos e eosinófílos no septo alveolar, quando comparados os pacientes com SPHL e os controles (Tabela 5 e 6).

Tabela 5 - Principais alterações histopatológicas encontrados na luz e revestimento alveolar de pacientes com síndrome pulmonar hemorrágica na leptospirose e grupo controle com hemorragia.

\begin{tabular}{llll}
\hline \multicolumn{1}{c}{$\begin{array}{c}\text { Alterações } \\
\text { histopatológicas }\end{array}$} & $\begin{array}{l}\text { Pacientes com } \\
\text { leptospirose e } \\
\text { hemorragia } \\
\text { pulmonar (n=30) }\end{array}$ & $\begin{array}{l}\text { Controles com } \\
\text { hemorragia } \\
\text { pulmonar } \\
\text { (n=7) }\end{array}$ & $\begin{array}{l}\text { Valor } \\
\text { de p }\end{array}$ \\
\hline Luz alveolar & & & \\
Hemorragia recente & $14 / 30(47 \%)$ & $5 / 7(71 \%)$ & 0.40 \\
Edema & $29 / 30(97 \%)$ & $7 / 7(100 \%)$ & 1.00 \\
Macrófagos $\geq 2$ & $23 / 30(77 \%)$ & $2 / 7(29 \%)$ & 0.02 \\
Neutrófilos $\geq 1$ & $15 / 30(50 \%)$ & $2 / 7(29 \%)$ & 0.42 \\
Linfócitos=1 & $29 / 30(97 \%)$ & $6 / 7(86 \%)$ & 0.35 \\
Plasmócitos=0 & $18 / 30(60 \%)$ & $6 / 7(86 \%)$ & 0.38 \\
Eosinófilos=0 & $26 / 30(87 \%)$ & $7 / 7(100 \%)$ & 0.41 \\
& & & \\
Revestimento & & & $<0.01$ \\
Necrose de pneumócito I & $30 / 30(100 \%)$ & $0 / 7(0 \%)$ & $<0.01$ \\
Necrose de pneumócito II & $30 / 30(100 \%)$ & $0 / 7(0 \%)$ & $<0.01$ \\
\hline Regeneração de pneumócito II & $30 / 30(100 \%)$ & $0 / 7(0 \%)$ & \\
\hline
\end{tabular}


Tabela 6 - Principais alterações histopatológicas encontradas no septo alveolar de pacientes com síndrome pulmonar hemorrágica na leptospirose e grupo controle com hemorragia.

\begin{tabular}{llll}
\hline \multicolumn{1}{c}{$\begin{array}{c}\text { Alterações } \\
\text { histopatológicas }\end{array}$} & $\begin{array}{l}\text { Pacientes com } \\
\text { leptospirose e } \\
\text { hemorragia } \\
\text { pulmonar }(\mathbf{n}=\mathbf{3 0})\end{array}$ & $\begin{array}{l}\text { Controles com } \\
\text { hemorragia } \\
\text { pulmonar } \\
(\mathbf{n}=7)\end{array}$ & $\begin{array}{l}\text { Valor } \\
\text { de } p\end{array}$ \\
\hline Septo Alveolar & & & \\
Espessamento Septal $\geq 1$ & $28 / 30(93 \%)$ & $1 / 7(14 \%)$ & $<0.01$ \\
Congestão $\geq 1$ & $29 / 30(97 \%)$ & $5 / 7(71 \%)$ & 0.09 \\
Edema $\geq 1$ & $29 / 30(97 \%)$ & $2 / 7(29 \%)$ & $<0.01$ \\
Fibrina & $28 / 30(93 \%)$ & $0 / 7(0 \%)$ & $<0.01$ \\
Fibrose & $1 / 30(3 \%)$ & $1 / 7(14 \%)$ & 0.38 \\
Macrófagos $\geq 2$ & $5 / 30(17 \%)$ & $0 / 7(0 \%)$ & 0.55 \\
Linfócitos $\geq 1$ & $30 / 30(100 \%)$ & $7 / 7(100 \%)$ & 1.00 \\
Neutrófilos $\geq 1$ & $10 / 30(33 \%)$ & $0 / 7(0 \%)$ & 0.16 \\
Plasmócitos $\geq 1$ & $24 / 30(80 \%)$ & $2 / 7(29 \%)$ & 0.02 \\
Eosinófilos $=0$ & $30 / 30(100 \%)$ & $7 / 7(100 \%)$ & 1.00 \\
\hline
\end{tabular}

Dividimos os pacientes com SPHL $(\mathrm{n}=30)$ em dois grupos, baseado na mediana de duração de ventilação mecânica. Os pacientes que usaram ventilação mecânica por menos de 2 dias apresentaram menor freqüência de macrófagos no lúmen alveolar, comparado àqueles que utilizaram ventilação mecânica por mais de 2 dias $(31 \%$ versus $80 \%$, respectivamente, $\mathrm{p}=0.04)$. 


\subsection{Avaliação imuno-histoquímica}

Leptospiras intactas foram raramente observadas no tecido pulmonar dos pacientes com SPHL. Comparados com os outros órgãos, como fígado e rim, o pulmão apresentou pequena quantidade de antígenos de leptospira distribuídos irregularmente no tecido pulmonar em luz dos capilares ou em suas paredes, no interstício septal ou na luz dos alvéolos. Ocasionalmente, esse material antigênico apresentou-se como debris granulares no citoplasma de macrófagos. A detecção do antígeno de leptospira não se correlacionou com a intensidade de hemorragia pulmonar.

Através das reações imuno-histoquímicas avaliamos a presença de IgM, IgG, $\operatorname{IgA}$

e complemento C3, nos pulmões de pacientes com SPHL $(n=30)$ e controles com hemorragia $(n=7)$. Três padrões de imunomarcação foram observados nos pacientes com SPHL: (A) marcação linear delicada, como uma membrana, recobrindo a superfície luminal alveolar de pneumócitos I e II (12/17, 71\%); (MF) marcação multifocal, aleatória nos septos alveolares (5/17, 29\%); e (I) marcação fraca granular, focal, intraalveolar (Figura 9). 


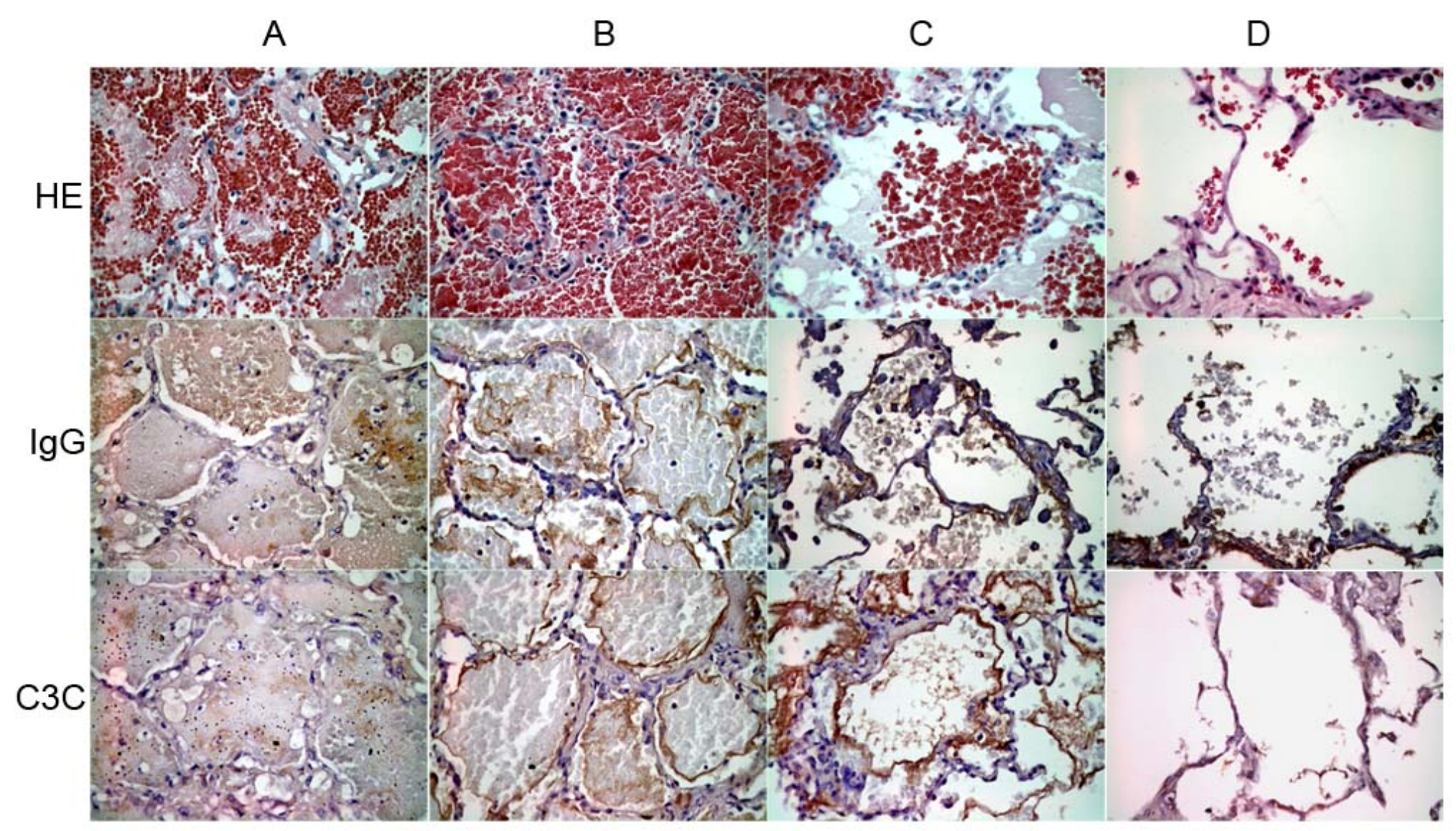


Figura 9 - Histologia e reação de imuno-histoquímica no tecido pulmonar evidenciando os diversos padrões observados nos pacientes com leptospirose e nos controles com hemorragia pulmonar (400x). (A) Fragmentos de tecido pulmonar de controles com hemorragia alveolar difusa (HE) demonstrando ausência de deposição linear de imunoglobulina e complemento C3C; (B) Tecido pulmonar de pacientes com SPHL demonstrando hemorragia alveolar difusa (HE) e deposição linear delicada de imunoglobulina e $\mathrm{C} 3 \mathrm{C}$ adjacente à superfície alveolar (padrão A de marcação); (C) Tecido pulmonar de paciente com SPHL demonstrando moderada hemorragia (HE) e um padrão misto de marcação A e MF (D) Tecido pulmonar de pacientes com SPHL demonstrando hemorragia (HE) e marcação randômica, multifocal nos septos alveolares (padrão MF de marcação). HE = HematoxilinaEosina.

Como mostrado na figura 9, o padrão (A) de marcação esteve presente nos pacientes com hemorragia pulmonar intensa, e esse foi o padrão mais freqüentemente observado. O padrão (MF) associado ao padrão (A) de marcação foi observado em casos que evidenciavam leve a moderada hemorragia alveolar. O padrão (MF) não esteve associado a uma distribuição linear nos capilares ou membrana basal de septos alveolares.

Das 30 amostras de tecido pulmonar examinadas, 18 foram positivas para deposição de IgA, 17 para IgM, 16 para IgG e 17 para C3 (Figura 10, 11, 12 e 13). 4 amostras de tecido pulmonar examinadas foram inconclusivas. Todas as 17 amostras positivas para C3 apresentavam marcação para no mínimo duas classes de imunoglobulinas (Tabela 7). 

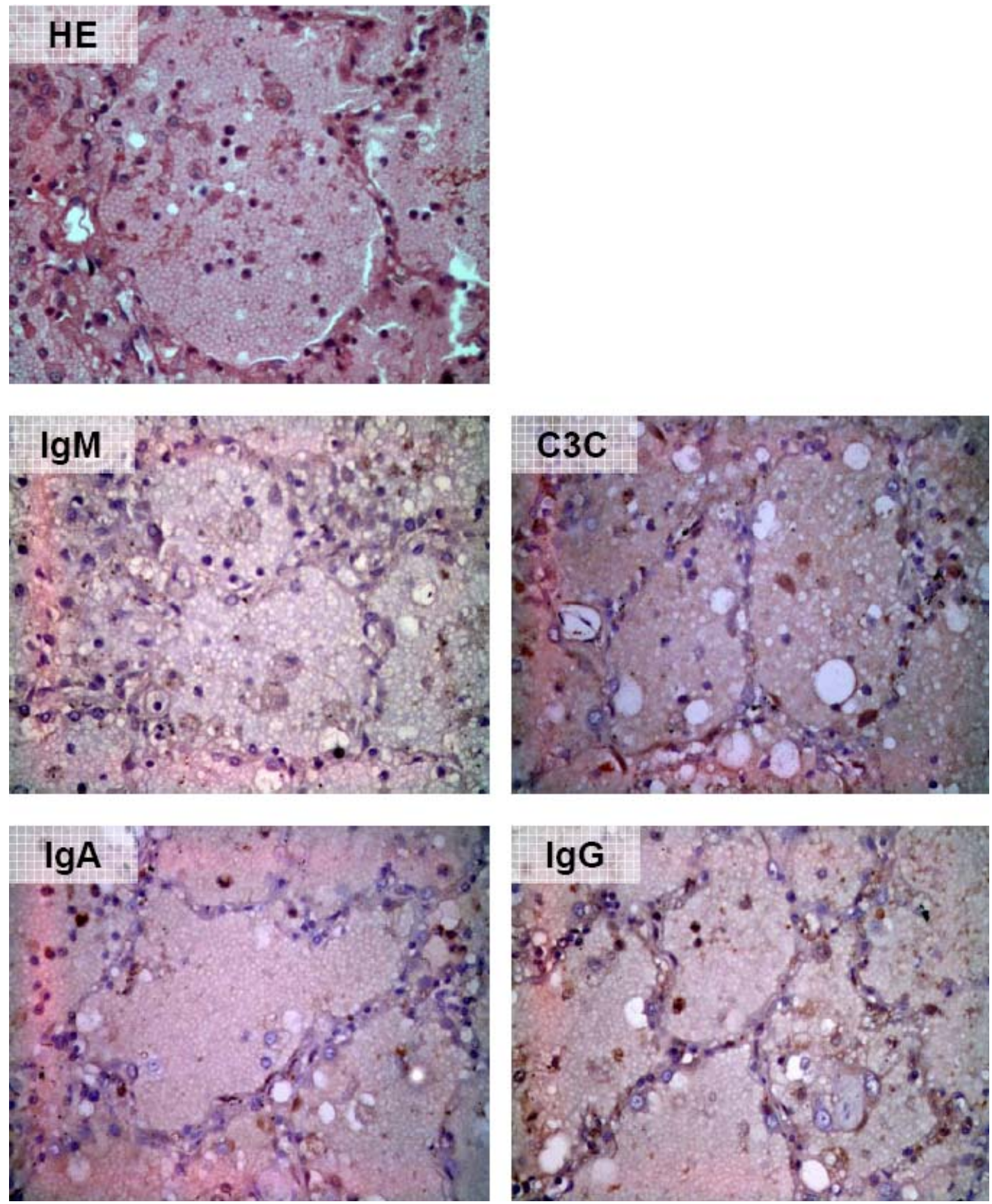

Figura 10 - Histologia e reação de imuno-histoquímica no tecido pulmonar de um paciente do grupo controle. (400x). HE = Hematoxilina-Eosina. 

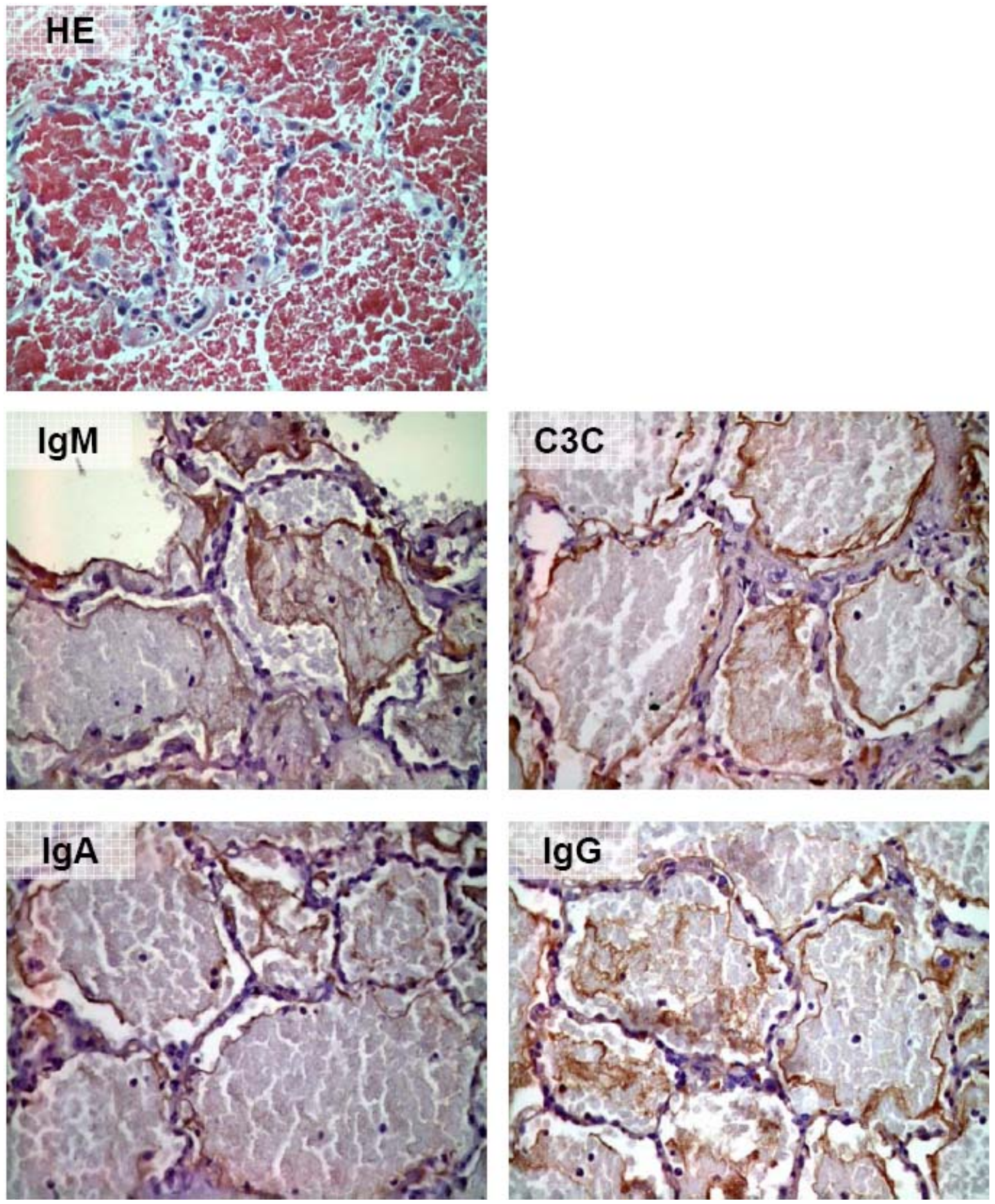

Figura 11 - Histologia e reação de imuno-histoquímica no tecido pulmonar de um paciente com SPHL com predomínio do padrão A de marcação. (400x). HE = Hematoxilina-Eosina. 

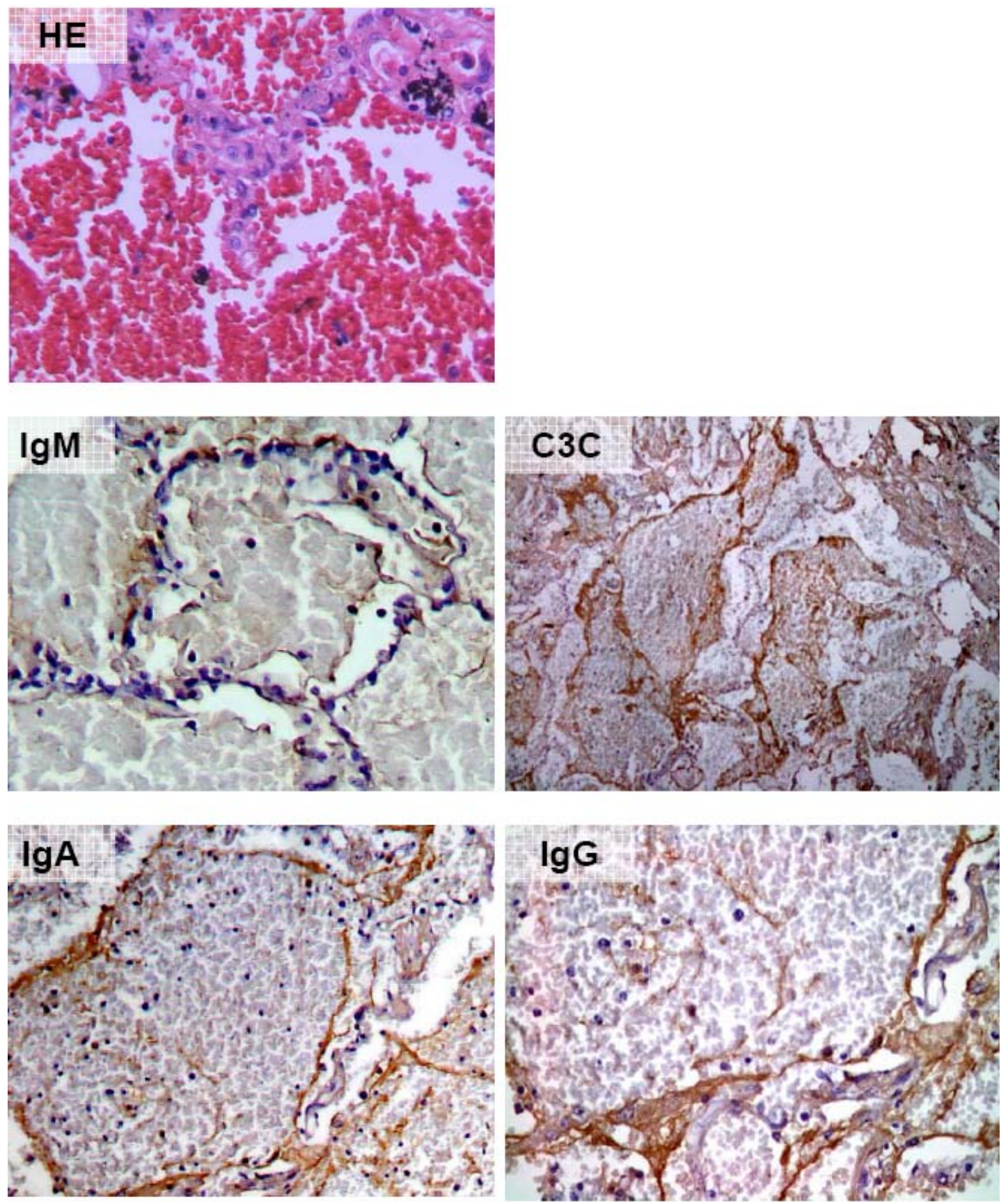

Figura 12 - Histologia e reação de imuno-histoquímica no tecido pulmonar de um paciente com SPHL com padrão A e MF de marcação. (400x). HE = HematoxilinaEosina. 

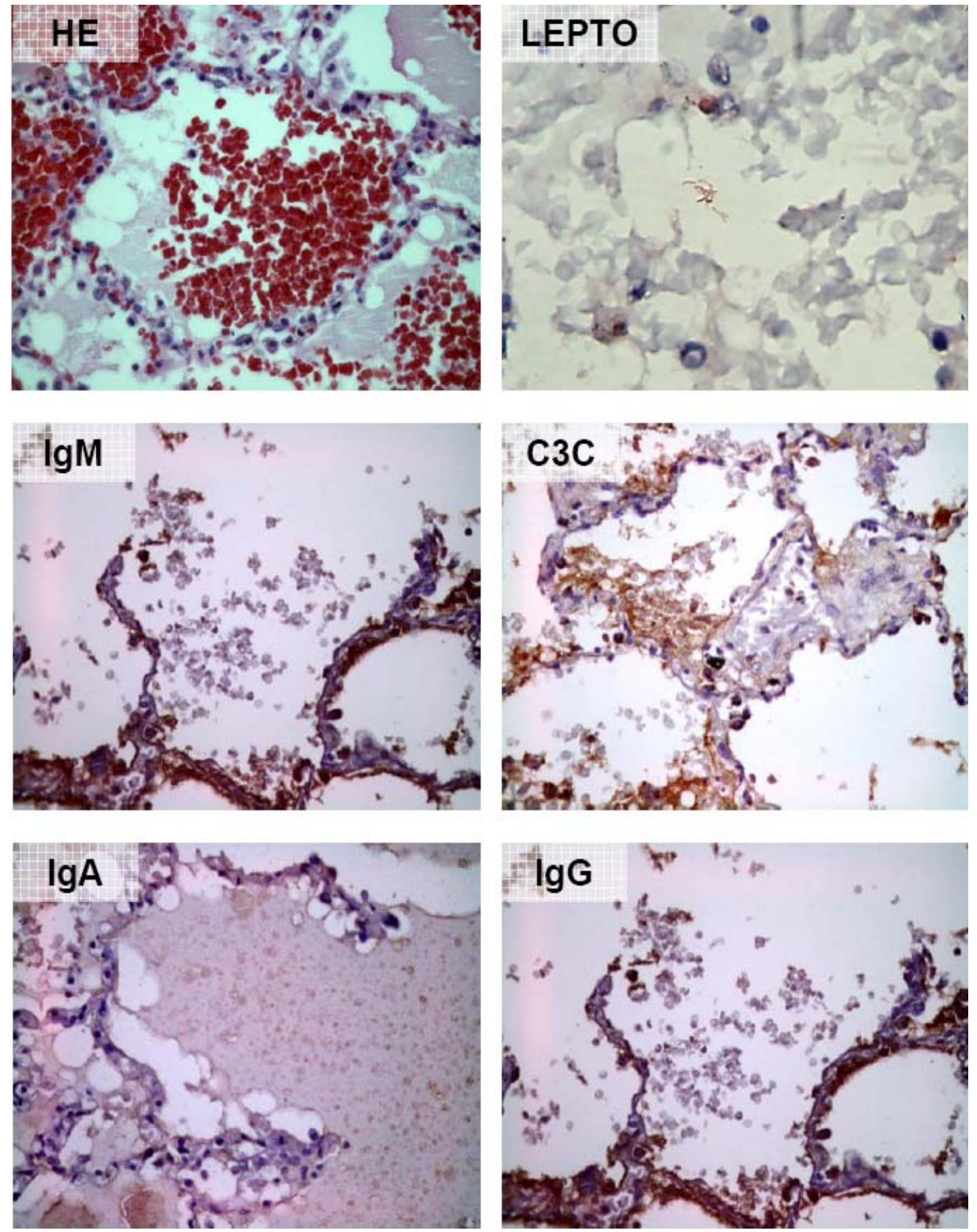

Figura 13 - Histologia e reação de imuno-histoquímica no tecido pulmonar de um paciente com SPHL com predomínio do padrão MF de marcação. (400x). HE = Hematoxilina-Eosina. LEPTO=Leptospira 
Tabela 7 - Reações de imuno-histoquímica realizadas em tecido pulmonar de pacientes com síndrome pulmonar hemorrágica na leptospirose e grupo controle com hemorragia.

\begin{tabular}{lll}
\hline Imunohistoquímica & $\begin{array}{l}\text { Pacientes com } \\
\text { leptospirose e hemorragia } \\
\text { pulmonar (n=30) }\end{array}$ & $\begin{array}{l}\text { Controles com } \\
\text { hemorragia } \\
\text { pulmonar (n=7) }\end{array}$ \\
\hline IgG & $16 / 30(53 \%)$ & $0 / 7(0 \%)$ \\
IgM & $17 / 30(57 \%)$ & $0 / 7(0 \%)$ \\
IgA & $18 / 30(60 \%)$ & $0 / 7(0 \%)$ \\
Complemento C3C & $17 / 30(57 \%)$ & $0 / 7(0 \%)$ \\
\hline
\end{tabular}

Pacientes com hemorragia pulmonar recente demonstraram maior freqüência de deposição de C3 (11/14) quando comparados com pacientes que apresentavam hemorragia alveolar e evidência de fagocitose e pigmentos de hemossiderina (6/16) $(p=0.02)($ Tabela 8$)$ 
Tabela 8 - Características clínicas e microscópicas dos 30 casos fatais de leptospirose.

\begin{tabular}{|c|c|c|c|c|c|c|c|c|c|c|c|c|}
\hline \multirow[b]{2}{*}{ No. } & \multirow[b]{2}{*}{ Idade } & \multirow[b]{2}{*}{ Sexo } & \multirow[b]{2}{*}{ VM } & \multirow[b]{2}{*}{$\mathrm{PI} / \mathrm{II}$} & \multirow[b]{2}{*}{ HPR } & \multicolumn{3}{|c|}{$\begin{array}{l}\text { Espaço } \\
\text { alveolar }\end{array}$} & \multicolumn{4}{|c|}{ Imuno-histoquímica } \\
\hline & & & & & & $\mathrm{M}$ & $\mathrm{N}$ & $\mathrm{L}$ & $\operatorname{Ig} \mathrm{A}$ & IgM & $\operatorname{IgG}$ & C3C \\
\hline 2 & 70 & $\mathrm{M}$ & 0 & + & + & 3 & 0 & 1 & + & + & + & + \\
\hline 3 & 33 & $\mathrm{M}$ & 8 & + & - & 3 & 1 & 1 & - & - & - & - \\
\hline 5 & 59 & $\mathrm{M}$ & 5 & + & - & 2 & 1 & 1 & - & - & - & - \\
\hline 7 & 54 & $\mathrm{M}$ & 2 & + & - & 2 & 0 & 1 & - & - & - & - \\
\hline 8 & 20 & $\mathrm{M}$ & 3 & + & + & 2 & 1 & 1 & + & + & + & + \\
\hline 10 & 52 & $\mathrm{M}$ & 6 & + & - & 2 & 0 & 1 & + & + & + & + \\
\hline 11 & 31 & $\mathrm{M}$ & 1 & + & + & 1 & 0 & 1 & + & + & - & + \\
\hline 13 & 58 & $\mathrm{M}$ & 4 & + & - & 2 & 1 & 1 & - & - & - & - \\
\hline 17 & 22 & $\mathrm{M}$ & 7 & + & - & 3 & 2 & 1 & - & - & - & - \\
\hline 18 & 22 & $\mathrm{~F}$ & 0 & + & + & 1 & 0 & 1 & + & + & + & + \\
\hline 19 & 30 & $\mathrm{M}$ & 5 & + & + & 2 & 0 & 1 & + & + & + & + \\
\hline 20 & 69 & M & 1 & + & + & 2 & 0 & 1 & + & + & + & + \\
\hline 21 & 56 & $\mathrm{M}$ & 0 & + & + & 2 & 1 & 1 & + & + & + & + \\
\hline 22 & 63 & M & 2 & + & - & 3 & 1 & 1 & - & - & - & - \\
\hline 23 & 19 & $\mathrm{~F}$ & 0 & + & - & 1 & 0 & 1 & IC & IC & IC & IC \\
\hline 24 & 27 & $\mathrm{~F}$ & 0 & + & - & 2 & 0 & 1 & IC & IC & IC & IC \\
\hline 27 & 56 & M & 0 & + & + & 2 & 1 & 1 & + & + & + & + \\
\hline 28 & 48 & $\mathrm{~F}$ & 0 & + & + & 1 & 0 & 1 & + & - & - & - \\
\hline 32 & 21 & $\mathrm{M}$ & 1 & + & + & 1 & 1 & 1 & + & + & + & + \\
\hline 34 & 40 & $\mathrm{M}$ & 0 & + & + & 1 & 0 & 0 & IC & IC & IC & IC \\
\hline 35 & 55 & $\mathrm{~F}$ & 1 & + & + & 1 & 1 & 1 & + & + & + & + \\
\hline 36 & 53 & $\mathrm{~F}$ & 10 & + & - & 3 & 1 & 1 & + & + & + & + \\
\hline 37 & 54 & $\mathrm{M}$ & 0 & + & - & 2 & 0 & 1 & - & - & - & - \\
\hline 38 & 44 & $\mathrm{M}$ & 2 & + & + & 2 & 1 & 1 & IC & IC & IC & IC \\
\hline 42 & 40 & $\mathrm{M}$ & 8 & + & - & 2 & 0 & 1 & + & + & + & + \\
\hline 43 & 35 & $\mathrm{~F}$ & 2 & + & - & 2 & 1 & 1 & + & + & + & + \\
\hline 44 & 40 & $\mathrm{M}$ & 13 & + & - & 2 & 1 & 1 & - & - & - & - \\
\hline 45 & 53 & $\mathrm{M}$ & 0 & + & - & 3 & 1 & 1 & + & + & + & + \\
\hline 46 & 49 & $\mathrm{M}$ & 0 & + & + & 2 & 0 & 1 & + & + & + & + \\
\hline 47 & 59 & $\mathrm{M}$ & 0 & + & - & 2 & 0 & 1 & + & + & + & + \\
\hline
\end{tabular}

NOTA: M-Masculino; F-Feminino; +-Positivo; --Negativo; IC-Inconclusivo; VMDias de ventilação mecânica; PI/II- Pneumócito I e II necrose e regeneração; HPRHemorragia pulmonar recente; M, N, e L- análise semi-quantitativa da presença de macrófagos, linfócitos e neutrófilos no espaço alveolar. 


\subsection{Ausência de anticorpos anti-membrana basal e anti-fosfolípide nos soros de pacientes com SPHL}

Soro de pacientes com leptospirose, com e sem hemorragia alveolar, identificados durante vigilância ativa hospitalar na cidade de Salvador ${ }^{5}$, foram avaliados no intuito de identificar a presença de auto-anticorpos contra a membrana basal e presença de anticorpo anticardiolipina. Também nessa avaliação utilizamos soro controles de indivíduos sadios de banco de sangue. Não conseguimos demonstrar diferenças estatisticamente significativas em relação à concentração desses auto-anticorpos contra membrana basal, quando comparados soros de pacientes com leptospirose com e sem hemorragia alveolar, colhidos em diferentes momentos e soros de indivíduos sadios provenientes do banco de sangue. (Figura 10 e 11). Amostras de soros foram coletadas ao longo do tempo em pacientes com leptospirose com e sem hemorragia pulmonar. Geralmente a primeira amostra foi coletada na primeira semana de internação hospitalar e a segunda após 15 dias. Observamos diferenças estatisticamente significativas quando comparamos os títulos de anticorpos IgM anticardiolipina entre a primeira e a segunda amostra coletada no grupo de pacientes com SPHL e no grupo sem hemorragia pulmonar $(\mathrm{p}<0.01 \mathrm{e} p=0.04$, respectivamente) (Figura 11). Entretanto quando avaliamos anticorpos anti-cardiolipina da classe IgG observamos que apenas o grupo de pacientes com hemorragia pulmonar apresenta aumento desses títulos estatisticamente significativo quando comparados a primeira e segunda amostra coletadas $(\mathrm{p}=0.01)$ (Figura 11). Quando avaliamos a relação IgG/IgM anti-fosfolípide entre os pacientes com leptospirose com e sem hemorragia 
pulmonar, vimos que esta relação esta aumentada naqueles com SPHL $(p=0.01)$

(Figura 11).
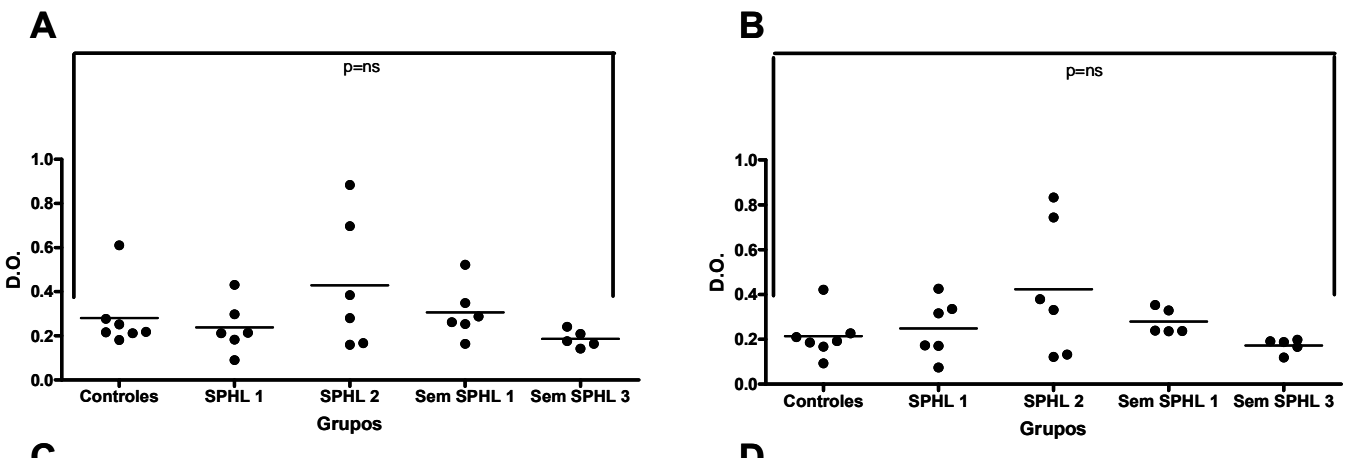

C

D
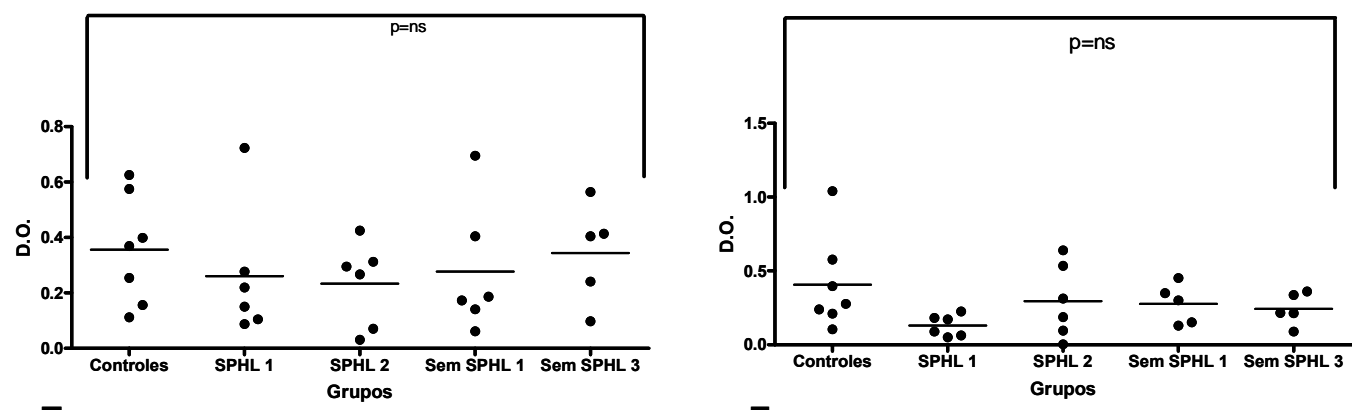

E

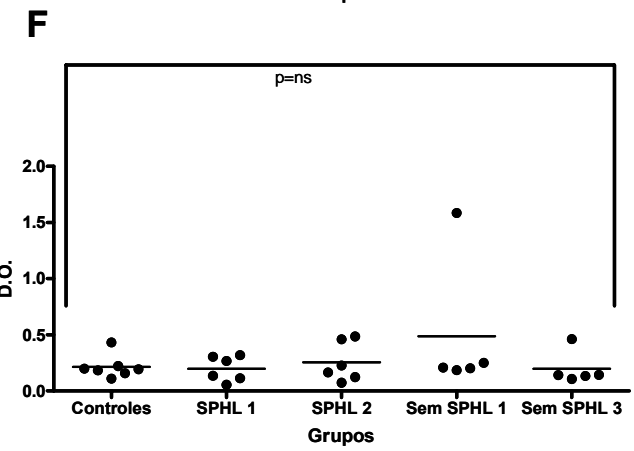

Figura 14 - Títulos de anticorpos anti-membrana basal. (A) domínio a1NC1, (B) domínio a2NC1, (C) domínio a3NC1, (D) domínio a5NC1, (E) Matrixgel, (F) Colágeno tipo IV digerido (domínios a1 e a2). Cinco grupos de soros avaliados: Indivíduos saídos de banco de sangue (Controles); primeira amostra (SPHL 1) e segunda amostra (SPHL 2) coletadas de pacientes com síndrome pulmonar hemorrágica da leptospirose; e primeira (Sem SPHL 1) e segunda amostra (Sem SPHL 3) de pacientes com leptospirose sem síndrome pulmonar hemorrágica. 


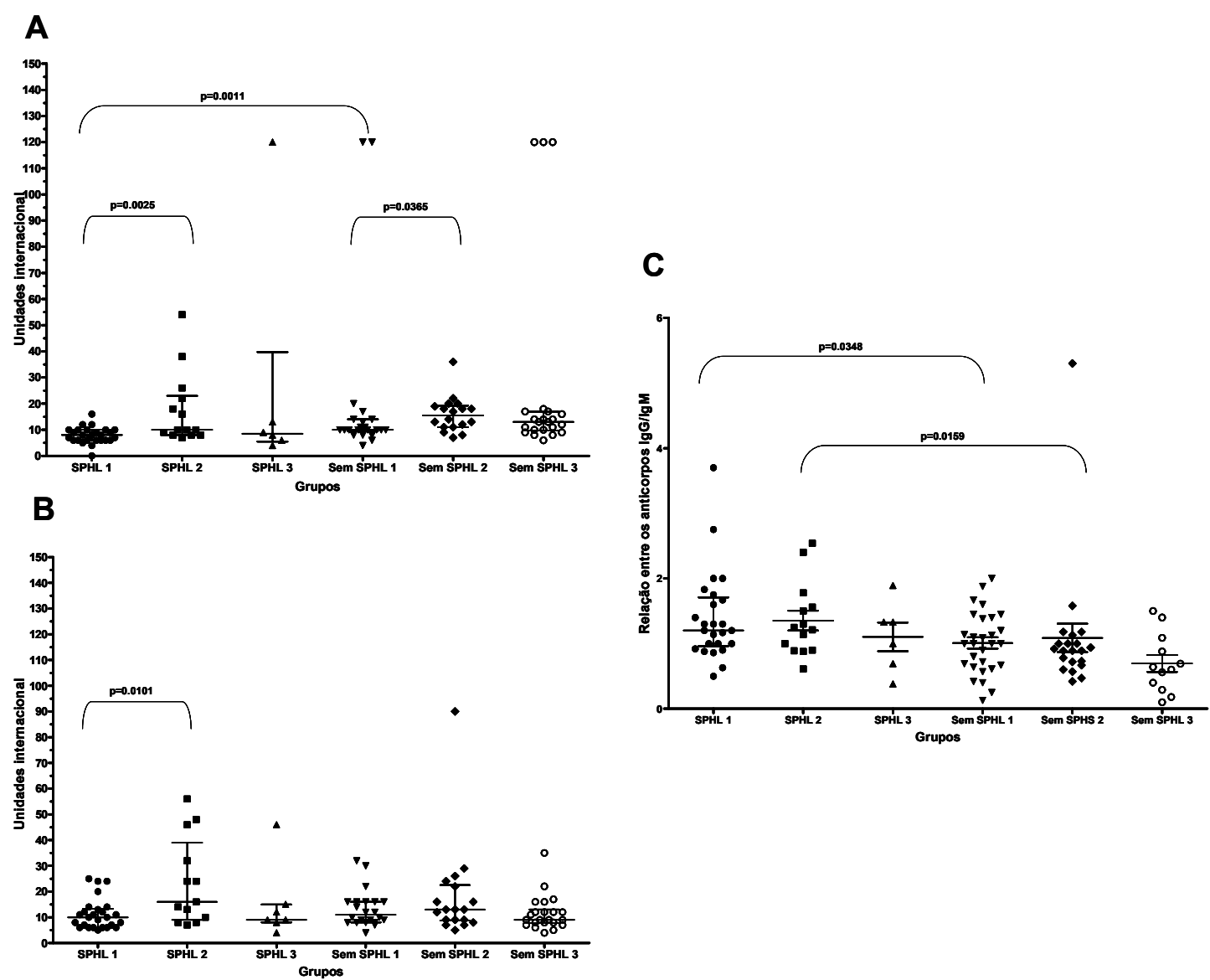

Figura 15 - Títulos de anticorpos anti-fosfolípide. (A) anticorpo $\operatorname{IgM}$, (B) anticorpo IgM, (C) relação IgG/IgM. Seis grupos de soros avaliados: Primeira (SPHL 1), segunda (SPHL 2) e terceira amostra (SPHL 3) coletadas de pacientes com síndrome pulmonar hemorrágica da leptospirose e primeira (Sem SPHL 1) e segunda (Sem SPHL 2) e terceira amostra (Sem SPHL 3) de pacientes com leptospirose sem síndrome pulmonar hemorrágica. 


\section{DISCUSSÃO}

SPHL é a maior causa de morte em pacientes com síndrome de Weil. No Brasil, a letalidade relacionada à SPHL varia entre 55 a $74 \% 16,17$. A melhor compreensão dos mecanismos relacionados à patogênese da doença pode determinar a base para novas intervenções terapêuticas, além de permitir a identificação de biomarcadores relacionados à severidade da leptospirose. O presente estudo sugere que a deposição linear de imunoglobulina ( $\operatorname{IgA}, \operatorname{IgG}, \operatorname{IgM})$ e complemento na superfície luminar alveolar podem estar relacionados com os desfechos severos da hemorragia pulmonar na leptospirose humana.

Durante um período de 17 anos (1988 a 2005), 37 necropsias de pacientes com leptospirose, foram realizadas no Serviço de Verificação de Óbito do HCFMUSP. Trinta destas necropsias formaram a casuística deste estudo.

Entre os fatores demográficos avaliados, houve maior prevalência do sexo masculino (23/30), o que se assemelha aos diversos estudos reportados no Brasil e no Mundo 5, 32, 34, 39-41. A hipótese original para explicar a predominância masculina baseia-se na maior exposição, quer pelo fator profissional, quer por exercer os homens a maior parte dos trabalhos de limpeza em época de inundações. Entretanto, Jasen et al. (2007) identificaram que o sexo masculino é fator de risco independente para aquisição da formas severas da doença ${ }^{40}$. Todavia, um recente estudo brasileiro (Gouveia et al. 2008) identificou que entre 474 pacientes internados com leptospirose, $85 \%$ eram do sexo masculino, entretanto o sexo feminino foi identificado como fator de risco para hemorragia pulmonar ${ }^{17}$. Pesquisas futuras 
poderão esclarecer se o gênero masculino tem algum fator genético ou hormonal que contribua para definir essa predileção, além daqueles fatores já conhecidos e ligados à maior exposição a que é submetido o sexo masculino. Investigações futuras deverão também ser conduzidas no sentido de clarificar os achados de ser o sexo feminino associado ao maior risco de desenvolvimento de SPHL.

A média de idade foi 44.4 anos $( \pm 15.3)$ variando de 19 a 70 anos. Nossa casuística representa a faixa etária mais acometida pela doença à semelhança das várias séries publicadas na literatura no Brasil e mundialmente. Lomar et al. (1989) relataram que entre 1726 casos que estiveram internados no Instituto de Infectologia Emílio Ribas em São Paulo, no período de 1980 e 1988, 70,3\% apresentavam idade entre 10 e 39 anos, com maior predomínio na faixa etária dos 20 aos 29 anos ${ }^{104}$. Ko et al. (1999) relataram que entre 326 casos que estiveram internados no Hospital Couto Maia em Salvador, no período de 10 de março a 2 de novembro de 1996, a média de idade foi de $35.9( \pm 15.9)$ anos ${ }^{5}$. Daher et al. (1999) relataram que entre 110 pacientes estudados entre 1985 e 1996 em Fortaleza, a média de idade foi de 41 $( \pm 18)$ anos ${ }^{91}$. Segundo o SINAN (Sistema de Informações em Agravos de Notificação) entre 2001 e 2006 foram notificados 20.575 casos de leptospirose sendo que $82 \%$ apresentavam idade entre 15 e $59^{155}$.

As diferenças de raça observadas no grupo estudado devem-se à diferente composição étnica da população do País, não havendo uma maior suscetibilidade específica. 
Algumas profissões podem estar relacionadas à aquisição da doença, principalmente aquelas com exposição a locais contaminados. No presente estudo nenhuma profissão especifica foi considerada como fator de risco para infecção. Maior relevância se dá ao modo de exposição que não necessariamente se correlaciona com a atividade profissional. Os meios de exposições mais importantes foram: contato com roedores, incluindo presença de ratos peridomiciliares, (9), água de enchentes (8), fossa ou esgoto (5), rio ou córrego (4) limpeza ou manipulação de lixo (3).

Uma vez que atividade profissional não foi determinante como meio de exposição à leptospira, avaliamos os locais de moradia dos pacientes estudados. Percebemos que a maior parte residia em zonas periféricas da cidade de São Paulo, onde muitas vezes há deficiências de redes de esgoto, falta de canalização de rios e córregos coleta inadequada de lixo, fatores estes que favorecem a proliferação de roedores.

Um terço dos pacientes apresentou algum tipo de comorbidade, sendo as doenças cardiovasculares as mais prevalentes, além de tabagismo e etilismo. Alguns dessas comorbidades, relatadas podem estar relacionadas a evoluções desfavoráveis que já foram associadas à leptospirose grave. Garcia et al. (2000) avaliando fatores de risco para o acometimento pulmonar na leptospirose, identificaram que o único fator de risco para o envolvimento pulmonar foi tabagismo ${ }^{137}$. Embora os fatores de risco contribuitórios para o desenvolvimento de SPHL ainda não estejam totalmente delineados, a nossa casuística que apresentou apenas 9 pacientes 
tabagistas. não permite esclarecer se o tabagismo é um importante fator de risco para o desencadeamento do acometimento pulmonar na leptospirose.

Os pacientes apresentaram tempo médio de sintomas antes da internação hospitalar de 6 dias (variando entre 4 a 13 dias). O tempo decorrido desde a internação até o momento do óbito (mediana de 3 dias, variando entre 0 e 13 dias) foi curto. Além disso, $74 \%$ dos pacientes já no momento da admissão apresentavam algum tipo de sangramento e $81 \%$ já tinham algum tipo de alteração respiratória (taquipnéia ou insuficiência respiratória), com relação PA/FIO2 mediana de 193, evidenciando um comprometimento pulmonar importante. Estes dados refletem a gravidade da doença nesses pacientes desde a admissão hospitalar e a precocidade dos sintomas respiratórios o que pode ter favorecido o desfecho desfavorável.

A maioria dos pacientes apresentou alterações laboratoriais compatíveis com leptospirose, como elevação da creatinina (mediana de $6.1 \mathrm{mg} / \mathrm{dl}$ ) e elevação de bilirrubinas totais (mediana de $18.7 \mathrm{mg} / \mathrm{dl}$ ) 5, 16, 91, 97. Dezenove pacientes necessitaram de diálise. A mediana do nível sérico de potássio foi de 4,7 meq/L, variando de 3,4 a 8,4 meq/L). Insuficiência renal com níveis séricos de potássio normais ou baixos é descrito por diversos autores como característicos da leptospirose com insuficiência renal e esta relacionada ao mecanismo patogênico de lesão e aos distúrbios morfofuncionais nos túbulos proximais renais ${ }^{82}$. Marotto et al. (1999) evidenciaram que em pacientes com síndrome de Weil, valores de potássio sérico superiores a $4 \mathrm{meq} / \mathrm{L}$ estão associados ao óbito ${ }^{16}$. Em nossa casuística 21/26 pacientes foram admitidos com valores de potássio sérico superior a 4 meq/L. Associado ao quadro de insuficiência renal e icterícia, os pacientes apresentavam 
discreta elevação dos níveis séricos das aminotransferases, semelhante aos níveis descritos por outros autores $5,16,91,97$.

Discreta alteração do tempo/atividade de protrombina foi observada no presente estudo. Entretanto, diversos autores relacionam essa alteração à deficiência de vitamina $\mathrm{K}$ e não a quadro de coagulação intravascular disseminada (CIVD). Nicodemo et al. (1989) encontrou valores normais do fator $\mathrm{V}$ em 19/20 pacientes e aumento do fibrinogênio plasmático em 8/18 pacientes $^{11}$. Lomar et al. (1990) verificou elevação do fibrinogênio na fase aguda em $20 / 21$ pacientes ${ }^{104}$. Um estudo recente mostrou que a CIVD esteve presente em 46\% dos pacientes com leptospirose e fenômenos hemorrágicos, ${ }^{121}$.Apesar de na Leptospirose haver um comprometimento global da hemóstase, os estudos que exploraram a possibilidade do consumo de plaquetas por CIVD obtiveram resultados controversos. Em nossa casuística não foram evidenciadas alterações microscópicas nos pulmões sugestivas de CIVD, tal como a presença de microtrombos na microvasculatura que caracterizaria de modo inequívoco a CIVD em nível tecidual.

A trombocitopenia foi uma das alterações laboratoriais mais evidentes na nossa casuística (mediana de 54.000 por mm3, variando entre 10.000 e 222.000 $\mathrm{mm} 3$ ), o que esta de acordo com vários relatos da literatura, onde 50-80\% dos pacientes apresentam baixos níveis de plaquetas. A trombocitopenia foi inicialmente relacionada à severidade da doença, principalmente nas formas graves com insuficiência renal ${ }^{119}$. Todavia outros estudos não associaram presença ou intensidade da trombocitopenia, com manifestações hemorrágicas, nem com 
mortalidade ${ }^{16,120}$. Um estudo recente relacionou a presença de trombocitopenia com severidade da doença e risco de sangramento ${ }^{121}$.

O padrão histológico dos pacientes com SPHL difere dos de outras causas de hemorragia pulmonar como diáteses hemorrágicas, hipertensão venosa, outras infecções, tumores, colagenoses, particularmente quando se explora a presença de imunoglobulinas e complemento "in situ" nas áreas de hemorragia pulmonar ${ }^{156}$.

O comprometimento pulmonar peculiar, aliado a manifestações hemorrágicas intra-alveolares, determinado pela Leptospirose pode co-existir com o quadro de dano alveolar difuso (DAD) semelhante ao que ocorre por outras causas. A presença de DAD concomitante às lesões peculiares da Leptospirose foi visto em nosso estudo. O diagnóstico anátomo-patológico da fase aguda de DAD é baseado na presença de membrana hialina, associado à presença de hemácias e neutrófilos no lúmen alveolar e importante destruição do revestimento epitelial alveolar. ${ }^{142}{ }^{157}$.

$\mathrm{O}$ aspecto anátomo-patológico mais característico do envolvimento pulmonar na Leptospirose foi aquele de necrose de pneumócitos I e II, e deposição linear de imunoglobulinas e complemento na superfície luminal alveolar dos pacientes com SPHL. Cumpre ressaltar que tal tipo de associação de alterações não foi observado em nenhum dos pacientes controles que apresentavam hemorragia pulmonar por outras causas. Essa constatação confere a peculiaridade do acometimento pulmonar observado no curso da Leptospirose grave.

Em todos os 17 casos no qual esteve presente a deposição de C3, também foi encontrado a deposição de $\operatorname{IgM}$, IgG e IGA, o que converge para indicar a 
importância da associação desses dois elementos depositados nos alvéolos na lesão pulmonar desencadeada pela Leptospirose.

O tipo de marcação mais comumente observado nos casos de SPHL foi aquele de deposição de imunoglobulinas (IgM, IgG, IgA) e complemento (C3) que assumiram a morfologia de um padrão linear de deposição adjacente à superfície alveolar, revestindo os pneumócitos necróticos ou em regeneração. Esse padrão foi fortemente associado à hemorragia alveolar intensa (padrão A).

Verificamos também que as imunoglobulinas e o complemento também adotaram um padrão de marcação mulfocal (MF), observado com menor freqüência que o padrão linear e sendo esses depósitos identificados principalmente nos septos alveolares.

No tecido pulmonar dos pacientes com leptospirose e nos controles, evidenciamos ainda a presença de marcação sob a forma de diminutos depósitos granulares ,presentes por entre as hemácias nas áreas centrais da luz alveolar (padrão I), Interpretamos esse tipo de padrão como decorrente de deposição inespecífica de imunoglobulinas circulantes e complemento, fazendo parte do componente plasmático da hemorragia alveolar.

O padrão de deposição linear (padrão A) de imunoglobulinas e complemento recobrindo os pneumócitos I e II pode interferir na barreira alvéolo capilar . A lesão e a perda da integridade dos pneumócitos I e II alteram o transporte de fluídos e a remoção de fluídos do espaço alveolar. ${ }^{144}$. Associado a esse fato há uma redução da produção e da taxa de troca das substâncias surfactantes, dessa forma reduzindo a capacidade de troca de oxigênio e gás carbônico. Juntos, esses eventos podem 
resultar em hemorragia alveolar ${ }^{158}$. A presença de deposição multifocal de imunoglobulinas (padrão MF) associada a congestão, edema e discreto infiltrado inflamatório nos septos alveolares, colaboram para o agravamento do comprometimento das trocas respiratórias e contribuem para a gravidade da SPHL

Nossa hipótese para justificar o comprometimento pulmonar nos casos de SPHL, baseada nos achados da presente investigação e aliados a outros já demonstrados em pesquisas anteriores seria que inicialmente ocorreria, como é próprio de Leptospirose, um aumento da permeabilidade vascular devido à ativação endotelial e distúrbios funcionais dessas células ${ }^{12,152,159,160}$. Assim sendo, aconteceria na doença vários eventos já plenamente demonstradas tais como: ahemolisinas putativas que podem estar implicadas na lesão endotelial, como Hap1 (hemolysis-associated protein 1) ou LipL32 (lipoprotein of Leptospira with 32kDa) 61, 127, Sph (sphingomyelinase) ${ }^{128}$ e $\mathrm{Sph} 2{ }^{52}$. b- genes que foram recentemente identificados e que podem contribuir para a lesão tecidual tais como os receptores de proteínas quimiotáticas (presente apenas nas cepas patogênicas) associados à quimiotaxia e que poderiam explicar a predileção da leptospira em acometer vasos. c- o peptidoglicano extraído da parede celular de Leptospira interrogans que induz a liberação de TNF- $\alpha$ de monócitos humanos e ativa a aderência de neutrófilos à células endoteliais $^{76}$. d- já foi descrito na Leptospirose a produção de resposta tipo Th1, pró-inflamatória, com níveis elevados de fator de necrose tumoral alfa (TNF- $\alpha$ ), estritamente relacionado à severidade do quadro clínico e a letalidade na doença. e-a indução de TNF- $\alpha$ por fatores tóxicos bacterianos desencadeia resposta inflamatória 
local e sistêmica, resultando então em dano capilar. f- já foi descrito na Leptosirose aumento da produção de oxido nítrico ${ }^{161,162}$ e o aumento da permeabilidade das junções intercelulares ${ }^{12,160}$.

Em conseqüência do aumento da permeabilidade dos capilares em nível dos septos alveolares ocorreria extravasamento de $\operatorname{IgM}, \operatorname{IgG}$ e $\operatorname{IgA}$ para o septo alveolar sob a forma de focos múltipos e também para o espaço alveolar ai se depositando sob a forma de depósitos lineares contínuos na superfície luminar dos pneumócitos. A deposição tecidual local de imunoglobulina mediaria a ativação do complemento e a deposição de C3. O complemento ativado levaria à necrose dos pneumócitos, hemorragia no lúmen alveolar, inflamação septal e intra-alveolar (Figura 16) 


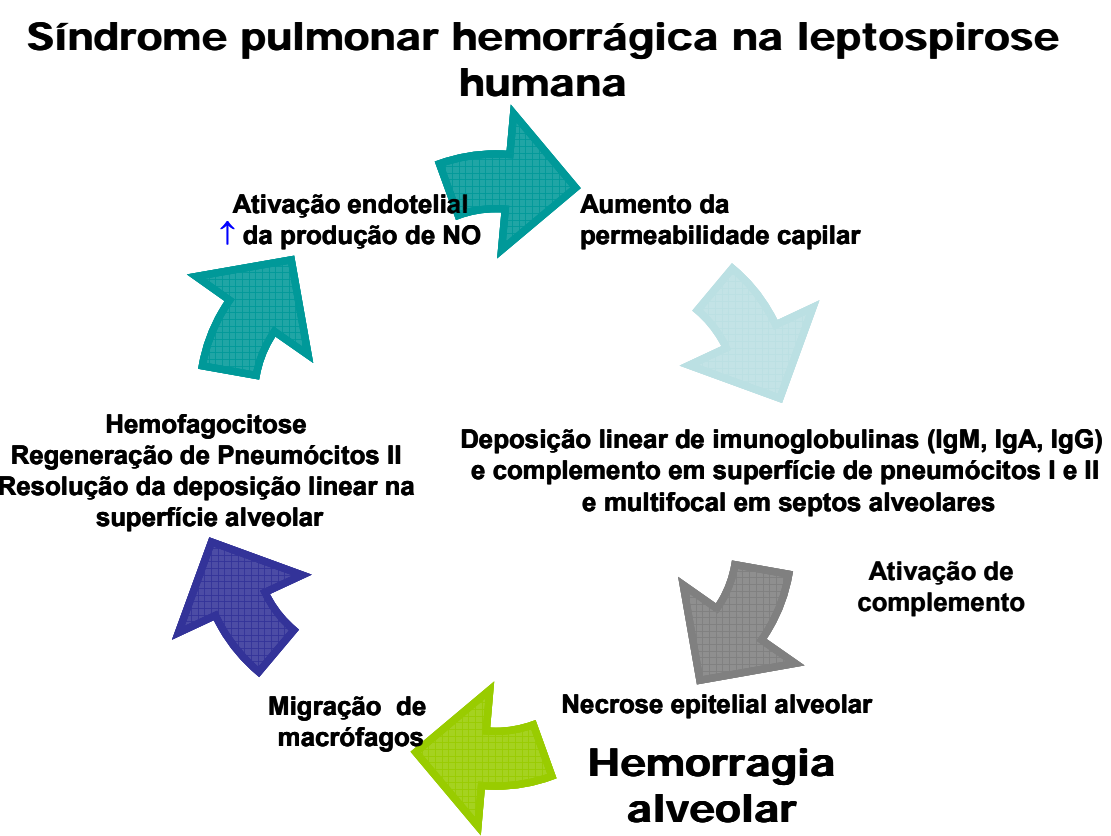

Figura 16 -Mecanismo patogênico proposto para a síndrome pulmonar hemorrágica na leptospirose

As razões relacionadas a não detecção de $\mathrm{C} 3$ em 13 dos 30 tecidos pulmonares dos pacientes com SPHL não são claras, mas provavelmente refletem a limpeza desses depósitos pelos macrófagos que se encontram no lúmen alveolar. Como demonstrando anteriormente, a ausência de deposição de C3 foi correlacionada com o aumento de macrófagos no lúmen alveolar e com o aumento do tempo de ventilação mecânica. Alternativamente, a ausência de deposição de C3 pode ser explicada pelas características intrínsecas relacionas à meia-vida curta do $\mathrm{C}^{3} \mathrm{C}^{163}$.

Poucas informações relacionadas aos mecanismos patológicos associados a SPHL estão disponíveis. Quatro estudos prévios demonstraram a presença de anticorpos anticardiolipina nos pacientes com leptospirose ${ }^{8,148-150}$. Uma série de 
casos encontrou correlação entre a presença desses anticorpos no soro e apresentação de complicações severas relacionadas à leptospirose ${ }^{148}$. Todavia, através da microscopia eletrônica, Nicodemo et al. (1997) não encontraram nenhuma evidência anatomopatológica característica de síndrome anti-fosfolipide, tais como: necrose das células endoteliais, ruptura, trombos ou exposição do colágeno subendotelial nas áreas de tecido pulmonar com hemorragia ${ }^{12}$. Além disso, após re-análise por microscopia eletrônica de sete amostras de tecido pulmonar de nossos pacientes, também não foi possível identificar características ultra-estruturais compatíveis com a síndrome anti-fosfolípide.

Nally et al.(2004), em estudo experimental, sugeriram que as alterações patológicas no pulmão poderiam estar relacionadas a doença de Goodpasture ${ }^{15}$. Os autores descreveram por imunofluorêscencia a deposição com aspecto membranoso de imunoglobulinas e complemento, seguindo um padrão de membrana basal nos septos alveolares, fato que caracterizaria de ponto de vista morfológico a síndrome de Goodpasture no modelo de cobaia. Deve-se ressaltar que estudo dos próprios autores $^{77}$ utilizando a microscopia eletrônica naquele modelo experimental não confirmou a deposição de material eletrodenso representativo de imunoglobulina delineando a membrana basal capilar-alveolar ${ }^{12,}{ }^{15}$. Os mesmos autores não encontraram nos rins evidências histopatológicas compatíveis com a síndrome de Goodpasture no seu modelo experimental.

$\mathrm{O}$ aspecto ultraestrutural que caracterizaria os depósitos de membrana basal também não foram encontrados nos pulmões dos pacientes estudados por Nicodemo et $\mathrm{al}^{74}$. Nos casos humanos de nossa casuística também não foi observada necrose 
das células endoteliais, nem tão pouco infiltrado significante de neutrófilos nos septos alveolares. Estes eventos fazem parte do quadro morfológico descrito na síndrome de Goodpasture. O exame histológico dos rins dos nossos pacientes com SPHL, também não demonstrou características morfológicas da doença Goodpasture. Dessa maneira julgamos que o envolvimento dos pulmões na Leptospirose não é superponível àquele classicamente relatado nessa síndrome.

Para investigar a hipótese de que as lesões dos pulmões na Leptospirose pudessem decorrer de auto-anticorpos dirigidos contra a membrana basal alvéolocapilar fizemos a pesquisa dos mesmos em soros de pacientes com leptospirose com e sem SPHL (identificados durante vigilância hospitalar ativa para leptospirose na cidade de Salvador ${ }^{5}$ ) e soros de indivíduos sadios doadores do banco de sangue. Pesquisamos também os anticorpos anti-cardiolipina. Os resultados dessas investigações não mostraram nenhuma diferença estatisticamente significativa em relação às concentrações desses anticorpos, quando comparados pacientes com leptospirose com e sem hemorragia e controles. A ausência desses auto-anticorpos reforça a hipótese de que os prováveis mecanismos de lesão não estão relacionados à doença de Goodpasture ou síndrome anti-fosfolípide. Observamos um aumento sustentado dos anticorpos da classe IgG no grupo de pacientes com hemorragia pulmonar, além de uma maior relação de anticorpos $\operatorname{IgG} / \operatorname{IgM}$ anti-fosfolípide no grupo de pacientes com leptospirose e hemorragia pulmonar. Daher et al. (2002) correlacionam a presença desses anticorpos com fenômenos hemorrágicos ${ }^{8}$.

Estudo conduzido por Abdulkader et al. (2002) descreveu que os pacientes com leptospirose que apresentaram títulos de $\operatorname{IgG}>1: 400$ na primeira amostra, 
permaneceram com febre por mais tempo e tiveram maior comprometimento renal e pulmonar ${ }^{164}$. Esses resultados associados aos encontrados em nosso estudo sugerem que a gravidade da leptospirose com síndrome pulmonar hemorrágica pulmonar pode estar associada à intensidade da resposta humoral ${ }^{164}$.

Apesar da clara deposição de anticorpos e C3 ao longo da superfície alveolar, novas avaliações são necessárias para excluir a possibilidade de que aspectos inespecíficos associados à ativação endotelial levaram a deposição inespecífica de complemento e imunoglobulina ${ }^{12,159,165}$. É necessário que se avaliem os soros dos pacientes com SPHL contra o tecido pulmonar normal para verificar a especificidade desses auto-anticorpos contra componentes alveolares, como pneumócito I e II.

$\mathrm{Na}$ prática, futuros estudos são imprescindíveis para caracterizar essa aparente resposta auto-imune. A identificação de possíveis auto-anticorpos envolvidos poderá auxiliar no diagnóstico de pacientes com risco elevado de desenvolver SPHL. Além disso, se um processo autoimune é a causa de complicações hemorrágicas na leptospirose humana, terapias efetivas deverão ser desenvolvidas para a remoção desses auto-anticorpos do sangue ou dirigidas para diminuição da sua produção. 


\section{CONCLUSÕES}

- Os casos fatais de pacientes com síndrome pulmonar hemorrágica na leptospirose apresentam os sintomas clássicos da síndrome de Weil (icterícia, insuficiência renal, fenômenos hemorrágicos), predominantemente são adultos jovens, do sexo masculino, sendo a exposição a áreas de risco a principal forma de aquisição da doença.

- Os pacientes com SPHL já na admissão apresentavam sinais de gravidade como trombocitopenia intensa, insuficiência renal com potássio maior que 4 meq/L, e insuficiência respiratória, fatores que certamente contribuíram para a evolução rápida para o óbito.

- O quadro morfológico da pneumopatia hemorrágica própria da leptospirose freqüentemente co-existiu com a ocorrência de dano alveolar difuso, cuja correspondência clínica é a síndrome da angústia respiratória do adulto (SARA) diagnosticada nos paciente pela diminuição da relação $\mathrm{PaO} 2 / \mathrm{FiO} 2$ e exclusão de outras causas de aumento de permeabilidade alvéolo capilar.

- O comprometimento pulmonar na leptospirose humana grave ocorre principalmente sob a forma de uma pneumopatia hemorrágica com características peculiares, cujo quadro morfológico difere de outras hemorragias pulmonares. Caracteriza-se pela deposição linear de 
imunoglobulina (IgM, $\operatorname{IgG}$ e $\operatorname{IgA}$ ) e complemento(C3) na superfície luminal alveolar de pneumócitos I e II e multifocal nos septos alveolares. Associa-se à intensa necrose de pneumócitos I e II, regeneração de pneumócitos II, além de inflamação septal e alveolar.

- A deposição de imunoglobulina e complemento em tecido pulmonar de pacientes com hemorragia pulmonar e leptospirose configurou 3 padrões: 1marcação linear delicada, como uma membrana, recobrindo a superfície luminal alveolar de pneumócitos I e II. 2- marcação multifocal, aleatória ao longo do septo alveolar. 3- marcação fraca granular, focal, intra-alveolar. Esses padrões são provavelmente resultantes do aumento da permeabilidade capilar própria da leptospirose, ocorrendo numa situação de aumento de anticorpos específicos circulantes.

- Os achados desse trabalho indicam que os mecanismos patológicos envolvidos na síndrome pulmonar hemorrágica na leptospirose humana não estão relacionados à coagulação vascular disseminada, à síndrome de Goodpasture ou à síndrome anti-fosfolípide. 


\section{ANEXOS}

\subsection{Anexo A - Aprovação do projeto pelo comitê de ética e pesquisa}

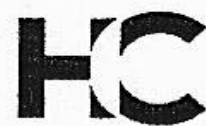

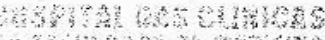

\section{APROVACÃ̃O}

A Comissão de Ética para Análise de Projetos de Pesquisa - CAPPesq da Diretoria Clínica do Hospital das Clínicas e da Faculdade de Medicina da Universidade de São Paulo, em sessão de 09.11.05, APROVOU o Protocolo de Pesquisa $n^{\circ} 813 / 05$, intitulado: "Fisiopatologia da Síndrome de hemorragia pulmonar nos pacientes com Leptospirose" apresentado pelo Departamento de PATOLOGIA, inclusive o Termo de Consentimento Livre e Esclarecido.

Cabe ao pesquisador elaborar e apresentar à CAPPesq, os relatórios parciais e final sobre a pesquisa (Resolução do Conselho Nacional de Saúde $n^{\circ} 196$, de 10.10.1996, inciso IX. 2, letra "c")

Pesquisador(a) Responsável: Profa. Dra. Maria Irma Seixas Duarte Pesquisador (a) Executante: Dr. Julio Henrique Rosa Croda

CAPPesq, 09 de Novembro de 2005.

$$
\text { livis Ridio }
$$

PROF. DR. EUCLIDES AYRES DE CASTILHO Presidente da Comissão de Ética para Análise de Projetos de Pesquisa

Comissão de Ética para Anátise de Projetos de Pesquisa do HCFMUSP e da FMUSP Clinica do Hospital das Clinicas da Faculdade de Medicina da Universidade de São Paul$$
\text { Diretoria Clinica do Hospital das Clinicas da Facaldade de Medicina da Universidade de }
$$

Fone: 011 - 30696442 tax: 011. 30696492 - e-mail : cappesq@hcnet.usp.br / secretariacappesq2ohenet. usp.br 


\subsection{Anexo B - Questionário aplicado à coleta de dados da casuística selecionada}

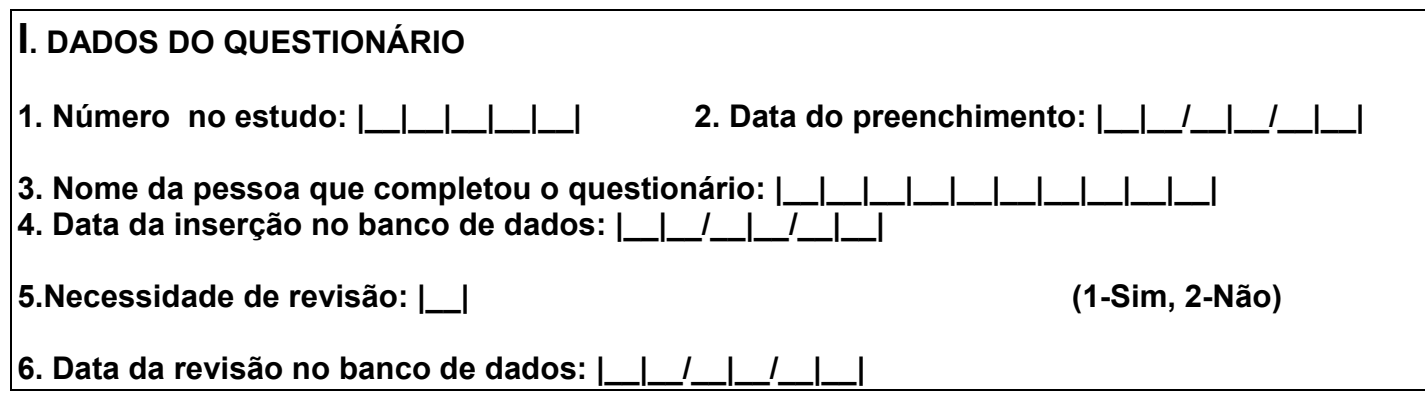

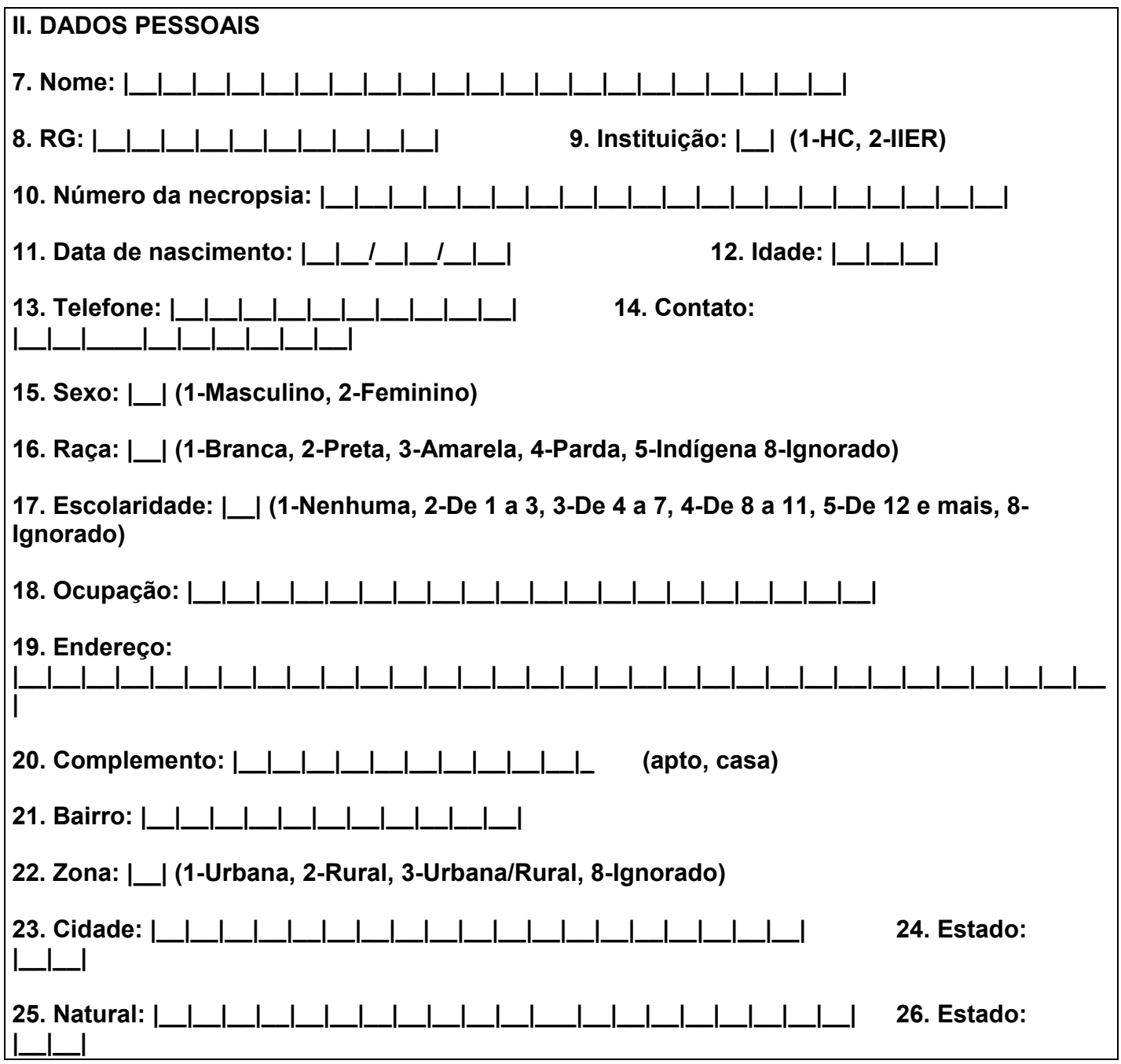




\begin{tabular}{|c|c|}
\hline $\begin{array}{l}\text { III. DADOS EPIDEMIOLÓGICOS } \\
\text { Situação de Risco ocorrida nos } 25 \text { dias que Ante } \\
\text { 27. Lavoura }\end{array}$ & $\begin{array}{l}\text { os Primeiros sintomas: } \\
\text { __ (1-Sim, 2-Não, 8-Ignorado) }\end{array}$ \\
\hline 28. Lixo & I_l (1-Sim, 2-Não, 8-Ignorado) \\
\hline 29. Limpeza de Caixa d água & I_l (1-Sim, 2-Não, 8-Ignorado) \\
\hline 30. Água ou Lama de Enchente & L_l (1-Sim, 2-Não, 8-Ignorado) \\
\hline 31. Água de Rio, Córrego, Lago & I_l (1-Sim, 2-Não, 8-Ignorado) \\
\hline 32. Fossa, Esgoto & L__ (1-Sim, 2-Não, 8-Ignorado) \\
\hline 33. Criação de animais & I__ (1-Sim, 2-Não, 8-Ignorado) \\
\hline 34. Carcaça de animais & I__ (1-Sim, 2-Não, 8-Ignorado) \\
\hline 35. Contato direto com roedores & |_ (1-Sim, 2-Não, 8-Ignorado) \\
\hline 36. Outras: $\mid$ & 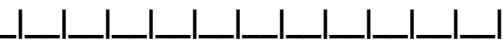 \\
\hline 37. Data dos Primeiros Sintomas: $\mid$ & \\
\hline 38. Comorbidades: I__ & 8-Ignorado) \\
\hline Se sim quais? & \\
\hline 39. Diabetes mellitus: ا__ & 41.HAS: I_l \\
\hline 42. Insuf. Renal Crônica: $\left.\right|_{\_}$| 43. Insuf. Coronari & _ 44. Insuf. Hepática crônica: |_ \\
\hline 46. ICC: $\left.\right|_{(1-\operatorname{Sim}, 2}$ & 47. Outras: I_l \\
\hline
\end{tabular}




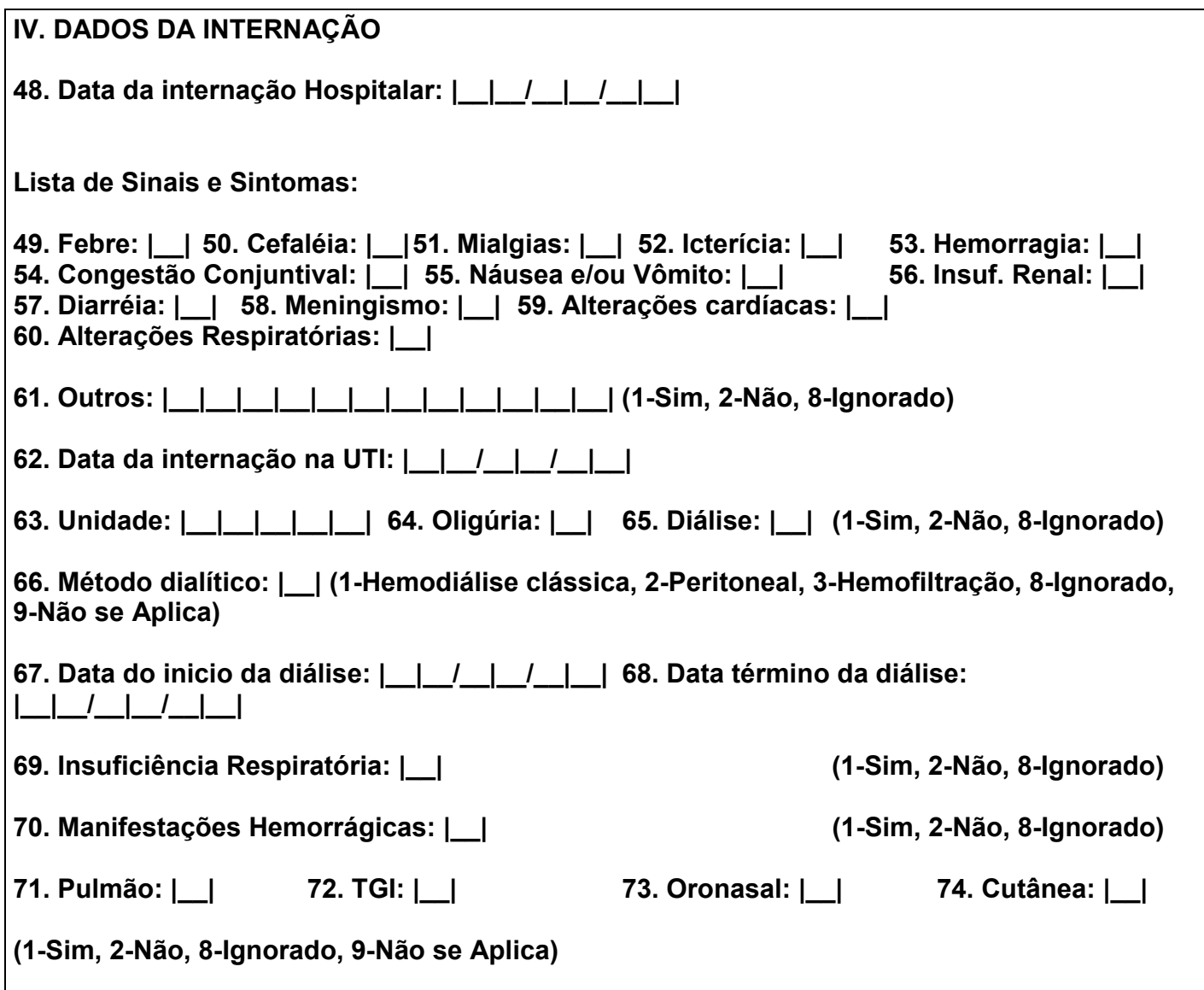


Variáveis para cálculo de escores prognósticos nas primeiras $24 \mathrm{hs}$ de internação

\begin{tabular}{|c|c|c|}
\hline VARIÁVEL & MAIOR VALOR & MENOR VALOR \\
\hline Temperatura & 76. & 77. \\
\hline Freqüência cardíaca & 78. & 79. \\
\hline Freqüência respiratória & 80. & 81. \\
\hline Pressão arterial média $=(\mathrm{PAS}+2 \times \mathrm{PAD}) / 3$ & 82. & 83. \\
\hline Troca Gasosa & Medida1 & Medida 2 \\
\hline FIO2 & 84. & 85. \\
\hline $\mathrm{PaO2}$ & 86. & 87. \\
\hline $\mathrm{PaCO} 2$ & 88. & 89. \\
\hline VARIÁVEL & MAIOR VALOR & MENOR VALOR \\
\hline PH arterial & 90. & 91. \\
\hline Sódio & 92. & 93. \\
\hline Potássio & 94. & 95. \\
\hline Creatinina & 96. & 97. \\
\hline Hematócrito & 98. & 99. \\
\hline Leucócitos & 100. & 101. \\
\hline Plaquetas & 102. & 103. \\
\hline Bilirrubina total & 104. & 105. \\
\hline $\begin{array}{l}\text { Escala de coma de Glasgow(valor prévio à } \\
\text { sedação) }\end{array}$ & 106. & 107. \\
\hline \multicolumn{3}{|l|}{ MEDIDAS DO SWAN GANZ } \\
\hline Débito Cardíaco & 108. & \\
\hline Pwedge & 109. & \\
\hline Resistência & 110. & \\
\hline PVC & 111. & \\
\hline Pressão de Átrio Direto & 112. & \\
\hline
\end{tabular}

113. Insuficiência Renal aguda? I_

114. Pós operatório Eletivo?

115. APACHE II: |___ا__ 


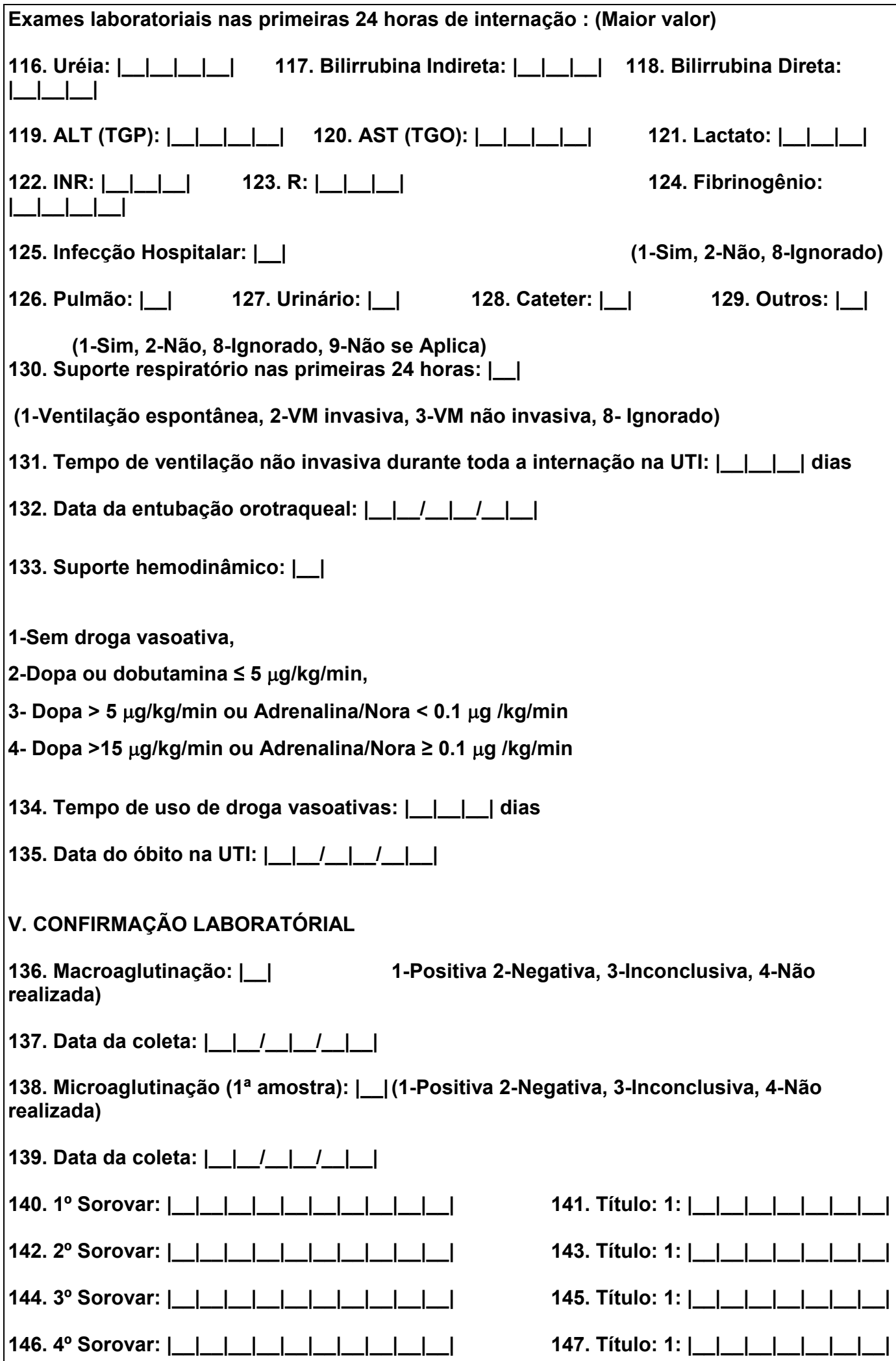


148. $5^{\circ}$ Sorovar: $\mid+1+1+1+1+1+1+1$

149. Título: $1:$ |______ا____ا_ا_

150. Microaglutinação (1 ${ }^{\text {a }}$ amostra): | | (1-Positiva 2-Negativa, 3-Inconclusiva, 4-Não realizada)

151. Data da coleta: $\mid$

152. $1^{\circ}$ Sorovar:

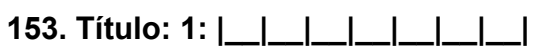

154. $2^{\circ}$ Sorovar:

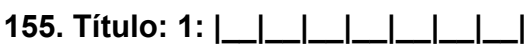

156. Cultura: ا__ (1-Positiva 2-Negativa, 3-Inconclusiva, 4-Não realizada)

157. Data da coleta: I_L_L_L____

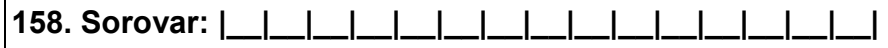

159. Elisa-IgM: I__ (1-Positiva 2-Negativa, 3-Inconclusiva, 4-Não realizada)

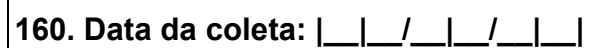




\section{REFERÊNCIAS}

1. Levett PN. Leptospirosis. Clin Microbiol Rev. 2001 Apr;14(2):296-326.

2. McBride AJ, Athanazio DA, Reis MG, Ko AI. Leptospirosis. Curr Opin Infect Dis. 2005 Oct;18(5):376-86.

3. Bharti AR, Nally JE, Ricaldi JN, Matthias MA, Diaz MM, Lovett MA, Levett PN, Gilman RH, Willig MR, Gotuzzo E, Vinetz JM. Leptospirosis: a zoonotic disease of global importance. Lancet Infect Dis. 2003 Dec;3(12):757-71.

4. Laras K, Cao BV, Bounlu K, Nguyen TK, Olson JG, Thongchanh S, Tran NV, Hoang KL, Punjabi N, Ha BK, Ung SA, Insisiengmay S, Watts DM, Beecham HJ, Corwin AL. The importance of leptospirosis in Southeast Asia. Am J Trop Med Hyg. 2002 Sep;67(3):278-86.

5. Ko AI, Galvao Reis M, Ribeiro Dourado CM, Johnson WD, Jr., Riley LW. Urban epidemic of severe leptospirosis in Brazil. Salvador Leptospirosis Study Group. Lancet. 1999 Sep 4;354(9181):820-5.

6. Picardeau M, Bulach DM, Bouchier C, Zuerner RL, Zidane N, Wilson PJ, Creno S, Kuczek ES, Bommezzadri S, Davis JC, McGrath A, Johnson MJ, Boursaux-Eude C, Seemann T, Rouy Z, Coppel RL, Rood JI, Lajus A, Davies JK, Medigue C, Adler B. Genome sequence of the saprophyte Leptospira biflexa provides insights into the evolution of Leptospira and the pathogenesis of leptospirosis. PLoS ONE. 2008;3(2):e1607.

7. Faine SA, B. Bolin, C. Perolat, P. Leptospira and leptospirosis. 2nd ed. Melbourne, Australia: MediSci,; 1999. 
8. Trevejo RT, Rigau-Perez JG, Ashford DA, McClure EM, Jarquin-Gonzalez C, Amador JJ, de los Reyes JO, Gonzalez A, Zaki SR, Shieh WJ, McLean RG, Nasci RS, Weyant RS, Bolin CA, Bragg SL, Perkins BA, Spiegel RA. Epidemic leptospirosis associated with pulmonary hemorrhage-Nicaragua, 1995. J Infect Dis. 1998 Nov;178(5):1457-63.

9. Gouveia EL, Metcalfe J, de Carvalho AL, Aires TS, Villasboas-Bisneto JC, Queirroz A, Santos AC, Salgado K, Reis MG, Ko AI. Leptospirosis-associated Severe Pulmonary Hemorrhagic Syndrome, Salvador, Brazil. Emerg Infect Dis. 2008 Mar;14(3):505-8.

10. Marotto PC, Nascimento CM, Eluf-Neto J, Marotto MS, Andrade L, Sztajnbok J, Seguro AC. Acute lung injury in leptospirosis: clinical and laboratory features, outcome, and factors associated with mortality. Clin Infect Dis. 1999 Dec;29(6):1561-3.

11. Panaphut T, Domrongkitchaiporn S, Thinkamrop B. Prognostic factors of death in leptospirosis: a prospective cohort study in Khon Kaen, Thailand. Int J Infect Dis. 2002 Mar;6(1):52-9.

12. Yersin C, Bovet P, Merien F, Clement J, Laille M, Van Ranst M, Perolat P. Pulmonary haemorrhage as a predominant cause of death in leptospirosis in Seychelles. Trans R Soc Trop Med Hyg. 2000 Jan-Feb;94(1):71-6.

13. Segura ER, Ganoza CA, Campos K, Ricaldi JN, Torres S, Silva H, Cespedes MJ, Matthias MA, Swancutt MA, Lopez Linan R, Gotuzzo E, Guerra H, Gilman RH, Vinetz JM. Clinical spectrum of pulmonary involvement in leptospirosis in a region 
of endemicity, with quantification of leptospiral burden. Clin Infect Dis. 2005 Feb $1 ; 40(3): 343-51$.

14. Sanders EJ, Rigau-Perez JG, Smits HL, Deseda CC, Vorndam VA, Aye T, Spiegel RA, Weyant RS, Bragg SL. Increase of leptospirosis in dengue-negative patients after a hurricane in Puerto Rico in 1996 [correction of 1966]. Am J Trop Med Hyg. 1999 Sep;61(3):399-404.

15. Campanella N. Infectious diseases and natural disasters: the effects of Hurricane Mitch over Villanueva municipal area, Nicaragua. Public Health Rev. 1999;27(4):311-9.

16. Update: outbreak of acute febrile illness among athletes participating in EcoChallenge-Sabah 2000--Borneo, Malaysia, 2000. MMWR Morb Mortal Wkly Rep. 2001 Jan 19;50(2):21-4.

17. Update: leptospirosis and unexplained acute febrile illness among athletes participating in triathlons--Illinois and Wisconsin, 1998. MMWR Morb Mortal Wkly Rep. 1998 Aug 21;47(32):673-6.

18. Morgan J, Bornstein SL, Karpati AM, Bruce M, Bolin CA, Austin CC, Woods CW, Lingappa J, Langkop C, Davis B, Graham DR, Proctor M, Ashford DA, Bajani M, Bragg SL, Shutt K, Perkins BA, Tappero JW. Outbreak of leptospirosis among triathlon participants and community residents in Springfield, Illinois, 1998. Clin Infect Dis. 2002 Jun 15;34(12):1593-9.

19. Sejvar J, Bancroft E, Winthrop K, Bettinger J, Bajani M, Bragg S, Shutt K, Kaiser R, Marano N, Popovic T, Tappero J, Ashford D, Mascola L, Vugia D, Perkins 
B, Rosenstein N. Leptospirosis in "Eco-Challenge" athletes, Malaysian Borneo, 2000. Emerg Infect Dis. 2003 Jun;9(6):702-7.

20. Jackson LA, Kaufmann AF, Adams WG, Phelps MB, Andreasen C, Langkop CW, Francis BJ, Wenger JD. Outbreak of leptospirosis associated with swimming. Pediatr Infect Dis J. 1993 Jan;12(1):48-54.

21. Tangkanakul W, Smits HL, Jatanasen S, Ashford DA. Leptospirosis: an emerging health problem in Thailand. Southeast Asian J Trop Med Public Health. 2005 Mar;36(2):281-8.

22. Reis RB, Ribeiro GS, Felzemburgh RD, Santana FS, Mohr S, Melendez AX, Queiroz A, Santos AC, Ravines RR, Tassinari WS, Carvalho MS, Reis MG, Ko AI. Impact of environment and social gradient on leptospira infection in urban slums. PLoS Negl Trop Dis. 2008;2(4):e228.

23. WHO. Leptospirosis worldwide, 1999. Wkly Epidemiol Rec. 1999 Jul 23;74(29):237-42.

24. Pappas G, Papadimitriou P, Siozopoulou V, Christou L, Akritidis N. The globalization of leptospirosis: worldwide incidence trends. Int J Infect Dis. 2008 Jul;12(4):351-7.

25. WHO. Human leptospirosis: guidance for diagnosis, surveillance and control. Malta: World Health Organization. 2003.

26. Johnson MA, Smith H, Joeph P, Gilman RH, Bautista CT, Campos KJ, Cespedes M, Klatsky P, Vidal C, Terry H, Calderon MM, Coral C, Cabrera L, Parmar PS, Vinetz JM. Environmental exposure and leptospirosis, Peru. Emerg Infect Dis. 2004 Jun;10(6):1016-22. 
27. Lilenbaum W, Ribeiro V, Martin E, Bispo V. [Serologic study for detecting anti-Leptospira antibodies in Rattus norvegicus from Duque de Caxias, Rio de Janeiro, Brazil]. Rev Latinoam Microbiol. 1993 Oct-Dec;35(4):357-80.

28. Everard CO, Edwards CN, Everard JD, Carrington DG. A twelve-year study of leptospirosis on Barbados. Eur J Epidemiol. 1995 Jun;11(3):311-20.

29. Jansen A, Stark K, Schneider T, Schoneberg I. Sex differences in clinical leptospirosis in Germany: 1997-2005. Clin Infect Dis. 2007 May 1;44(9):e69-72.

30. Lopes AA, Costa E, Costa YA, Sacramento E, de Oliveira Junior AR, Lopes MB, Lopes GB. Comparative study of the in-hospital case-fatality rate of leptospirosis between pediatric and adult patients of different age groups. Rev Inst Med Trop Sao Paulo. 2004 Jan-Feb;46(1):19-24.

31. Riley LW, Ko AI, Unger A, Reis MG. Slum health: diseases of neglected populations. BMC Int Health Hum Rights. 2007;7:2.

32. UN-HABITAT. The challenge of the slums: Global report on human settlements; 2003.

33. Romero EC, Bernardo CC, Yasuda PH. Human leptospirosis: a twenty-nineyear serological study in Sao Paulo, Brazil. Rev Inst Med Trop Sao Paulo. 2003 SepOct;45(5):245-8.

34. Dias JP, Teixeira MG, Costa MC, Mendes CM, Guimaraes P, Reis MG, Ko A, Barreto ML. Factors associated with Leptospira $s p$ infection in a large urban center in northeastern Brazil. Rev Soc Bras Med Trop. 2007 Sep-Oct;40(5):499-504.

35. Johnson RC, Harris VG. Differentiation of pathogenic and saprophytic letospires. I. Growth at low temperatures. J Bacteriol. 1967 Jul;94(1):27-31. 
36. Ellinghausen HC, Jr., McCullough WG. Nutrition of Leptospira Pomona and Growth of 13 Other Serotypes: Fractionation of Oleic Albumin Complex and a Medium of Bovine Albumin and Polysorbate 80. Am J Vet Res. 1965 Jan;26:45-51.

37. Ellinghausen HC, Jr., McCullough WG. Nutrition of Leptospira Pomona and Growth of 13 Other Serotypes: a Serum-Free Medium Employing Oleic Albumin Complex. Am J Vet Res. 1965 Jan;26:39-44.

38. Bulach DM, Kalambaheti T, de la Pena-Moctezuma A, Adler B. Functional analysis of genes in the rfb locus of Leptospira borgpetersenii serovar Hardjo subtype Hardjobovis. Infect Immun. 2000 Jul;68(7):3793-8.

39. Vijayachari P, Ahmed N, Sugunan AP, Ghousunnissa S, Rao KR, Hasnain SE, Sehgal SC. Use of fluorescent amplified fragment length polymorphism for molecular epidemiology of leptospirosis in India. J Clin Microbiol. 2004 Aug;42(8):3575-80.

40. Merien F, Portnoi D, Bourhy P, Charavay F, Berlioz-Arthaud A, Baranton G. A rapid and quantitative method for the detection of Leptospira species in human leptospirosis. FEMS Microbiol Lett. 2005 Aug 1;249(1):139-47.

41. Artiushin S, Timoney JF, Nally J, Verma A. Host-inducible immunogenic sphingomyelinase-like protein, Lk73.5, of Leptospira interrogans. Infect Immun. 2004 Feb;72(2):742-9.

42. Bourhy P, Louvel H, Saint Girons I, Picardeau M. Random insertional mutagenesis of Leptospira interrogans, the agent of leptospirosis, using a mariner transposon. J Bacteriol. 2005 May;187(9):3255-8. 
43. Ren SX, Fu G, Jiang XG, Zeng R, Miao YG, Xu H, Zhang YX, Xiong H, Lu G, Lu LF, Jiang HQ, Jia J, Tu YF, Jiang JX, Gu WY, Zhang YQ, Cai Z, Sheng HH, Yin HF, Zhang Y, Zhu GF, Wan M, Huang HL, Qian Z, Wang SY, Ma W, Yao ZJ, Shen Y, Qiang BQ, Xia QC, Guo XK, Danchin A, Saint Girons I, Somerville RL, Wen YM, Shi MH, Chen Z, Xu JG, Zhao GP. Unique physiological and pathogenic features of Leptospira interrogans revealed by whole-genome sequencing. Nature. 2003 Apr 24;422(6934):888-93.

44. Nascimento AL, Ko AI, Martins EA, Monteiro-Vitorello CB, Ho PL, Haake DA, Verjovski-Almeida S, Hartskeerl RA, Marques MV, Oliveira MC, Menck CF, Leite LC, Carrer H, Coutinho LL, Degrave WM, Dellagostin OA, El-Dorry H, Ferro ES, Ferro MI, Furlan LR, Gamberini M, Giglioti EA, Goes-Neto A, Goldman GH, Goldman MH, Harakava R, Jeronimo SM, Junqueira-de-Azevedo IL, Kimura ET, Kuramae EE, Lemos EG, Lemos MV, Marino CL, Nunes LR, de Oliveira RC, Pereira GG, Reis MS, Schriefer A, Siqueira WJ, Sommer P, Tsai SM, Simpson AJ, Ferro JA, Camargo LE, Kitajima JP, Setubal JC, Van Sluys MA. Comparative genomics of two Leptospira interrogans serovars reveals novel insights into physiology and pathogenesis. J Bacteriol. 2004 Apr;186(7):2164-72.

45. Bulach DM, Zuerner RL, Wilson P, Seemann T, McGrath A, Cullen PA, Davis J, Johnson M, Kuczek E, Alt DP, Peterson-Burch B, Coppel RL, Rood JI, Davies JK, Adler B. Genome reduction in Leptospira borgpetersenii reflects limited transmission potential. Proc Natl Acad Sci U S A. 2006 Sep 26;103(39):14560-5. 
46. Bourhy P, Salaun L, Lajus A, Medigue C, Boursaux-Eude C, Picardeau M. A genomic island of the pathogen Leptospira interrogans serovar Lai can excise from its chromosome. Infect Immun. 2007 Feb;75(2):677-83.

47. Lo M, Bulach DM, Powell DR, Haake DA, Matsunaga J, Paustian ML, Zuerner RL, Adler B. Effects of temperature on gene expression patterns in Leptospira interrogans serovar Lai as assessed by whole-genome microarrays. Infect Immun. 2006 Oct;74(10):5848-59.

48. Yang HL, Zhu YZ, Qin JH, He P, Jiang XC, Zhao GP, Guo XK. In silico and microarray-based genomic approaches to identifying potential vaccine candidates against Leptospira interrogans. BMC Genomics. 2006;7:293.

49. Silva EF, Medeiros MA, McBride AJ, Matsunaga J, Esteves GS, Ramos JG, Santos CS, Croda J, Homma A, Dellagostin OA, Haake DA, Reis MG, Ko AI. The terminal portion of leptospiral immunoglobulin-like protein LigA confers protective immunity against lethal infection in the hamster model of leptospirosis. Vaccine. 2007 Aug 14;25(33):6277-86.

50. Lee SH, Kim KA, Park YG, Seong IW, Kim MJ, Lee YJ. Identification and partial characterization of a novel hemolysin from Leptospira interrogans serovar lai. Gene. 2000 Aug 22;254(1-2):19-28.

51. Nally JE, Whitelegge JP, Bassilian S, Blanco DR, Lovett MA. Characterization of the outer membrane proteome of Leptospira interrogans expressed during acute lethal infection. Infect Immun. 2007 Feb;75(2):766-73.

52. Falkow S. Molecular Koch's postulates applied to microbial pathogenicity. Rev Infect Dis. 1988 Jul-Aug;10 Suppl 2:S274-6. 
53. Picardeau M, Brenot A, Saint Girons I. First evidence for gene replacement in Leptospira spp. Inactivation of L. biflexa flaB results in non-motile mutants deficient in endoflagella. Mol Microbiol. 2001 Apr;40(1):189-99.

54. Ristow P, Bourhy P, da Cruz McBride FW, Figueira CP, Huerre M, Ave P, Girons IS, Ko AI, Picardeau M. The OmpA-like protein Loa22 is essential for leptospiral virulence. PLoS Pathog. 2007 Jul;3(7):e97.

55. Croda J, Figueira CP, Wunder EA, Jr., Santos CS, Reis MG, Ko AI, Picardeau M. Targeted Mutagenesis in Pathogenic Leptospira: Disruption of the LigB Gene Does Not Affect Virulence in Animal Models of Leptospirosis. Infect Immun. 2008 Sep 22.

56. Tu V, Adler B, Faine S. The role of macrophages in the protection of mice against leptospirosis: in vitro and in vivo studies. Pathology. 1982 Oct;14(4):463-8.

57. Wang B, Sullivan JA, Sullivan GW, Mandell GL. Role of specific antibody in interaction of leptospires with human monocytes and monocyte-derived macrophages. Infect Immun. 1984 Dec;46(3):809-13.

58. Meri T, Murgia R, Stefanel P, Meri S, Cinco M. Regulation of complement activation at the C3-level by serum resistant leptospires. Microb Pathog. 2005 Oct;39(4):139-47.

59. Matsunaga J, Sanchez Y, Xu X, Haake DA. Osmolarity, a key environmental signal controlling expression of leptospiral proteins LigA and LigB and the extracellular release of LigA. Infect Immun. 2005 Jan;73(1):70-8.

60. Choy HA, Kelley MM, Chen TL, Moller AK, Matsunaga J, Haake DA. Physiological osmotic induction of Leptospira interrogans adhesion: LigA and LigB 
bind extracellular matrix proteins and fibrinogen. Infect Immun. 2007 May;75(5):2441-50.

61. Atzingen MV, Barbosa AS, De Brito T, Vasconcellos SA, de Morais ZM, Lima DM, Abreu PA, Nascimento AL. Lsa21, a novel leptospiral protein binding adhesive matrix molecules and present during human infection. BMC Microbiol. 2008;8:70.

62. Hauk P, Macedo F, Romero EC, Vasconcellos SA, de Morais ZM, Barbosa AS, Ho PL. In LipL32, the major leptospiral lipoprotein, the $\mathrm{C}$ terminus is the primary immunogenic domain and mediates interaction with collagen IV and plasma fibronectin. Infect Immun. 2008 Jun;76(6):2642-50.

63. Matsunaga J, Barocchi MA, Croda J, Young TA, Sanchez Y, Siqueira I, Bolin CA, Reis MG, Riley LW, Haake DA, Ko AI. Pathogenic Leptospira species express surface-exposed proteins belonging to the bacterial immunoglobulin superfamily. Mol Microbiol. 2003 Aug;49(4):929-45.

64. Alves VA, Gayotto LC, De Brito T, Santos RT, Wakamatsu A, Vianna MR, Sakata EE. Leptospiral antigens in the liver of experimentally infected guinea pig and their relation to the morphogenesis of liver damage. Exp Toxicol Pathol. 1992 Dec;44(7):425-34.

65. Cinco M, Vecile E, Murgia R, Dobrina P, Dobrina A. Leptospira interrogans and Leptospira peptidoglycans induce the release of tumor necrosis factor alpha from human monocytes. FEMS Microbiol Lett. 1996 May 1;138(2-3):211-4.

66. Werts C, Tapping RI, Mathison JC, Chuang TH, Kravchenko V, Saint Girons I, Haake DA, Godowski PJ, Hayashi F, Ozinsky A, Underhill DM, Kirschning CJ, 
Wagner H, Aderem A, Tobias PS, Ulevitch RJ. Leptospiral lipopolysaccharide activates cells through a TLR2-dependent mechanism. Nat Immunol. 2001 Apr;2(4):346-52.

67. de Fost M, Hartskeerl RA, Groenendijk MR, van der Poll T. Interleukin 12 in part regulates gamma interferon release in human whole blood stimulated with Leptospira interrogans. Clin Diagn Lab Immunol. 2003 Mar;10(2):332-5.

68. Tajiki H, Salomao R. Association of plasma levels of tumor necrosis factor alpha with severity of disease and mortality among patients with leptospirosis. Clin Infect Dis. 1996 Nov;23(5):1177-8.

69. Klimpel GR, Matthias MA, Vinetz JM. Leptospira interrogans activation of human peripheral blood mononuclear cells: preferential expansion of TCR gamma delta + T cells vs TCR alpha beta+ T cells. J Immunol. 2003 Aug 1;171(3):1447-55.

70. De Francesco Daher E, Oliveira Neto FH, Ramirez SM. Evaluation of hemostasis disorders and anticardiolipin antibody in patients with severe leptospirosis. Rev Inst Med Trop Sao Paulo. 2002 Mar-Apr;44(2):85-90.

71. Wagenaar JF, Goris MG, Sakundarno MS, Gasem MH, Mairuhu AT, de Kruif MD, Ten Cate H, Hartskeerl R, Brandjes DP, van Gorp EC. What role do coagulation disorders play in the pathogenesis of leptospirosis? Trop Med Int Health. $2007 \mathrm{Jan} ; 12(1): 111-22$

72. Louvel H, Bommezzadri S, Zidane N, Boursaux-Eude C, Creno S, Magnier A, Rouy Z, Medigue C, Saint Girons I, Bouchier C, Picardeau M. Comparative and functional genomic analyses of iron transport and regulation in Leptospira spp. $\mathrm{J}$ Bacteriol. 2006 Nov;188(22):7893-904. 
73. Nicodemo AC, Del Negro G, Amato Neto V. Thrombocytopenia and leptospirosis. Rev Inst Med Trop Sao Paulo. 1990 Jul-Aug;32(4):252-9.

74. Nicodemo AC, Duarte MI, Alves VA, Takakura CF, Santos RT, Nicodemo EL. Lung lesions in human leptospirosis: microscopic, immunohistochemical, and ultrastructural features related to thrombocytopenia. Am J Trop Med Hyg. 1997 Feb;56(2):181-7.

75. Nicodemo AC, Medeiros N, del Negro G, Amato Neto V. [Hematologic changes in leptospirosis]. Rev Inst Med Trop Sao Paulo. 1989 Mar-Apr;31(2):71-9.

76. Yang HL, Jiang XC, Zhang XY, Li WJ, Hu BY, Zhao GP, Guo XK. Thrombocytopenia in the experimental leptospirosis of guinea pig is not related to disseminated intravascular coagulation. BMC Infect Dis. 2006;6:19.

77. Nally JE, Chantranuwat C, Wu XY, Fishbein MC, Pereira MM, Da Silva JJ, Blanco DR, Lovett MA. Alveolar septal deposition of immunoglobulin and complement parallels pulmonary hemorrhage in a guinea pig model of severe pulmonary leptospirosis. Am J Pathol. 2004 Mar;164(3):1115-27.

78. Alves VA, Gayotto LC, Yasuda PH, Wakamatsu A, Kanamura CT, De Brito T. Leptospiral antigens (L. interrogans serogroup ictero-haemorrhagiae) in the kidney of experimentally infected guinea pigs and their relation to the pathogenesis of the renal injury. Exp Pathol. 1991;42(2):81-93.

79. Andrade L, de Francesco Daher E, Seguro AC. Leptospiral nephropathy. Semin Nephrol. 2008 Jul;28(4):383-94. 
80. Alves VA, Vianna MR, Yasuda PH, De Brito T. Detection of leptospiral antigen in the human liver and kidney using an immunoperoxidase staining procedure. J Pathol. 1987 Feb;151(2):125-31.

81. De Brito T, Freymuller E, Hoshino S, Penna DO. Pathology of the kidney and liver in the experimental leptospirosis of the guinea-pig. A light and electron microscopy study. Virchows Arch Pathol Anat Physiol Klin Med. 1966 Apr $13 ; 341(1): 64-78$.

82. Alves VA, Yasuda PH, Yamashiro EH, Santos RT, Yamamoto LU, de Brito T. An immunohistochemic assay to localize leptospires in tissue specimens. Rev Inst Med Trop Sao Paulo. 1986 May-Jun;28(3):170-3.

83. Arean VM. The pathologic anatomy and pathogenesis of fatal human leptospirosis (Weil's disease). Am J Pathol. 1962 Apr;40:393-423.

84. de Brito T, Morais CF, Yasuda PH, Lancellotti CP, Hoshino-Shimizu S, Yamashiro E, Alves VA. Cardiovascular involvement in human and experimental leptospirosis: pathologic findings and immunohistochemical detection of leptospiral antigen. Ann Trop Med Parasitol. 1987 Jun;81(3):207-14.

85. Farr RW. Leptospirosis. Clin Infect Dis. 1995 Jul;21(1):1-6; quiz 7-8.

86. Silva HR, Tanajura GM, Tavares-Neto J, Gomes Md Mde L, Linhares Ad Ada C, Vasconcelos PF, Ko AI. [Aseptic meningitis syndrome due to enterovirus and Leptospira sp in children of Salvador, Bahia]. Rev Soc Bras Med Trop. 2002 MarApr;35(2):159-65. 
87. Dupont H, Dupont-Perdrizet D, Perie JL, Zehner-Hansen S, Jarrige B, Daijardin JB. Leptospirosis: prognostic factors associated with mortality. Clin Infect Dis. 1997 Sep;25(3):720-4.

88. Daher E, Zanetta DM, Cavalcante MB, Abdulkader RC. Risk factors for death and changing patterns in leptospirosis acute renal failure. Am J Trop Med Hyg. 1999 Oct;61(4):630-4.

89. Abgueguen P, Delbos V, Blanvillain J, Chennebault JM, Cottin J, Fanello S, Pichard E. Clinical aspects and prognostic factors of leptospirosis in adults. Retrospective study in France. J Infect. 2008 Sep;57(3):171-8.

90. Doudier B, Garcia S, Quennee V, Jarno P, Brouqui P. Prognostic factors associated with severe leptospirosis. Clin Microbiol Infect. 2006 Apr;12(4):299-300.

91. Chang ML, Yang CW, Chen JC, Ho YP, Pan MJ, Lin CH, Lin DY. Disproportional exaggerated aspartate transaminase is a useful prognostic parameter in late leptospirosis. World J Gastroenterol. 2005 Sep 21;11(35):5553-6.

92. Chawla V, Trivedi TH, Yeolekar ME. Epidemic of leptospirosis: an ICU experience. J Assoc Physicians India. 2004 Aug;52:619-22.

93. Tantitanawat S, Tanjatham S. Prognostic factors associated with severe leptospirosis. J Med Assoc Thai. 2003 Oct;86(10):925-31.

94. Lomar AV, Diament D, Torres JR. Leptospirosis in Latin America. Infect Dis Clin North Am. 2000 Mar;14(1):23-39, vii-viii.

95. Cumberland P, Everard CO, Wheeler JG, Levett PN. Persistence of antileptospiral IgM, IgG and agglutinating antibodies in patients presenting with acute febrile illness in Barbados 1979-1989. Eur J Epidemiol. 2001;17(7):601-8. 
96. Effler PV, Bogard AK, Domen HY, Katz AR, Higa HY, Sasaki DM. Evaluation of eight rapid screening tests for acute leptospirosis in Hawaii. J Clin Microbiol. 2002 Apr;40(4):1464-9.

97. Fonseca Cde A, Teixeira MM, Romero EC, Tengan FM, Silva MV, ShikanaiYasuda MA. Leptospira DNA detection for the diagnosis of human leptospirosis. J Infect. 2006 Jan;52(1):15-22.

98. Palaniappan RU, Chang YF, Hassan F, McDonough SP, Pough M, Barr SC, Simpson KW, Mohammed HO, Shin S, McDonough P, Zuerner RL, Qu J, Roe B. Expression of leptospiral immunoglobulin-like protein by Leptospira interrogans and evaluation of its diagnostic potential in a kinetic ELISA. J Med Microbiol. 2004 Oct;53(Pt 10):975-84.

99. Croda J, Ramos JG, Matsunaga J, Queiroz A, Homma A, Riley LW, Haake DA, Reis MG, Ko AI. Leptospira immunoglobulin-like proteins as a serodiagnostic marker for acute leptospirosis. J Clin Microbiol. 2007 May;45(5):1528-34.

100. Srimanote P, Wongdeethai N, Jieanampunkul P, Samonkiert S, Leepiyasakulchai C, Kalambaheti T, Prachayasittikul V. Recombinant ligA for leptospirosis diagnosis and ligA among the Leptospira spp. clinical isolates. J Microbiol Methods. 2008 Jan;72(1):73-81.

101. Lomar AV. Evaluation of the hemostasis in leptospirosis. Rev Soc Bras Med Trop. 1990 Apr-Jun;23(2):127.

102. Tanomkiat W, Poonsawat P. Pulmonary radiographic findings in 118 leptospirosis patients. Southeast Asian J Trop Med Public Health. 2005 Sep;36(5):1247-51. 
103. Marchiori E, Muller NL. Leptospirosis of the lung: high-resolution computed tomography findings in five patients. J Thorac Imaging. $2002 \mathrm{Apr} ; 17(2): 151-3$.

104. Takafuji ET, Kirkpatrick JW, Miller RN, Karwacki JJ, Kelley PW, Gray MR, McNeill KM, Timboe HL, Kane RE, Sanchez JL. An efficacy trial of doxycycline chemoprophylaxis against leptospirosis. N Engl J Med. 1984 Feb 23;310(8):497-500. 105. Sehgal SC, Sugunan AP, Murhekar MV, Sharma S, Vijayachari P. Randomized controlled trial of doxycycline prophylaxis against leptospirosis in an endemic area. Int J Antimicrob Agents. 2000 Feb;13(4):249-55.

106. Gonsalez CR, Casseb J, Monteiro FG, Paula-Neto JB, Fernandez RB, Silva MV, Camargo ED, Mairinque JM, Tavares LC. Use of doxycycline for leptospirosis after high-risk exposure in Sao Paulo, Brazil. Rev Inst Med Trop Sao Paulo. 1998 Jan-Feb;40(1):59-61.

107. Yan Y, Chen Y, Liou W, Ding J, Chen J, Zhang J, Zhang A, Zhou W, Gao Z, Ye X, Xiao Y. An evaluation of the serological and epidemiological effects of the outer envelope vaccine to leptospira. J Chin Med Assoc. 2003 Apr;66(4):224-30.

108. Martinez R, Perez A, Quinones Mdel C, Cruz R, Alvarez A, Armesto M, Fernandez C, Menendez J, Rodriguez I, Baro M, Diaz M, Rodriguez J, Sierra G, Obregon AM, Toledo ME, Fernandez N. [Efficacy and safety of a vaccine against human leptospirosis in Cuba]. Rev Panam Salud Publica. 2004 Apr;15(4):249-55.

109. Andrade L, Cleto S, Seguro AC. Door-to-dialysis time and daily hemodialysis in patients with leptospirosis: impact on mortality. Clin J Am Soc Nephrol. 2007 Jul;2(4):739-44. 
110. McClain JB, Ballou WR, Harrison SM, Steinweg DL. Doxycycline therapy for leptospirosis. Ann Intern Med. 1984 May;100(5):696-8.

111. Watt G, Padre LP, Tuazon ML, Calubaquib C, Santiago E, Ranoa CP, Laughlin LW. Placebo-controlled trial of intravenous penicillin for severe and late leptospirosis. Lancet. 1988 Feb 27;1(8583):433-5.

112. Panaphut T, Domrongkitchaiporn S, Vibhagool A, Thinkamrop B, Susaengrat W. Ceftriaxone compared with sodium penicillin $g$ for treatment of severe leptospirosis. Clin Infect Dis. 2003 Jun 15;36(12):1507-13.

113. Amato MB, Barbas CS, Medeiros DM, Magaldi RB, Schettino GP, LorenziFilho G, Kairalla RA, Deheinzelin D, Munoz C, Oliveira R, Takagaki TY, Carvalho CR. Effect of a protective-ventilation strategy on mortality in the acute respiratory distress syndrome. N Engl J Med. 1998 Feb 5;338(6):347-54.

114. Shenoy VV, Nagar VS, Chowdhury AA, Bhalgat PS, Juvale NI. Pulmonary leptospirosis: an excellent response to bolus methylprednisolone. Postgrad Med J. 2006 Sep;82(971):602-6.

115. Theilen HJ, Luck C, Hanisch U, Ragaller M. Fatal intracerebral hemorrhage due to leptospirosis. Infection. 2002 Apr;30(2):109-12.

116. Guedes e Silva JB, Paiva LM, Pereira da Silva JJ, de Souza Netto BA. Pathological involvement of human gastrocnemius muscle in leptospirosis (a study in 63 patients). Rev Bras Pesqui Med Biol. 1980 Apr;13(1-3):9-13.

117. Pereira MM, Da Silva JJ, Pinto MA, Da Silva MF, Machado MP, Lenzi HL, Marchevsky RS. Experimental leptospirosis in marmoset monkeys (Callithrix 
jacchus): a new model for studies of severe pulmonary leptospirosis. Am J Trop Med Hyg. 2005 Jan;72(1):13-20.

118. da Silva JJ, Netto BA, Lilembaum W, Alvim ME, de Oliveira AV. The hemorrhagic syndrome of leptospirosis: an experimental study in guinea pigs. Rev Soc Bras Med Trop. 1995 Jul-Sep;28(3):169-77.

119. Edwards CN, Nicholson GD, Everard CO. Thrombocytopenia in leptospirosis. Am J Trop Med Hyg. 1982 Jul;31(4):827-9.

120. Raoult D, Jeandel P, Mailloux M, Rougier Y. Thrombocytopenia and renal failure in leptospirosis. Am J Trop Med Hyg. 1983 Nov;32(6):1464.

121. Chierakul W, Tientadakul P, Suputtamongkol Y, Wuthiekanun V, Phimda K, Limpaiboon R, Opartkiattikul N, White NJ, Peacock SJ, Day NP. Activation of the coagulation cascade in patients with leptospirosis. Clin Infect Dis. 2008 Jan $15 ; 46(2): 254-60$.

122. Somers CJ, Al-Kindi S, Montague S, O'Connor R, Murphy PG, Jeffers M, Enright H. Erythroid hypoplasia associated with leptospirosis. J Infect. 2003 Jul;47(1):85-6.

123. Edwards CN, Nicholson GD, Hassell TA, Everard CO, Callender J. Thrombocytopenia in leptospirosis: the absence of evidence for disseminated intravascular coagulation. Am J Trop Med Hyg. 1986 Mar;35(2):352-4.

124. Kahn JB. A case of Weil's disease requiring steroid therapy for thrombocytopenia and bleeding. Am J Trop Med Hyg. 1982 Nov;31(6):1213-5. 
125. Davenport A, Rugman FP, Desmond MJ, Ganta R. Is thrombocytopenia seen in patients with leptospirosis immunologically mediated? J Clin Pathol. 1989 Apr;42(4):439-40.

126. Turgut M, Sunbul M, Bayirli D, Bilge A, Leblebicioglu H, Haznedaroglu I. Thrombocytopenia complicating the clinical course of leptospiral infection. J Int Med Res. 2002 Sep-Oct;30(5):535-40.

127. Haake DA, Chao G, Zuerner RL, Barnett JK, Barnett D, Mazel M, Matsunaga J, Levett PN, Bolin CA. The leptospiral major outer membrane protein LipL32 is a lipoprotein expressed during mammalian infection. Infect Immun. 2000 Apr;68(4):2276-85.

128. Lee SH, Kim S, Park SC, Kim MJ. Cytotoxic activities of Leptospira interrogans hemolysin $\mathrm{SphH}$ as a pore-forming protein on mammalian cells. Infect Immun. 2002 Jan;70(1):315-22.

129. Jaroonvesama N, Viranuvatti V, Charoenlarp K. Coagulation studies in leptospirosis. Southeast Asian J Trop Med Public Health. 1975 Dec;6(4):562-6.

130. Higgins R, Cousineau G. The pathogenesis of leptospirosis I. Hemorrhages in experimental leptospirosis in guinea pigs. Can J Comp Med. 1977 Apr;41(2):174-81. 131. Sitprija V, Pipatanagul V, Mertowidjojo K, Boonpucknavig V, Boonpucknavig S. Pathogenesis of renal disease in leptospirosis: Clinical and experimental studies. Kidney Int. 1980 Jun;17(6):827-36.

132. Navarro CE, Kociba GJ. Hemostatic changes in dogs with experimental Leptospira interrogans serovar icterohaemorrhagiae infection. Am J Vet Res. 1982 May;43(5):904-6. 
133. Park SK, Lee SH, Rhee YK, Kang SK, Kim KJ, Kim MC, Kim KW, Chang WH. Leptospirosis in Chonbuk Province of Korea in 1987: a study of 93 patients. Am J Trop Med Hyg. 1989 Sep;41(3):345-51.

134. O'Neil KM, Rickman LS, Lazarus AA. Pulmonary manifestations of leptospirosis. Rev Infect Dis. 1991 Jul-Aug;13(4):705-9.

135. Zaki SR, Shieh WJ. Leptospirosis associated with outbreak of acute febrile illness and pulmonary haemorrhage, Nicaragua, 1995. The Epidemic Working Group at Ministry of Health in Nicaragua. Lancet. 1996 Feb 24;347(9000):535-6.

136. Wagenaar JF, de Vries PJ, Hartskeerl RA. Leptospirosis with pulmonary hemorrhage, caused by a new strain of serovar Lai: Langkawi. J Travel Med. 2004 Nov-Dec;11(6):379-81.

137. Martinez Garcia MA, de Diego Damia A, Menendez Villanueva R, Lopez Hontagas JL. Pulmonary involvement in leptospirosis. Eur J Clin Microbiol Infect Dis. 2000 Jun;19(6):471-4.

138. Carvalho CR, Bethlem EP. Pulmonary complications of leptospirosis. Clin Chest Med. 2002 Jun;23(2):469-78.

139. Spichler A, Athanazio D, Buzzar M, Castro B, Chapolla E, Seguro A, Vinetz JM. Using death certificate reports to find severe leptospirosis cases, Brazil. Emerg Infect Dis. 2007 Oct;13(10):1559-61.

140. Dolhnikoff M, Mauad T, Bethlem EP, Carvalho CR. Leptospiral pneumonias. Curr Opin Pulm Med. 2007 May;13(3):230-5. 
141. Dolhnikoff M, Mauad T, Bethlem EP, Carvalho CR. Pathology and pathophysiology of pulmonary manifestations in leptospirosis. Braz $\mathrm{J}$ Infect Dis. 2007 Feb;11(1):142-8.

142. Ware LB, Matthay MA. The acute respiratory distress syndrome. N Engl J Med. 2000 May 4;342(18):1334-49.

143. Wang CN, John L, Chang TF, Cheng WJ, Lou MY, Hung AT. Studies on Anicteric Leptospirosis. I. Clinical Manifestations and Antibiotic Therapy. Chin Med J (Engl). 1965 May;84:283-91.

144. Andrade L, Rodrigues Jr AC, Sanches TR, Souza RB, Seguro AC. Leptospirosis leads to dysregulation of sodium transporters in the kidney and lung. Am J Physiol Renal Physiol. 2006 Aug 29.

145. Hudson BG, Tryggvason K, Sundaramoorthy M, Neilson EG. Alport's syndrome, Goodpasture's syndrome, and type IV collagen. N Engl J Med. 2003 Jun $19 ; 348(25): 2543-56$

146. Bolton WK. Goodpasture's syndrome. Kidney Int. 1996 Nov;50(5):1753-66.

147. Donaghy M, Rees AJ. Cigarette smoking and lung haemorrhage in glomerulonephritis caused by autoantibodies to glomerular basement membrane. Lancet. 1983 Dec 17;2(8364):1390-3.

148. Rugman FP, Pinn G, Palmer MF, Waite M, Hay CR. Anticardiolipin antibodies in leptospirosis. J Clin Pathol. 1991 Jun;44(6):517-9.

149. Santiago M, Martinelli R, Reis MG, Reis EA, Ko A, Fontes RD, Silva MP, Nascimento EG, de Jesus R, Pierangeli S, Espinola R, Gharavi A. Diagnostic performance of anti-beta2 glycoprotein I and anticardiolipin assays for clinical 
manifestations of the antiphospholipid syndrome. Clin Rheumatol. 2004 Dec;23(6):485-9.

150. Tattevin P, Dupeux S, Hoff J. Leptospirosis and the antiphospholipid syndrome. Am J Med. 2003 Feb 1;114(2):164.

151. Pereira MM, Andrade J, Marchevsky RS, Ribeiro dos Santos R. Morphological characterization of lung and kidney lesions in $\mathrm{C} 3 \mathrm{H} / \mathrm{HeJ}$ mice infected with Leptospira interrogans serovar icterohaemorrhagiae: defect of CD4+ and CD8+ T-cells are prognosticators of the disease progression. Exp Toxicol Pathol. 1998 Jun;50(3):191-8.

152. Yang GG, Hsu YH. Nitric oxide production and immunoglobulin deposition in leptospiral hemorrhagic respiratory failure. J Formos Med Assoc. 2005 Oct;104(10):759-63.

153. Bobrow MN, Harris TD, Shaughnessy KJ, Litt GJ. Catalyzed reporter deposition, a novel method of signal amplification. Application to immunoassays. J Immunol Methods. 1989 Dec 20;125(1-2):279-85.

154. Gharavi AE, Harris EN, Asherson RA, Hughes GR. Anticardiolipin antibodies: isotype distribution and phospholipid specificity. Ann Rheum Dis. 1987 Jan;46(1):1-6.

155. SINAN. Casos confirmados notificados no Sistema de Informação de Agravos de Notificação 2008.

156. Mills SE. Sternberg's Diagnostic Surgical Pathology. Philadelphia: LIPPINCOTT WILLIANS \& WILKINS; 2004. 
157. Blennerhassett JB. Shock lung and diffuse alveolar damage pathological and pathogenetic considerations. Pathology. 1985 Apr;17(2):239-47.

158. Castranova V, Rabovsky J, Tucker JH, Miles PR. The alveolar type II epithelial cell: a multifunctional pneumocyte. Toxicol Appl Pharmacol. 1988 May;93(3):472-83.

159. Gomez RM, Vieira ML, Schattner M, Malaver E, Watanabe MM, Barbosa AS, Abreu PA, de Morais ZM, Cifuente JO, Atzingen MV, Oliveira TR, Vasconcellos SA, Nascimento AL. Putative outer membrane proteins of Leptospira interrogans stimulate human umbilical vein endothelial cells (HUVECS) and express during infection. Microb Pathog. 2008 Aug 20.

160. De Brito T, Bohm GM, Yasuda PH. Vascular damage in acute experimental leptospirosis of the guinea-pig. J Pathol. 1979 Aug;128(4):177-82.

161. Maciel EA, Athanazio DA, Reis EA, Cunha FQ, Queiroz A, Almeida D, McBride AJ, Ko AI, Reis MG. High serum nitric oxide levels in patients with severe leptospirosis. Acta Trop. 2006 Dec;100(3):256-60.

162. Hsu YH, Chen HI. The involvement of nitric oxide and beta-adrenergic pathway signalling in pulmonary oedema and fluid clearance. Pathology. 2007 Dec;39(6):612-3.

163. Seifert PS, Messner M, Roth I, Bhakdi S. Analysis of complement C3 activation products in human atherosclerotic lesions. Atherosclerosis. 1991 Nov;91(1-2):155-62. 
164. Abdulkader RC, Daher EF, Camargo ED, Spinosa C, da Silva MV. Leptospirosis severity may be associated with the intensity of humoral immune response. Rev Inst Med Trop Sao Paulo. 2002 Mar-Apr;44(2):79-83.

165. Vieira ML, D'Atri LP, Schattner M, Habarta AM, Barbosa AS, de Morais ZM, Vasconcellos SA, Abreu PA, Gomez RM, Nascimento AL. A novel leptospiral protein increases ICAM-1 and E-selectin expression in human umbilical vein endothelial cells. FEMS Microbiol Lett. 2007 Nov;276(2):172-80. 
10. APÊNDICES

10.1. Apêndice A - Artigo submetido ao "The Journal Pathology" 
1 Leptospirosis Pulmonary Hemorrhage Syndrome is Associated with Linear Deposition of

2 Immunoglobulin and Complement on the Alveolar Surface

3

4 Running title: leptospirosis pulmonary hemorrhage syndrome

5

6 Julio Croda ${ }^{1}$, Amaro Nunes Duarte Neto $^{1}$, Roosecelis Araújo Brasil ${ }^{1}$, Carla Pagliari ${ }^{1}$, Antonio

7 Carlos Nicodemo ${ }^{2}$, Maria Irma Seixas Duarte ${ }^{1}$

8

$9{ }^{1}$ Laboratory of Pathology of Transmissible Diseases, Department of Pathology, Hospital das

10 Clínicas, Faculdade de Medicina da Universidade de São Paulo, São Paulo, Brazil

112 Infectious and Parasitic Diseases Division, Hospital das Clínicas, Faculdade de Medicina da

12 Universidade de São Paulo, São Paulo, Brazil

13

14 Support: J Croda received a scholarship from the Research Support Foundation of the State of

15 São Paulo (2007/00083-2).

16

17 Word count of the text: 2421

18

19 Potential conflicts of interest: none reported.

20

21 Correspondence should be addressed to: Maria Irma Seixas Duarte. Universidade de São Paulo,

22 Faculdade de Medicina, Departamento de Patologia, Av. Dr. Arnaldo, 455 - $1^{\circ}$ andar, sala 1115, 
23 Cerqueira César, São Paulo, São Paulo 01246-903, Brazil. Phone: 5511 3061-7238. Fax: 5511

24 3061-7238. E-mail: miduarte@usp.br

25 


\section{Abstract}

27 Leptospirosis is a zoonotic infection associated with severe diseases such as leptospirosis

28 pulmonary hemorrhage syndrome (LPHS). The cause of pulmonary hemorrhage is unclear.

29 Understanding whether mechanisms processes are involved in LPHS will be important in

30 developing treatment regimens for this life-threatening syndrome. In present study, we evaluated

3130 lung specimens from LPHS patients and seven controls by histology and

32 immunohistochemistry (IgM, $\operatorname{IgG}, \operatorname{IgA}$, and C3) in order to describe the pathologic features

33 associated with this syndrome. Immunoglobulin deposits were detected on the alveolar surface of

34 18/30 LPHS patients. Three staining patterns were observed for the immunoglobulins and C3 in

35 the lung tissues of LPHS patients: (A) delicate linear staining adjacent to the alveolar surface,

36 which was indicative of a membrane covering the luminal surface of type I and II pneumocyte

37 cells; (MF) heterogeneous staining which was sporadically distributed along the alveolar septum;

38 and (I) weak, focal intra-alveolar granular staining. Human LPHS has individual and unique

39 histological patterns that differ from those of other causes of pulmonary hemorrhage. The present

40 study found that the deposition of linear immunoglobulins ( $\operatorname{IgA}, \operatorname{IgG}, \operatorname{IgM})$ and complement on

41 the alveolar surface may play a role in the pathogenesis of pulmonary hemorrhage in human

42 leptospirosis.

43

44 Keywords: Leptospira, leptospirosis, pulmonary hemorrhage syndrome, immunoglobulin,

45 pathogenesis, immunohistochemistry, lung 


\section{Introduction}

47 More than 500,000 cases of leptospirosis are estimated to occur worldwide each year [1.].

48 Leptospirosis is an environmentally-transmitted zoonotic disease: the major mode of

49 transmission is contact with water or soil contaminated with urine from animals infected with the

50 Leptospira bacterium [1-3.]. Infection produces a broad spectrum of clinical manifestations,

51 ranging from self-limiting febrile illness to Weil's disease, which is the classic severe form of the

52 disease characterized by jaundice, acute renal failure and bleeding. The Nicaragua outbreak in

531995 raised awareness of the importance of leptospirosis as a cause of a pulmonary hemorrhage

54 syndrome [4.]. Reports from Asia and the Americas now indicate that leptospirosis has become a

55 major cause of hemorrhagic fever [5-10.]. The fatality rates from leptospirosis pulmonary

56 hemorrhage syndrome (LPHS) are more than 50\% [6, 7, 10.].

57 There is an urgent need to improve therapy and supportive care for patients with LPHS. Novel

58 therapies such as plasma exchange and corticotherapy may be beneficial $[11,12$.$] . Therefore,$

59 increased understanding of the disease pathogenesis is crucial. It is generally believed that

60 neither thrombocytopenia nor the decrease in clotting factors in leptospirosis patients is sufficient

61 on its own to account for the observed bleeding diathesis [13-16.]. Histological and electron

62 microscopy studies in human and guinea pig models were not able to demonstrate significant

63 intravascular thrombi and small vessel fibrin deposition $[13,16,17$.$] . A recent report$

64 demonstrated that immunoglobulin and complement were deposited along alveolar septum in a

65 guinea pig model of leptospirosis [16.]. Also, immunoglobulin deposition on the alveolar septum

66 and alveolar space were observed in a human case of LPHS [18.]. However other than this single

67 case report [18.], these findings have not been reported in larger case series and whether an

68 autoimmune process does indeed contribute to the pathogenesis of LPHS. Understanding 
69 whether such processes found in experimental animals occur in humans will be important in

70 developing treatment regimens for this life-threatening syndrome. In the present study, we

71 examined lung samples from 30 patients who died of LPHS in Brazil using histology and

72 immunohistochemistry (IHC) to determine whether the presence of immunoglobulin and

73 complement deposits on alveolar surface was associated with this syndrome.

74

75 Patients and Methods

76 The records of the Death Verification Service from Department of Pathology, Hospital das

77 Clínicas, Faculdade de Medicina da Universidade de São Paulo were reviewed to identify all

78 deaths due leptospirosis pulmonary hemorrhage syndrome which occurred between January 1st

791988 and January 1st 2005. Confirmation of leptospirosis involved the following criteria: a >4-

80 fold rise in the microagglutination titer; a single titer greater than 1:400; and/or detection of

81 Leptospira in biopsy or autopsy specimens during immunohistochemical analysis.

82 In addition to analysis of autopsy specimens from LPHS cases, autopsy specimens were

83 evaluated as controls from seven patients with pulmonary hemorrhage which was confirmed to

84 be due to other diseases ( 2 patients with acute pulmonary edema associated with heart failure, 3

85 patients with disseminated intravascular coagulation associated with sepsis, 2 patients with

86 cirrhosis). Controls were randomly selected from the records of the Death Verification Service of

87 Sao Paulo state.

88 Information on demographics, past medical history, clinical presentation, laboratory findings and

89 outcome was extracted from the medical records and computerized laboratory records using a

90 standardized data entry form. 
91 Lung tissue samples were fixed in neutral-buffered $4 \%$ formaldehyde (Medical Chemical

92 Corporation, Torrance, CA) and processed according to standard methods which included

93 embedding in paraffin, sectioning into 4- $\mu \mathrm{m}$ serial sections, and staining with hematoxylin and

$94 \operatorname{eosin}(\mathrm{H} \& \mathrm{E})$. Sections were processed for immunohistochemical analyses using polyclonal

95 antibodies. Antibody binding and visualization were carried out using the streptavidin-biotin

96 peroxidase method, with an endogenous biotin blocking system (DAKO, Carpinteria, CA, USA).

97 The following polyclonal antibodies were used in this process: polyclonal rabbit anti-human IgA

98 (A0262/Dako), polyclonal rabbit anti-human IgM (A0425/Dako), polyclonal rabbit anti-human

99 IgG (A0423/Dako), and polyclonal rabbit anti-human C3C (A0062/Dako). The same protocol

100 was used to detect Leptospira antigens by a polyclonal rabbit antibody $[17,19,20$.$] .$

101 In the first moment one observer (J.C.) analyzed 6 paired H\&E and IHC lung sections to

102 determine the principal findings related to LPHS. In the second moment the 37 (30 LPHS

103 patients and 7 controls) sections were reanalyzed by one independent pathologist blinded to

104 patient identity, diagnosis and clinical course (R.A.B) using semiquantitative scores: $0=$

105 absence; $1=$ mild; $2=$ moderate; and $3=$ intense. In the alveoli space and the alveolar septae, the

106 observers scored the sections for macrophages, lymphocytes, neutrophils, plasma cells, and

107 eosinophils. In the alveoli wall and lumen, they scored the sections for necrosis, regeneration of

108 pneumocytes, giant cells, edema, hemorrhage, and hyaline membrane. The sections were also

109 scored for septum thickness, edema, capillary congestion, and fibrosis. The pathologist scored

110 the following findings based on standardized scoring protocols previous used [21.].

111 Data were entered into Epidata (version 3.0, U.S. Centers for Disease Control and Prevention)

112 and analyzed using the SAS system (version 9.1, SAS Institute). Results are expressed as the

113 median and interquartile range, or as percentages when appropriate. Differences in frequency 
114 were evaluated using the $\chi^{2}$ test or Fisher's exact test. Medians were compared using the Mann-

115 Whitney-Wilcoxon test. The study protocol was approved by the Investigational Review Board 116 of the Hospital das Clínicas, São Paulo University.

119 Results

120 During the study period, we identified necropsies from 37 LPHS patients. Necropsies from seven

121 patients were excluded because the paraffin blocks showed evidence of tissue autolysis, there

122 was inappropriate fixation with artifacts, or there was typical bacterial infection. This selection

123 resulted in a final sample of 30 leptospirosis patients who presented with well-defined clinical

124 and histological evidence of lung involvement.

125 Twenty three of $30(77 \%)$ leptospirosis patients were men, and the median age was 48.5 years

126 (range from 19 to 70). The median duration of symptoms before hospital admission was six days

127 (range from 4 to 13). The median platelet count and serum creatinine levels were 54,000

128 cells $/ \mathrm{mm}^{3}$ (range from 10,000 to 222,000 ) and $6.1 \mathrm{mg} / \mathrm{dl}$ (range from 0.6 to 14.2 ), respectively.

129 All patients required mechanical ventilation, which was performed for a median duration of two

130 days (range from 0 to 13). Dialysis was performed in 19 of $30(63 \%)$ cases. The median duration

131 of hospital stay was three days (range from 0 to 13) (Table 1).

132 The LPHS patients $(n=30)$ differed from control pulmonary hemorrhage patients $(n=7)$ in

133 several features: the presence of moderate to high levels of macrophages in the alveolar space

134 (77\% versus $29 \%$, respectively; $\mathrm{p}=0.02)$, the presence of the focal hyaline membrane on

135 alveolar surface $(100 \%$ versus $0 \% ; \mathrm{p}<0.01)$, extensive necrosis and regeneration of pneumocyte

136 II cells $(100 \%$ versus $0 \% ; \mathrm{p}<0.01)$ and the presence of plasma cells in the alveolar septum $(77 \%$ 
137 versus $29 \%$, respectively; $\mathrm{p}=0.02$ ). No statistically significant differences were observed in the

138 number of others cells in the alveolar septae between LPHS and control patients. Intact

139 leptospires were rarely detected in the lungs of LPHS patients. Reactive debris of granular

140 material associated with macrophages cells was occasionally detected. Leptospiral antigen was

141 not correlated with the intensity of the lesions. None of the patients showed microscopic

142 evidence for disseminated intravascular coagulation.

143 Lung tissues from 30 LPHS patients and seven controls were examined for the presence of IgM,

$144 \mathrm{IgG}, \mathrm{IgA}$, and the complement component C3. Three staining patterns were observed for each

145 immunoglobulin and C3 in the lung tissue from the LPHS patients (Figure 1): (A) delicate linear

146 staining adjacent to the alveolar surface, which was indicative of a membrane covering the

147 luminal surface of type I and II pneumocyte cells; (MF) heterogeneous staining which was

148 sporadically distributed along the alveolar septum; and (I) weak, focal intra-alveolar granular

149 staining. As shown in Figure 1, A-type staining was present in lung tissue samples with diffuse

150 alveolar hemorrhage. This was the most frequent staining pattern observed $(12 / 17,71 \%)$. MF-

151 type staining and a mix of MF- and A-type staining were observed in tissues showing mild

152 and/or moderate alveolar hemorrhage $(5 / 17,29 \%)$. The MF type was not predominantly

153 associated with either capillaries or epithelial basal membranes.

154 Of the 30 LPHS lung tissue samples, 18 were positive for $\operatorname{IgA}, 17$ for $\operatorname{IgM}, 16$ for $\operatorname{IgG}$, and 17

155 for C3. All 17 C3-positive samples were also positive for at least two Ig classes (Table 2).

156 Patients with more recent pulmonary hemorrhage demonstrated a higher frequency of $\mathrm{C} 3$ and

157 IgG depositions (11/14 and 10/14, respectively) than patients who presented with pulmonary

158 hemorrhage with phagocytosis of haemosiderin pigment $(6 / 16$ and $6 / 16$, respectively) $(\mathrm{p}=0.02)$. 
159 After separating LPHS patients into two groups based on the median duration of mechanical

160 ventilation, we found that patients who used mechanical ventilation for two days or less had a

161 lower frequency of specimens with macrophages in the alveolar lumen than patients who were

162 on mechanical ventilation for more than two days $(31 \%$ versus $80 \%, \mathrm{p}=0.04)$.

163

164 Discussion

165 LPHS is the major cause of death in patients with Weil's diseases. The case fatality rate in

166 patients with LPHS in Brazil ranged from 55 to 74\% [5, 7.]. Understanding the pathogenesis of

167 this disease would thus provide a basis for designing effective therapeutic interventions and

168 allow the identification of biomarkers related to leptospirosis severity. The present study suggest

169 that membranous depositions of linear immunoglobulins ( $\operatorname{IgA}, \operatorname{IgG}, \operatorname{IgM})$ and complement on an

170 alveolar surface may trigger fatal pulmonary hemorrhage in human leptospirosis patients.

171 Immunoglobulin deposits were detected on 18/30 LPHS patients, but were not detected in any of

172 the seven control hemorrhagic lung samples. In all 17 cases in which $\mathrm{C} 3$ deposition was present,

173 there was also deposition of $\operatorname{IgM}, \operatorname{IgG}$, and $\operatorname{IgA}$. Remarkably, the most common staining pattern

174 observed was a linear deposition adjacent to the alveolar surface. The MF-type staining was less

175 commonly observed and may have reflected the initial event that resulted in immunoglobulin and

176 complement deposition on the alveolar surface. Lung tissue from leptospirosis and control

177 patients displayed I-type staining, which was most likely related to the non-specific

178 immunoglobulin and C3 staining in the alveolar space that was filled by cells and plasma

179 components.

180 The linear deposit pattern (A-type staining) appeared to cover type I and II pneumocyte cells, 181 therefore leading to the hypothesis that such deposits could interfere with the epithelial barrier. 
182 The injury and loss of epithelial integrity to type I and II cells disrupt normal epithelial fluid

183 transport and impair the removal of edema fluid from the alveolar space [22.]. Moreover, injury

184 to type II cells could reduce the production and turnover rate of surfactant, as well as reduce the

185 capacity of oxygen and carbonic gas exchange [23.]. Together, these events could result in

186 diffuse alveolar hemorrhage.

187 Human LPHS has unique histological patterns that differ from other causes of pulmonary 188 hemorrhage such as bleeding diathesis, venous hypertension, other infections, tumor, collagen 189 diseases, pulmonary hemorrhagic syndrome and diffuse alveolar damage (DAD) [24.]. The 190 pathological diagnosis for acute phase DAD is based on the presence of hyaline membranes 191 associated with intra-alveolar red cells and neutrophilis [25.]. The LPHS patients, in addition to 192 having immunoglobulin and complement deposition, also displayed pathologic characteristics of 193 DAD [26.].

194 Little information regarding the pathologic mechanism of LPHS is available. Four previous 195 studies have demonstrated the presence of anticardiolipin antibodies in leptospirosis patients, and 196 one serie of cases found a correlation between the presence of these antibodies in the sera and 197 severe complications from leptospirosis [27-30.]. However, using electron microscopy, 198 Nicodemo and colleagues did not find any pathologic features such as endothelial cell necrosis, 199 rupture, thrombus, or exposed subendothelial collagen outside the hemorrhagic areas in the lung 200 that are seen in antiphospholipid syndromes. Furthermore, we reanalyzed seven lung samples 201 from previous LPHS patients [17.] and were also unable to identify ultrastructural characteristics 202 of antiphospholipid syndrome (data not shown).

203 Nally and colleagues suggested that the pathologic findings in the lung could be correlated with 204 Goodpasture's disease [16.]. However, electron microscopy studies in humans and guinea pig 
205

206

207

208

209

210

211

212

213

214

215 patients, leptospirosis patients without LPHS and healthy control individuals (unpublished data).

216 The absence of these autoantibodies reinforced the hypothesis that the putative mechanism of

217 injury is not related to Goodpasture's disease or anti-phospholipids syndrome.

218 Although it is clear that antibodies and C3 are deposited along the alveolar surface, additional

219 evaluation will be necessary to exclude the possibility that some cellular remnants related to cell

220 activation could cause the non-specific deposition of complement and/or immunoglobulin [17,

221 31, 32.]. Testing the sera of LPHS patients against normal lung tissues would verify the

222 specificity of theses autoantibodies to alveolar components such as type I and II pneumocytes.

223 Based on these findings, we speculated that the initial increase in vascular permeability due to

224 endothelial activation [17, 31.], overproduction of nitric oxide [33,34.] and enlarged open

225 junctions $[17,35$.$] would permit \operatorname{IgM}, \operatorname{IgG}$, and $\operatorname{IgA}$ leakage into the alveolar space. The MF-

226 type staining could reflect this initial phase of immunoglobulin leakage through the alveolar

227 septum. The immunglobulin deposition against type I and II pneumocyte cells could mediate the 
228 complement activation with C3 deposition. This could then lead to epithelial cell necrosis with

229 cell leakage and hemorrhage into the alveoli lumen. (Figure 2). The reasons for the failure to

230 detect $\mathrm{C} 3$ in 13 of the 30 infected lung tissues are unclear, but this may reflect a cleanup of

231 deposited C3 by the macrophages cells in the alveolar lumen, as the absence of C3 deposits

232 correlated with an increase of mononuclear cells in the alveolar lumen in patients with increased

233 mechanical ventilation time. Alternatively, the absence of C3 deposits could be explained by the 234 intrinsically short half-life of C3C[36.].

235 In practice, further studies to characterize this apparent autoimmune response and perhaps

236 identify the autoantibody involved could help to diagnose patients with increased risk of

237 developing LPHS. Moreover, if an autoimmune process is the cause of hemorrhagic

238 complications in human leptospirosis, effective therapies may involve removing autoantibodies

239 from the blood and decreasing their production.

241 Acknowledgements

242 This work is part of the doctoral thesis of J. Croda and A. N. Duarte Neto in the Department of

243 Pathology, Faculty of Medical Sciences, São Paulo University. We would like to thank Fernanda

244 Guedes and Elaine Fernandes for their assistance in performing immunohistochemistry.

246 References

248 1. McBride AJ, Athanazio DA, Reis MG, Ko AI. Leptospirosis. Curr Opin Infect Dis

$249 \quad 2005 ; \mathbf{1 8}: 376-386$.

$250 \quad$ 2. Levett PN. Leptospirosis. Clin Microbiol Rev 2001;14:296-326. 
251 3. Faine SA, B. Bolin, C. Perolat, P. Leptospira and leptospirosis. 2nd ed: Melbourne, $252 \quad$ Australia: MediSci, 1999.

253 4. Zaki SR, Shieh WJ. Leptospirosis associated with outbreak of acute febrile illness and 254 pulmonary haemorrhage, Nicaragua, 1995. The Epidemic Working Group at Ministry of $255 \quad$ Health in Nicaragua. Lancet 1996;347:535-536.

256 5. Marotto PC, Nascimento CM, Eluf-Neto J, Marotto MS, Andrade L, Sztajnbok J, et al. 257 Acute lung injury in leptospirosis: clinical and laboratory features, outcome, and factors $258 \quad$ associated with mortality. Clin Infect Dis 1999;29:1561-1563.

259 6. Panaphut T, Domrongkitchaiporn S, Thinkamrop B. Prognostic factors of death in 260 leptospirosis: a prospective cohort study in Khon Kaen, Thailand. Int J Infect Dis $261 \quad 2002 ; 6: 52-59$.

262 7. Gouveia EL, Metcalfe J, de Carvalho AL, Aires TS, Villasboas-Bisneto JC, Queirroz A, 263 et al. Leptospirosis-associated Severe Pulmonary Hemorrhagic Syndrome, Salvador, 264 Brazil. Emerg Infect Dis 2008;14:505-508.

265 8. Sehgal SC, Murhekar MV, Sugunan AP. Outbreak of leptospirosis with pulmonary 266 involvement in north Andaman. Indian J Med Res 1995;102:9-12.

267 9. Yersin C, Bovet P, Merien F, Clement J, Laille M, Van Ranst M, et al. Pulmonary 268 haemorrhage as a predominant cause of death in leptospirosis in Seychelles. Trans $R$ Soc 269 Trop Med Hyg 2000;94:71-76.

270 10. Segura ER, Ganoza CA, Campos K, Ricaldi JN, Torres S, Silva H, et al. Clinical 271 spectrum of pulmonary involvement in leptospirosis in a region of endemicity, with 272 quantification of leptospiral burden. Clin Infect Dis 2005;40:343-351. 
273 11. Shenoy VV, Nagar VS, Chowdhury AA, Bhalgat PS, Juvale NI. Pulmonary leptospirosis:

$274 \quad$ an excellent response to bolus methylprednisolone. Postgrad Med J 2006;82:602-606.

275 12. Tse KC, Yip PS, Hui KM, Li FK, Yuen KY, Lai KN, et al. Potential benefit of plasma

276 exchange in treatment of severe icteric leptospirosis complicated by acute renal failure.

277 Clin Diagn Lab Immunol 2002;9:482-484.

278 13. Yang HL, Jiang XC, Zhang XY, Li WJ, Hu BY, Zhao GP, et al. Thrombocytopenia in 279 the experimental leptospirosis of guinea pig is not related to disseminated intravascular 280 coagulation. BMC Infect Dis 2006;6:19.

281 14. Edwards CN, Nicholson GD, Hassell TA, Everard CO, Callender J. Thrombocytopenia in 282 leptospirosis: the absence of evidence for disseminated intravascular coagulation. Am J $283 \quad$ Trop Med Hyg 1986;35:352-354.

284 15. Nicodemo AC, Del Negro G, Amato Neto V. Thrombocytopenia and leptospirosis. Rev 285 Inst Med Trop Sao Paulo 1990;32:252-259.

286 16. Nally JE, Chantranuwat C, Wu XY, Fishbein MC, Pereira MM, Da Silva JJ, et al. 287 Alveolar septal deposition of immunoglobulin and complement parallels pulmonary 288 hemorrhage in a guinea pig model of severe pulmonary leptospirosis. Am J Pathol 289

290 17. Nicodemo AC, Duarte MI, Alves VA, Takakura CF, Santos RT, Nicodemo EL. Lung 291 lesions in human leptospirosis: microscopic, immunohistochemical, and ultrastructural 292 features related to thrombocytopenia. Am J Trop Med Hyg 1997;56:181-187.

293 18. Yang GG, Hsu YH. Nitric oxide production and immunoglobulin deposition in 294 leptospiral hemorrhagic respiratory failure. J Formos Med Assoc 2005;104:759-763. 
295 19. Alves VA, Vianna MR, Yasuda PH, De Brito T. Detection of leptospiral antigen in the 296 human liver and kidney using an immunoperoxidase staining procedure. J Pathol $297 \quad$ 1987;151:125-131.

298 20. Alves VA, Yasuda PH, Yamashiro EH, Santos RT, Yamamoto LU, de Brito T. An 299 immunohistochemic assay to localize leptospires in tissue specimens. Rev Inst Med Trop $300 \quad$ Sao Paulo 1986;28:170-173.

301 21. Moussallem TM, Guedes F, Fernandes ER, Pagliari C, Lancellotti CL, de Andrade HF, 302 Jr., et al. Lung involvement in childhood measles: severe immune dysfunction revealed 303 by quantitative immunohistochemistry. Hum Pathol 2007;38:1239-1247.

304 22. Andrade L, Rodrigues Jr AC, Sanches TR, Souza RB, Seguro AC. Leptospirosis leads to 305 dysregulation of sodium transporters in the kidney and lung. Am J Physiol Renal Physiol 3062006.

307 23. Castranova V, Rabovsky J, Tucker JH, Miles PR. The alveolar type II epithelial cell: a 308 multifunctional pneumocyte. Toxicol Appl Pharmacol 1988;93:472-483.

309 24. Mills SE. Sternberg's Diagnostic Surgical Pathology. LIPPINCOTT WILLIANS \& $310 \quad$ WILKINS: Philadelphia 2004.

31125 . Ware LB, Matthay MA. The acute respiratory distress syndrome. $N$ Engl J Med $312 \quad 2000 ; 342: 1334-1349$.

313 26. Blennerhassett JB. Shock lung and diffuse alveolar damage pathological and $314 \quad$ pathogenetic considerations. Pathology 1985;17:239-247.

315 27. Rugman FP, Pinn G, Palmer MF, Waite M, Hay CR. Anticardiolipin antibodies in 316 leptospirosis. J Clin Pathol 1991;44:517-519. 
317 28. Santiago M, Martinelli R, Reis MG, Reis EA, Ko A, Fontes RD, et al. Diagnostic

318 performance of anti-beta2 glycoprotein I and anticardiolipin assays for clinical

319 manifestations of the antiphospholipid syndrome. Clin Rheumatol 2004;23:485-489.

320 29. Tattevin P, Dupeux S, Hoff J. Leptospirosis and the antiphospholipid syndrome. Am J $321 \quad$ Med 2003;114:164.

322 30. De Francesco Daher E, Oliveira Neto FH, Ramirez SM. Evaluation of hemostasis

323 disorders and anticardiolipin antibody in patients with severe leptospirosis. Rev Inst Med $324 \quad$ Trop Sao Paulo 2002;44:85-90.

325 31. Gomez RM, Vieira ML, Schattner M, Malaver E, Watanabe MM, Barbosa AS, et al. 326 Putative outer membrane proteins of Leptospira interrogans stimulate human umbilical 327 vein endothelial cells (HUVECS) and express during infection. Microb Pathog 2008.

328 32. Vieira ML, D'Atri LP, Schattner M, Habarta AM, Barbosa AS, de Morais ZM, et al. A 329 novel leptospiral protein increases ICAM-1 and E-selectin expression in human umbilical $330 \quad$ vein endothelial cells. FEMS Microbiol Lett 2007;276:172-180.

331 33. Maciel EA, Athanazio DA, Reis EA, Cunha FQ, Queiroz A, Almeida D, et al. High 332 serum nitric oxide levels in patients with severe leptospirosis. Acta Trop 2006;100:256333260.

334 34. Hsu YH, Chen HI. The involvement of nitric oxide and beta-adrenergic pathway $335 \quad$ signalling in pulmonary oedema and fluid clearance. Pathology 2007;39:612-613.

336 35. De Brito T, Bohm GM, Yasuda PH. Vascular damage in acute experimental leptospirosis 337 of the guinea-pig. J Pathol 1979;128:177-182.

338 36. Seifert PS, Messner M, Roth I, Bhakdi S. Analysis of complement C3 activation products 339 in human atherosclerotic lesions. Atherosclerosis 1991;91:155-162. 
340

341 
342 Table 1. Clinical and laboratory findings of leptospirosis pulmonary hemorrhagic syndrome 343 patients.

344

Clinical characteristics

Age, median (IR)

Male sex, $\mathrm{n}(\%)$

Duration of symptoms, median (IR)

\section{Clinical symptoms on admission}

Fever, n(\%)

Muscle pain, n(\%)

Headache, n(\%)

Nausea or Vomiting, $\mathrm{n}(\%)$

Diarrhea, n(\%)

\section{Laboratory values}

Hematocrit \%, median (IR)

Leucocytes, cells $/ \mathrm{mm}^{3}$, median (IR)

Platelets, cells $/ \mathrm{mm}^{3,}$, median (IR)

Serum creatinine, mg/dl, median (IR)

Serum bilirubin, mg/dl, median (IR)

AST, mg/dl, median (IR)

ALT, mg/dl, median (IR)

Prothrombin time (INR), median (IR)

Partial Thromboplastin Ratio, median (IR)
No. (\% responses $)^{\mathrm{a}}$

$\begin{array}{ll}30(100 \%) & 48.5(40-56) \\ 30(100 \%) & 23(77 \%) \\ 25(83 \%) & 6 \text { days }(4-7)\end{array}$

$26(87 \%)$

$26(100 \%)$

$24(80 \%)$

$23(96 \%)$

$23(77 \%)$

$17(74 \%)$

$24(80 \%)$

$13(54 \%)$

$24(80 \%)$

$6(25 \%)$

$25(83 \%)$

$26(20-30)$

$26(87 \%)$

$1.6 \times 10^{4}\left(1.1-1.9 \times 10^{4}\right)$

$25(83 \%)$

$5.4 \times 10^{4}\left(3.6-10.0 \times 10^{4}\right)$

$26(87 \%)$

$6.1(4.0-7.6)$

$25(83 \%)$

$18.7(10.6-25.0)$

$21(70 \%)$

$105(51-221)$

$23(77 \%)$

77 (31-142)

$14(47 \%)$

$1.35(1.00-1.40)$

$13(43 \%)$

$1.1(0.9-1.5)$

\section{Clinical course}


Use of vasoactive drugs, $\mathrm{n}(\%)$

$27(90 \%)$

$22(81 \%)$

Duration of mechanical ventilation, median (IR)

$30(100 \%)$

2 day (0-5)

Dialysis, $\mathrm{n}(\%)$

$27(90 \%)$

$19(70 \%)$

Duration of hospitalization, median (IR)

$30(100 \%)$

3 days (1-6)

345

$346{ }^{a}$ Missing data during chart review

347 Definition of abbreviations: AST- aspartate aminotransferase; ALT-alanine aminotransferase;

348 INR-International normalized ratio. IR-Interquartile range 
349 Table 2. Clinical and microscope characteristics of 30 fatal cases of proven human leptospirosis.

Alveolar space $\quad$ IHC

$\begin{array}{lllllllllllllll}\text { Number } & \text { Age } & \text { Sex } & \text { MV } & \text { PI/II } & \text { RPH } & \text { M } & \text { N } & \text { L } & & \text { IgA } & \text { IgM } & \text { IgG } & \text { C3 }\end{array}$

\begin{tabular}{|c|c|c|c|c|c|c|c|c|c|c|c|c|}
\hline 2 & 70 & $\mathrm{M}$ & 0 & + & + & 3 & 0 & 1 & + & + & + & + \\
\hline 3 & 33 & $\mathrm{M}$ & 8 & + & - & 3 & 1 & 1 & - & - & - & - \\
\hline 5 & 59 & $\mathrm{M}$ & 5 & + & - & 2 & 1 & 1 & - & - & - & - \\
\hline 7 & 54 & $\mathrm{M}$ & 2 & + & - & 2 & 0 & 1 & - & - & - & - \\
\hline 8 & 20 & $\mathrm{M}$ & 3 & + & + & 2 & 1 & 1 & + & + & + & + \\
\hline 10 & 52 & $\mathrm{M}$ & 6 & + & - & 2 & 0 & 1 & + & + & + & + \\
\hline 11 & 31 & $\mathrm{M}$ & 1 & + & + & 1 & 0 & 1 & + & + & - & + \\
\hline 13 & 58 & $\mathrm{M}$ & 4 & + & - & 2 & 1 & 1 & - & - & - & - \\
\hline 17 & 22 & M & 7 & + & - & 3 & 2 & 1 & - & - & - & - \\
\hline 18 & 22 & $\mathrm{~F}$ & 0 & + & + & 1 & 0 & 1 & + & + & + & + \\
\hline 19 & 30 & $\mathrm{M}$ & 5 & + & + & 2 & 0 & 1 & + & + & + & + \\
\hline 20 & 69 & $\mathrm{M}$ & 1 & + & + & 2 & 0 & 1 & + & + & + & + \\
\hline 21 & 56 & $\mathrm{M}$ & 0 & + & + & 2 & 1 & 1 & + & + & + & + \\
\hline 22 & 63 & $\mathrm{M}$ & 2 & + & - & 3 & 1 & 1 & - & - & - & - \\
\hline 23 & 19 & $\mathrm{~F}$ & 0 & + & - & 1 & 0 & 1 & IC & IC & IC & IC \\
\hline 24 & 27 & $\mathrm{~F}$ & 0 & + & - & 2 & 0 & 1 & IC & IC & IC & IC \\
\hline 27 & 56 & $\mathrm{M}$ & 0 & + & + & 2 & 1 & 1 & + & + & + & + \\
\hline 28 & 48 & $\mathrm{~F}$ & 0 & + & + & 1 & 0 & 1 & + & - & - & - \\
\hline 32 & 21 & $\mathrm{M}$ & 1 & + & + & 1 & 1 & 1 & + & + & + & + \\
\hline
\end{tabular}




\begin{tabular}{|c|c|c|c|c|c|c|c|c|c|c|c|c|}
\hline 34 & 40 & $\mathrm{M}$ & 0 & + & + & 1 & 0 & 0 & $\mathrm{IC}$ & IC & $\mathrm{IC}$ & IC \\
\hline 35 & 55 & $\mathrm{~F}$ & 1 & + & + & 1 & 1 & 1 & + & + & + & + \\
\hline 36 & 53 & $\mathrm{~F}$ & 10 & + & - & 3 & 1 & 1 & + & + & + & + \\
\hline 37 & 54 & $\mathrm{M}$ & 0 & + & - & 2 & 0 & 1 & - & - & - & - \\
\hline 38 & 44 & $\mathrm{M}$ & 2 & + & + & 2 & 1 & 1 & IC & IC & IC & IC \\
\hline 42 & 40 & $\mathrm{M}$ & 8 & + & - & 2 & 0 & 1 & + & + & + & + \\
\hline 43 & 35 & $\mathrm{~F}$ & 2 & + & - & 2 & 1 & 1 & + & + & + & + \\
\hline 44 & 40 & $\mathrm{M}$ & 13 & + & - & 2 & 1 & 1 & - & - & - & - \\
\hline 45 & 53 & $\mathrm{M}$ & 0 & + & - & 3 & 1 & 1 & + & + & + & + \\
\hline 46 & 49 & $\mathrm{M}$ & 0 & + & + & 2 & 0 & 1 & + & + & + & + \\
\hline 47 & 59 & $\mathrm{M}$ & 0 & + & - & 2 & 0 & 1 & + & + & + & + \\
\hline
\end{tabular}

351 Definition of abbreviations: M-Male; F-Female; +-Positive; --Negative; IC-Inconclusive; MV-

352 Days of mechanical ventilation; PI/II-Type I and II pneumocyte cells necrosis and regeneration;

353 RPH-Recent pulmonary hemorrhage; M, N, and L-semi-quantitative presence of macrophages,

354 lymphocytes and neutrophils in the alveolar space.

355

356

357 


\section{$358 \quad$ Figure legend}

361 Figure 1. Alveolar hemorrhage in LPHS and control patients, as detected by histology and

362 immunohistochemistry in the alveolar area (Magnification, 400x). (A) Lung from control

363 patients with diffuse alveolar hemorrhage (HE) showing an absence of immunoglobulin and C3

364 deposition; (B) Lung from LPHS patients showing diffuse alveolar hemorrhage (HE) and a

365 delicate linear immunoglobulin and C3 deposition that is adjacent to the alveolar surface (A

366 staining pattern); (C) Lung from LPHS patients showing alveolar hemorrhage (HE) and mixed A

367 and MF staining pattern; and (D) Lung from LPHS patients (HE) showing hemorrhage and

368 random, multifocal staining along the alveolar septum (MF staining pattern). HE = Hematoxylin-

369 Eosin.

370

371 Figure 2. Proposed pathogenic mechanism involved in LPHS. 
Figure 1.

\section{A}

B

C

D

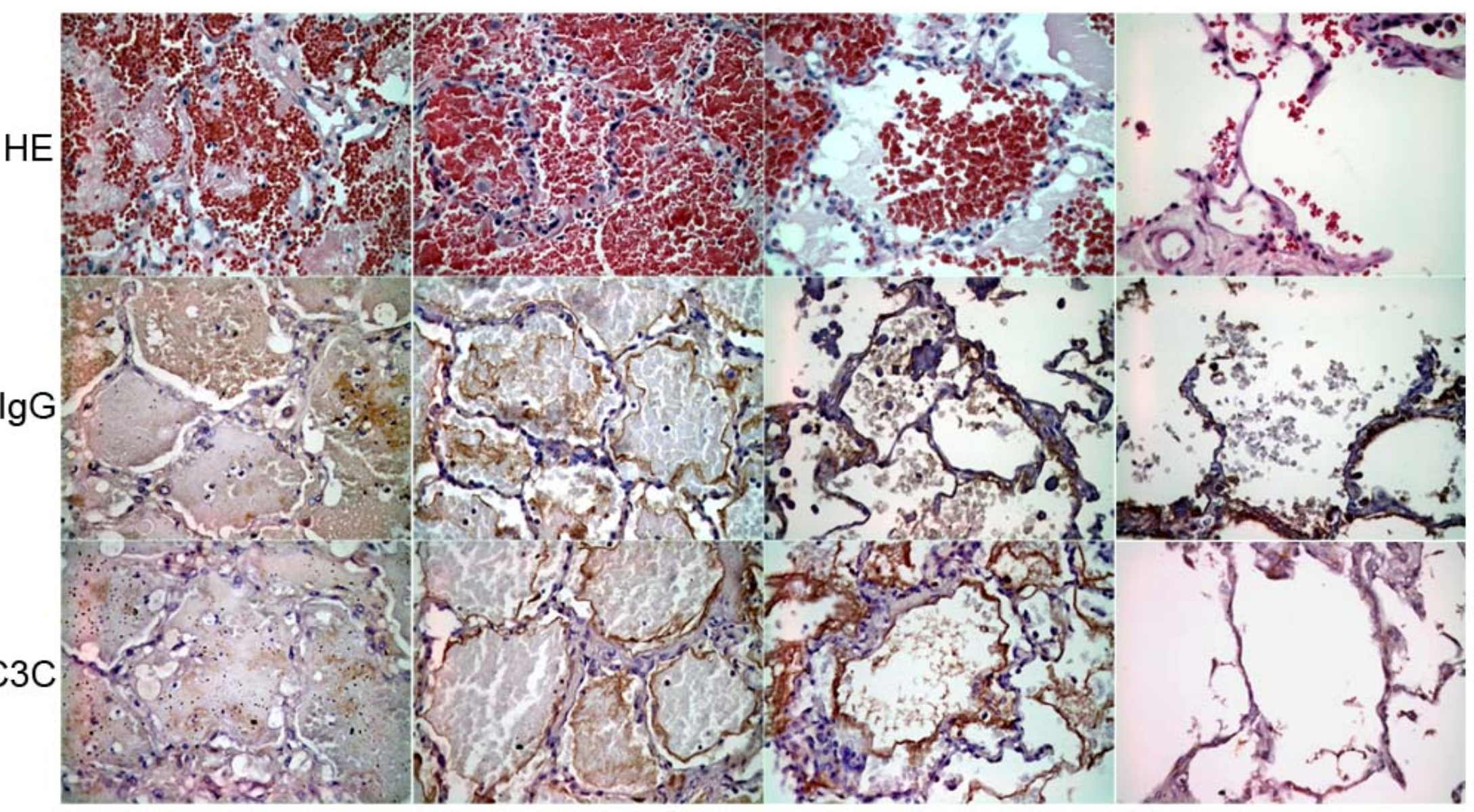


Figure 2.

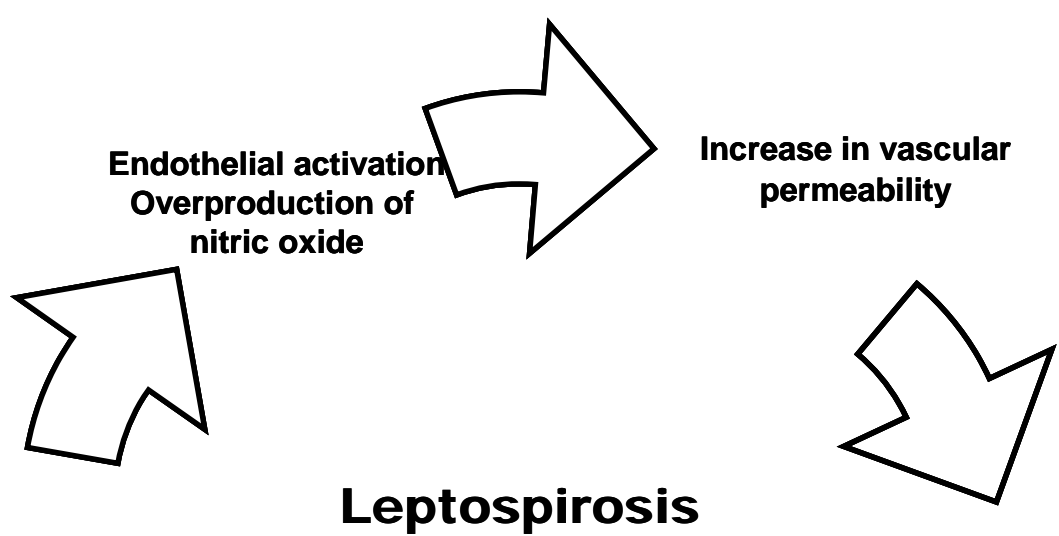

Hemaphogacitosis

Type II pneumocyte

regeneration

Cleanup of deposited C3

Pulmonary

Hemorrhage

Syndrome
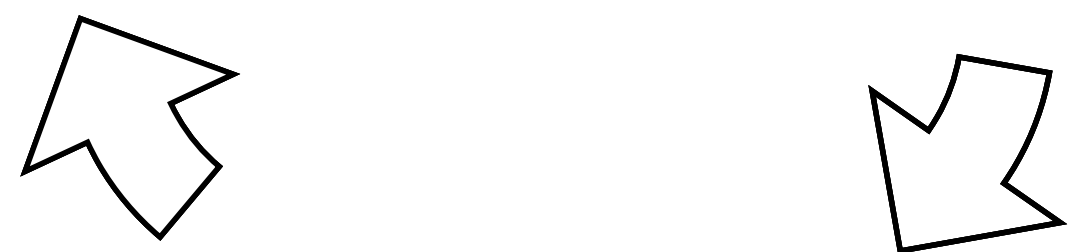

IgM, IgG and IgA deposition on alveolar septumand surface of type I and II pneumocyte

Complement

activation

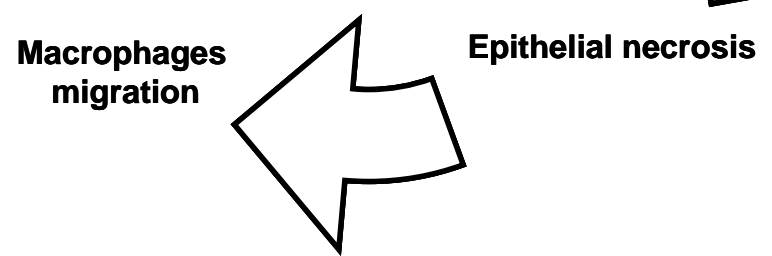

Alveolar hemorrhage 